\title{
COSTS AND BENEFITS OF AUTOMOTIVE FUEL ECONOMY IMPROVEMENT: A PARTIAL ANALYSIS
}

\author{
David L. Greene \\ Center for Transportation Analysis \\ Oak Ridge National Laboratory \\ K.G. Duleep \\ Energy and Environmental Analysis, Inc.
}

March 1992

Prepared by the

Oak Ridge National Laboratory

Oak Ridge, Tennessee 37831

managed by

MARTIN MARIETTA ENTERGY SYSTEMS, INC.

for the

U.S. DEPARTMENT OF ENERGY

under contract DE-AC05-84OR21400

\section{MASTER}


TABLE OF CONTENTS

LIST OF FIGURES $\ldots \ldots \ldots \ldots \ldots \ldots \ldots \ldots \ldots \ldots \ldots \ldots \ldots, \mathrm{v}$

LIST OF TABLES $\ldots \ldots \ldots \ldots \ldots \ldots \ldots \ldots \ldots \ldots \ldots \ldots \ldots \ldots \ldots \ldots \ldots \ldots \ldots$ vii

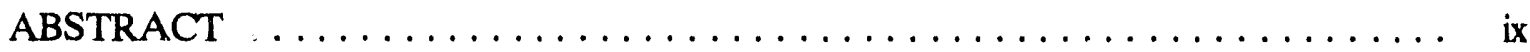

ACKNOWLEDGEMENTS $\ldots \ldots \ldots \ldots \ldots \ldots \ldots \ldots \ldots \ldots \ldots \ldots \ldots \ldots \ldots$

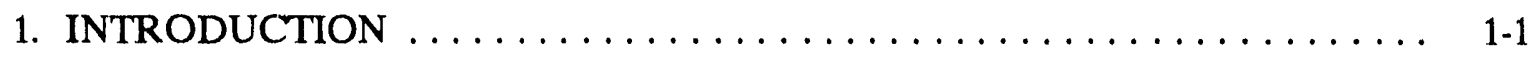

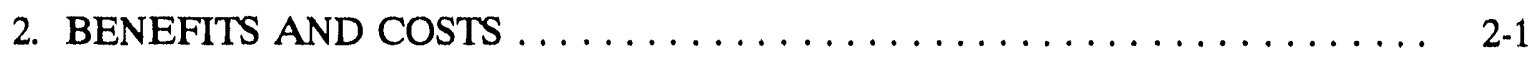

2.1 MPG IMPROVEMENTS AND COSTS OF FUEL ECONOMY

TECHNOLOGY ........................ $2-2$

2.2 HEDONIC COSTS OF WEIGHT AND PERFORMANCE $\ldots \ldots \ldots, 2-8$

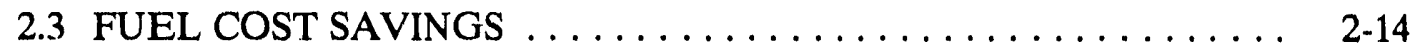

2.5 TRANSFER OF WEALTH VIA MONOPOLY PRICING ....... $2-20$

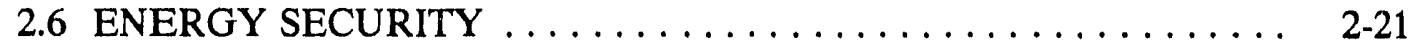

2.7 EMISSIONS COSTS AND BENEFITS $\ldots \ldots \ldots \ldots \ldots \ldots \ldots \ldots, 2-24$

2.8 CONSUMERS' SURPLUS EFFECTS $\ldots \ldots \ldots \ldots \ldots \ldots \ldots \ldots, 2-27$

3. MODELING AND ESTIMATION $\ldots \ldots \ldots \ldots \ldots \ldots \ldots \ldots \ldots \ldots, 3-1$

3.1 VEHICLE PRICE AND SALEES $\ldots \ldots \ldots \ldots \ldots \ldots \ldots \ldots \ldots, 3-3$

3.2 VEHICLE STOCK MODEL $\ldots \ldots \ldots \ldots \ldots \ldots \ldots \ldots \ldots, 3-4$

3.3 EFFECTS OF NEW CAR PRICE ON SCRAPPAGE $\ldots \ldots \ldots \ldots \ldots, 3-4$

3.4 VEHICLE USE ........................... $3-6$

3.5 FLEET AVERAGE WEIGHT AND EMISSIONS CHANGES $\ldots \ldots .3-7$

3.6 CALCULATION OF COSTS AND BENEFITS $\ldots \ldots \ldots \ldots \ldots \ldots$. $3-8$

4. ENERGY DEMAND SCENARIOS $\ldots \ldots \ldots \ldots \ldots \ldots \ldots \ldots \ldots, 4-1$

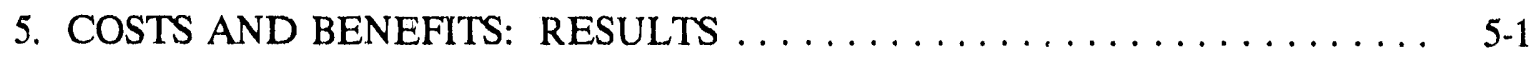

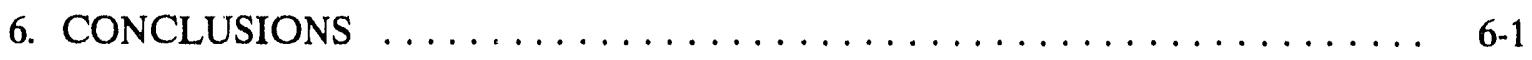

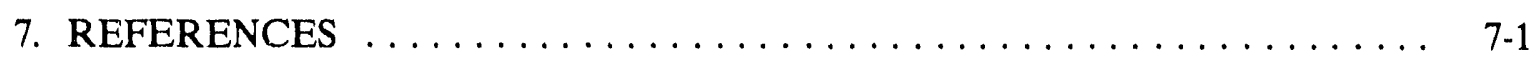

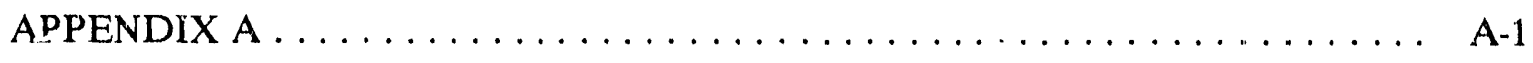

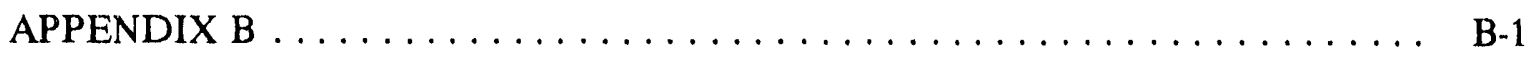




\section{LIST OF FIGURES}

Page

Figure 1. New Passenger Car and Light Truck Fuel Economy . . . . . . . . . 2-7

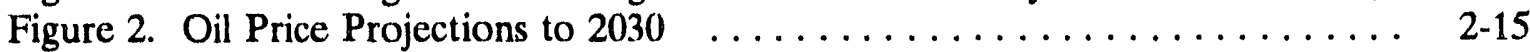

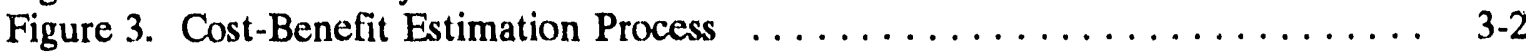

Figure 4. Hydrocarbon Emission Rates by Vehicle Age $\ldots \ldots \ldots \ldots \ldots \ldots \ldots$. . . . . .

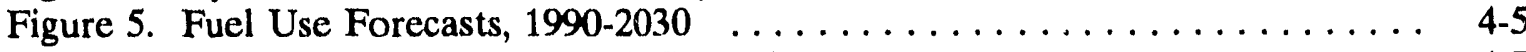

Figure 6. Fue Use Forecasts by MPG Scenario $\ldots \ldots \ldots \ldots \ldots \ldots \ldots \ldots \ldots \ldots$. . . . . . . . . . . . . . .

Figure 7. Net Present Value of Costs and Benefits ................ $5-5$

Figure 8. Effects of Oil Prices on NPV of Level 2 MPG $\ldots \ldots \ldots \ldots \ldots \ldots \ldots$ 


\section{LIST OF TABLES}

Page

Table 1. Fuel Economy Scenarios for New Passenger Cars. . . . . . . . . . . 2-5

Table 2. Fuel Economy Scenarios for New Light Trucks. . . . . . . . . . . . . 2-6

Table 3. Elasticity of World Oil Price with Respect to U.S. Uin Demand: Illustrative Calculations Based on Year 2000 Projections (Oil \$28/BBL in 1988\$). . . 2-20

Table 4. Elasticities of Scrappage with Respect to Price. . . . . . . . . . . . . 3-5

Table 5. Energy Price Projections (1989\$ per barrel for oil, per gallon for

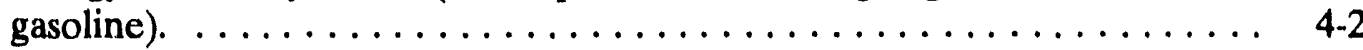

Table 6. Economic Growth, Population, and Vehicle Sales Projections. . . . . . . . 4-2

Table 7. Summary of Fuel Economy Costs and Benefits (Billions 1989\$). . . . . . . 5-2

Table 8. Key Assumptions Affecting Costs and Benefits. . . . . . . . . . . . . 5-4

Table 9. Summary of Fuel Economy Costs and Benefits (Billions 1989\$) Using Moderate Parameter Values. . . . . . . . . . . . . . . . . 5-8 


\begin{abstract}
This paper describes an exercise in estimating the costs and benefits of technologybased fuel economy improvements for automobiles and light trucks. Benefits quantified include vehicle costs, fuel savings, consumers' surplus effects, the effect of reduced weight on vehicle safety, impacts on emissions of $\mathrm{CO}_{2}$ and criteria pollutants, world oil market and energy security benefits, and the transfer of wealth from U.S. consumers to oil producers. A vehicle stock model is used to capture sales, scrappage, and vehicle use effects under three fuel price scenarios. Three alternative fuel economy levels for 2001 are considered, ranging from 32.9 to $36.5 \mathrm{MPG}$ for cars and 24.2 to $27.5 \mathrm{MPG}$ for light trucks. Overall, fuel economy improvements of this size are probably cost-effective. The size of the benefit, and even whether there is a benefit, strongly depends on the financial costs of fuel economy improvement and judgments about the values of energy security, emissions, safety, etc. Three sets of values for eight parameters are used to define the sensitivity of costs and benefits to key assumptions. The net present social value (1989\$) of costs and benefits ranges from a cost of $\$ 11$ billion to a benefit of $\$ 286$ billion. The critical parameters being the discount rate $(10 \%$ vs. $3 \%)$ and the values attached to externalities. The two largest components are always the direct vehicle costs and fuel savings, but these tend to counterbalance each other for the fuel economy levels examined here. Other major components are the wealth transfer, oil cost savings, $\mathrm{CO}_{2}$ emissions reductions, and energy security benefits. Safety impacts, emissions of criteria pollutants, and consumers' surplus effects are relatively minor components. The critical issues for automotive fuel economy are therefore: 1 ) the value of present versus future costs and benefits, 2) the values of external costs and benefits, and 3) the financially cost-effective level of MPG achievable by available technology.
\end{abstract}




\section{ACKNOWLEDGEMENTS}

The authors wish to thank the many individuals who provided helpful advice and criticism during the progress of this work, especially, Barry McNutt, Carmen Difiglio, Paul Leiby, Eric Stork, Paul McCarthy, Larry Hill, Howard Gruenspecht, Rich Theroux, Robert Larson, and Andrew Kleit. Any errors that may be in this work are our own responsibility. 


\section{COSTS AND BENEFITYS OF \\ AUTOMOTIVE FUEL ECONOMY IMPROVEMENT: \\ A PARTIAL ANALYSIS}

\section{INTRODUCTION}

No element of energy policy is as obvious to the American citizen as automotive fuel economy standards. Light duty vehicles (passenger cars and light trucks) account for over $60 \%$ of petroleum use in transportation and well over a third of total U.S. petroleum consumption. Because of the automobile's prominence in everyday life, motor vehicle fuel economy has symbolic as well as real significance. Serious policies to reduce petroleum use by cars and trucks send a clear message to producers and consumers that oil conservation is important.

But there is also a risk of exaggerating the importance of the automobile's oil demand, pushing efficiency too far, and causing substantial economic damage. Cars and trucks are ubiquitous in the economy, as well as in American culture. Their manufacture, use, care, and feeding requires an estimated one out of every seven U.S. workers (MVMA, 1989, p. 67). Motor vahicles comprise about $10 \%$ of consumer expenditures, motor fuel about $4 \%$. Efficiency improvements that are too expensive, or that significantly diminish the usefulness 
or desirability of motor vehicles to consumers could have total costs far exceeding their benefits.

This paper presents an estimation of the costs and benefits of passenger car and light truck fuel economy improvements between 1990 and 2001, using realistic estimates of miles per gallon (MPG) levels achievable and of their timing, and quantifying as many important secondary benefits as possible. The level of detail required for calculating such things as scrappage effects, emissions impacts, and vehicle weight changes precludes the use of general equilibrium models for estimating costs and benefits. The analysis is therefore partial in that motor vehicles are modeled without considering a full range of interdependencies with the economy as a whole. The analysis is also partial in that not all conceivable impacts are estimated. Apart from direct costs and savings to the consumer, certain environmental, energy market, safety, and consumers' surplus effects that have been identified as significantly affected by fuel economy, are measured. Each is described in detail below.

This effort differs from previous work (Shin, 1990) in that it: 1) considers an integrated scenario of fuel economy improvement and associated cost increases based on the adoption of specific fuel economy technologies over time, 2) explicitly models the effects on sales, scrappage, and vehicle use by vehicle vintage, 3) uses these detailed data to compute changes in emissions rates and average vehicle weight as well as fuel use, and 4) considers both passenger car and light truck fuel economy improvements. The analysis assumes that the fuel economy improvements are the result of fuel economy standards, and that the standards cause fuel economy technologies to be introduced, approximately in order of costeffectiveness. 
Finally, we explore the dependence of estimated costs and benefits on key assumptions about which there is either great scientific uncertainty, or where substantial differences of opinion may be expected among reasonable people. These include the correct value for discounting future costs and benefits, the time period over which to consider costs and benefits, as well as the precise values of environmental, energy security and other factors. Depending on the assumptions made, the net effect of fuel economy improvements considered may be tens of billions in present value savings or billions in costs. 


\section{BENEFITS AND COSTS}

Changes in automobile design and technology will have far reaching ramifications, both great and small. These may range from enhancing national security and mitigating global climate change to individual like or dislike of aerodynamic styling or other intangible aspects of new technology. Clearly it is neither possible nor appropriate to attempt to quantify every imaginable consequence. The factors listed below are at least partially quantifiable and most have been held to be important by other researchers.

\section{COSTS AND BENEFITS}

1. Cost of fuel economy technology to the consumer (monetary and hedonic).

2. Fuel cost savings to the economy (excluding taxes).

3. Oil import cost savings (monopsony price benefit).

4. Transfer of wealth to oil producers.

5. Safety impacts of weight reduction.

6. Energy security benefits.

7. Value of $\mathrm{CO}_{2}$ emissions reductions.

8. Value of motor vehicle emissions reductions or increases.

The first two are direct costs, the majority of which are borne directly by the motorist. The next two are indirect costs, but are not external to the market. Safety is also not an externality, the impacts being borne by the motorist as increased risk. The last three are market externalities. With regard to the transfer of income, although it seems clear to us that the appropriation of U.S. wealth as monopoly rent by a foreign monopolist is a cost to the United States, it is not generally counted as such because, 1) the wealth transfer is not in itself a loss of economic efficiency, and 2) since much of the wealth may return to the U.S. 
in the form of foreign investment, it will not necessarily result in a decrease in the growth of the U.S. national product. As we see it, the issue is whether it matters who owns U.S. wealth. We think it does, so we include it as a benefit even though there is no generally accepted method of measuring the cost of transferring U.S. wealth abroad.

Some have suggested there may be a potential congestion cost of increased driving due to the lower fuel cost per mile of travel when MPG increases. Since traffic congestion depends on an inadequate supply or pricing of infrastructure built by the public sector, the public sector will decide whether or not to accommodate the increased demand for travel. (The increase due to fuel economy will be $2 \%$, or less, over three or four decades, trivial in comparison to the total growth of vehicle travel.) Thus, it will be primarily a public decision whether to permit the increased travel demand to increase traffic congestion.

\subsection{MPG IMPROVEMENTS AND COSTS OF FUEL ECONOMY TECHNOLOGY}

Substantial fuel economy improvements can be made by using proven technologies already incorporated in at least one mass production vehicle prodist line. Over the years, the U.S. Department of Energy has carried out a series of studies assessing the potential of proven technology to increase auto and light truck MPG (e.g., Energy and Environmental Analysis, Inc., 1989; EEA, Inc., 1988a; EEA, Inc., 1988b; EEA, Inc., 1986). The central idea is that fuel economy can be most effectively increased by expanding the use of proven technology to product lines where the technology is technically applicable but is not now 
used. Thus, the fuel economy improvement potential depends on current market share, potential market share, and the effectiveness of each technology for increasing MPG.

Based on updated information from these studies, three fuel economy projections were developed for automobiles and light trucks (FEA, 1991). Descriptions of the technologies considered, their effects on fuel economy and their costs are contained in Appendix A. The Base Case projection is based on known product plans and includes technologies that are already cost-effective based on fuel savings over the first four years of vehicle operation and discounted at an annual rate of $10 \%$. This rule of thumb assumes that consumers absolutely discount fuel savings beyond the first four years, but could also be viewed as consumers using a discount rate much higher than $10 \%$. The Base Case is intended to represent what the marketplace is likely to do in the absence of intervention, and in response to technological advances (the gradual adoption of fuel economy technology) and slightly higher fuel prices. Two higher MPG scenarios were also developed, which we will simply call Level 2 and Level 3 . The Level 3 case assumes maximum use of proven ${ }^{1}$ fuel economy technology, regardless of its cost-effectiveness in improving MPG. The Level 2 scenario was chosen to be intermediate between the Base Case and Level 3. In every case, new vehicle fuel economy is assumed to improve through 2001 and remain constant thereafter. We project impacts through 2030 to: 1) allow for complete turnover of the vehicle stock, and 2) develop a sufficiently long period of costs and benefits to reasonably approximate the long-run outcome.

'Proven technology must be implemented in at least one mass-produced vehicle sold in the world today. This assures the exclusion of preproduction or exotic technologies. 
Since this study was completed, an alternative set of fuel economy technclogy cost and performance estimates has been published (SRI, 991). This new study, sponsored by the Motor Vehicle Manufacturer's Association (MVMA), is based on proprietary data provided to SRI by the domestic automobile manufacturers. The study indicates considerably higher costs and somewhat lower performance levels for most technologies. Although the results of SRI's work are not included here they will be considered in an upcoming report by the National Research Cuncil (1992).

Fuel economy levels, costs, weight and horsepower changes are shown in Tables 1 and 2. Domestic and imported fuel ecoromi :s were harmonically averaged to obtain average new car and new truck fuel economy using the assumed market shares also shown in Table 1. As one can see, there is a great deal of efficiency improvement in the Base Case itself (Figure 1). Average new car MPG increases 5.3 MPG from 27.6 MPG in 1990 to 32.9 MPG in 2001. Cost increases and some weight reduction accompany this $20 \%$ increase in MPG. Fuel economy technology costs amount to $\$ 225$ in 1995 and $\$ 545$ in 2001 . Weight peaks at 2,880 lbs. in 1995 and declines $150 \mathrm{lbs}$. to 2,730 by 2000 . Light truck MPG rises from 21 to 23.4 in the Base Case, 26.0 in Level 2, and approaches current new car fuel economy at 27.5 in the Level 3 case. Because the Level 2 and Level 3 scenarios are incremental improvements over the Base Case, the analysis of their costs and benefits will be close to an analysis of marginal costs and benefits of MPG.

Because the estimated technology costs represent full cost to the consumer, they include taxes paid by the manufacturer to the government. These are likely to comprise only a few percent of the total cost, and so we neglect them here. 
Table 1. Fuel Economy Scenarios for New Passenger Cars. (Costs in 1988\$)

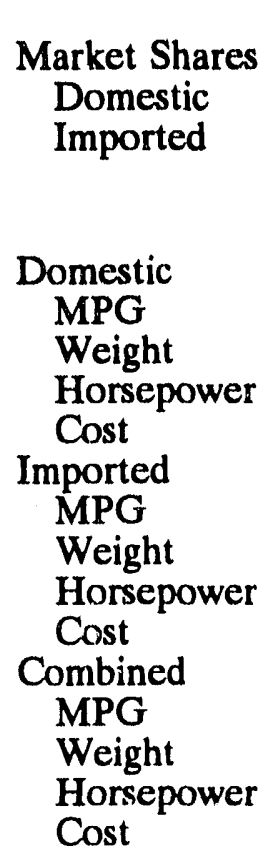

\begin{tabular}{|c|c|c|c|}
\hline 1988 & 1990 & 1995 & 2001 \\
\hline $\begin{array}{l}0.62 \\
0.38\end{array}$ & $\begin{array}{l}0.61 \\
0.39\end{array}$ & $\begin{array}{l}0.60 \\
0.40\end{array}$ & $\begin{array}{l}0.58 \\
0.42\end{array}$ \\
\hline \multicolumn{4}{|c|}{ Base Case } \\
\hline
\end{tabular}

Domestic

MPG

Weight

Horsepower

Cost

Imported

MPG

Weight

Horsepower

Cost

Combined

MPG

Weight

Horsepower

Cost

27.1

2885

123

\$0

31.4

2421

100

$\$ 0$

28.6

2709

114.3

$\$ 0$

Level 2

2001

34.2

2940

137

$\$ 713$

36.2

2440

115

$\$ 510$

35.0

2730

127.8

$\$ 628$

Changes over Base Case MPG

Cost

Weight

$\mathrm{HP} / \mathrm{Wt}$

\begin{tabular}{rcr}
26.6 & 28.0 & 31.8 \\
3011 & 3090 & 2940 \\
133 & 150 & 147 \\
$\$ 0$ & $\$ 257$ & $\$ 633$ \\
& & \\
29.5 & 30.8 & 34.6 \\
2601 & 2566 & 2440 \\
120.5 & 125 & 121 \\
$\$ 0$ & $\$ 177$ & $\$ 423$ \\
27.6 & 29.1 & 32.9 \\
2853 & 2880 & 2730 \\
128.2 & 140.0 & 136.1 \\
$\$ 0$ & $\$ 225$ & $\$ 545$ \\
\multicolumn{3}{c}{ Level 3 } \\
\multicolumn{3}{c}{ 1995 } \\
\end{tabular}

29.3

3040

138

$\$ 348$

35.8

2765

132

$\$ 995$

$31.9 \quad 37.5$

$2566 \quad 2332$

$115 \quad 107$

$\$ 201 \quad \$ 873$

$30.3 \quad 36.5$

$2850 \quad 2583$

$128.8 \quad 121.5$

$\$ 289 \$ \$ 944$

$\begin{array}{rrr}2.1 & 1.2 & 3.6 \\ \$ 83 & \$ 64 & \$ 399 \\ 0 & -30 & -147 \\ -. \% & -7 \% & -6 \%\end{array}$


Table 2. Fuel Economy Scenarios for New Light Trucks.

(Costs in 1988\$)

\begin{tabular}{|c|c|c|c|c|}
\hline & 1988 & 1990 & 1995 & 2001 \\
\hline \multicolumn{5}{|l|}{ Market Shares } \\
\hline Domestic & 0.81 & 0.81 & 0.81 & 0.81 \\
\hline \multirow[t]{2}{*}{ Imported } & 0.19 & 0.19 & 0.19 & 0.19 \\
\hline & \multicolumn{4}{|c|}{ Base Case } \\
\hline \multicolumn{5}{|l|}{ Domestic } \\
\hline MPG & 20.4 & 20.3 & 21.4 & 23.4 \\
\hline Weight & 4052 & 4148 & 4105 & 3900 \\
\hline Horsepower & 146 & 151 & 153 & 160 \\
\hline Cost & \$o & \$0 & $\$ 146$ & $\$ 350$ \\
\hline \multicolumn{5}{|l|}{ Imported } \\
\hline MPG & 24.6 & 23.6 & 26.1 & 28.8 \\
\hline Weight & 3295 & 3504 & 3490 & 3490 \\
\hline Horsepower & 104 & 119 & 111 & 119 \\
\hline Cost & $\$ 0$ & so & $\$ 175$ & $\$ 392$ \\
\hline \multicolumn{5}{|l|}{ Combined } \\
\hline MPG & 21.1 & 20.9 & 22.2 & 24.2 \\
\hline Weight & 3908 & 4026 & 3988 & 3822 \\
\hline Horsepower & 138.0 & 144.9 & 145.0 & 152.2 \\
\hline \multirow[t]{3}{*}{ Cost } & $\$ 0$ & $\$ 0$ & $\$ 152$ & $\$ 358$ \\
\hline & Level 2 & & \multicolumn{2}{|c|}{ Level 3} \\
\hline & 2001 & & $19 \overline{95}$ & 2001 \\
\hline \multicolumn{5}{|l|}{ Domestic } \\
\hline MPG & 25.2 & & 21.9 & 26.7 \\
\hline Weight & 3900 & & 4105 & 3695 \\
\hline Horsepower & 153 & & 150 & 142 \\
\hline Cost & $\$ 610$ & & $\$ 214$ & $\$ 1020$ \\
\hline \multicolumn{5}{|l|}{ Imported } \\
\hline MPG & 30.3 & & 26.5 & 31.3 \\
\hline Weight & 3320 & & 3490 & 3150 \\
\hline Horsepower & 111 & & 114 & 105 \\
\hline Cost & $\$ 497$ & & $\$ 207$ & $\$ 648$ \\
\hline \multicolumn{5}{|l|}{ Combined } \\
\hline MPG & 26.0 & & 22.7 & 27.5 \\
\hline Weight & 3790 & & 3988 & 3591 \\
\hline Horsepower & 14.5 .0 & & 143.2 & 135.0 \\
\hline Cost & $\$ 589$ & & $\$ 213$ & $\$ 949$ \\
\hline \multicolumn{5}{|c|}{ Changes over Base Case } \\
\hline MPG & 1.8 & & 0.5 & 3.2 \\
\hline Cost & $\$ 231$ & & $\$ 61$ & $\$ 591$ \\
\hline Weight & 32 & & $\mathbf{0}$ & -231 \\
\hline $\mathrm{HP} / \mathrm{Wt}$ & $-4 \%$ & & $0 \%$ & $-6 \%$ \\
\hline
\end{tabular}




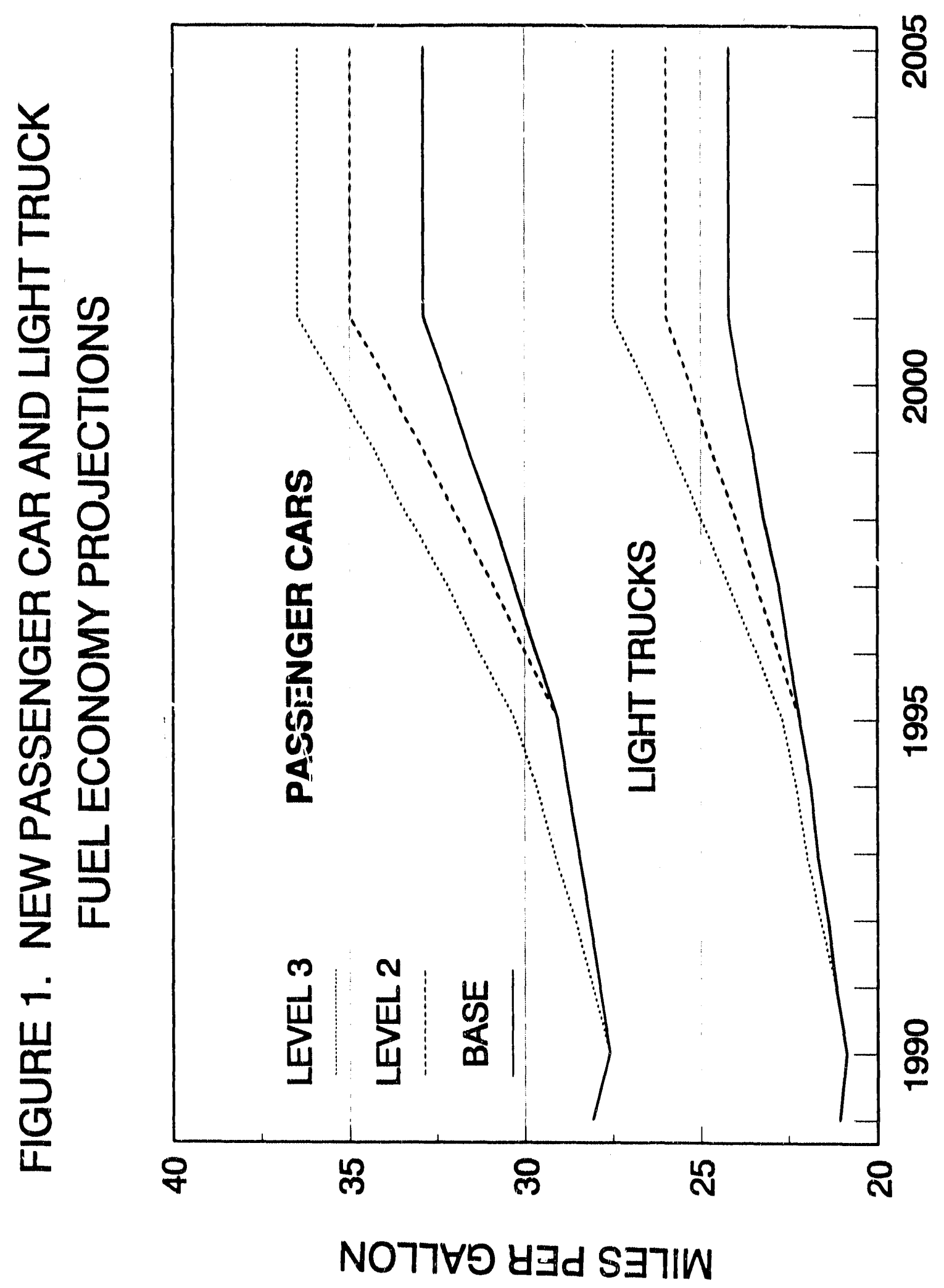

2-7 


\section{HEDONIC COSTS OF WEIGHT AND PERFORMANCE}

In ardition to the estimated direct cost of fuel economy technology, vehicle design and performance changes may also change the utility, or satisfaction the consumer derives from owning and operating the vehicle. These hedonic costs may be highly personal and are clearly difficult to quantify. Fuel economy technologies can affect various vehicle attributes from maintenance to appearance. By using only technologies already in use in at least one massproduced vehicle, we believe we eliminate most extreme effects. We also assume that manufacturers continue to design vehicles to make them as appealing as possible to tile consumer, given the specified MPG increases. We believe this leaves two fundamental vehicle characteristics which can be traded-off for fuel economy that still must be accounted for: 1) weight and 2) performance.

Although there is a substantial econometric literature on motor vehicle choice and consumers' valuation of vehicle attributes, there is no consensus about what values to attribute to performance or weight. To a great extent, this must be due to the high correlations between vehicle weight and other measures of size, performance, and luxury. Very likely, it is also due to the vague notion of weight as an attribute. Is weight valued per $\underline{\text { se, }}$ or only because it contributes to some other attribute consumers value for its own sake, such as safety? In a review of ten recent studies, Greene and Liu (1988) found that four included vehicle weight as an attribute. Estimated values per pound to an average car buyer ranged from $\$ 0.17$ to $\$ 13.38$, present value at time of purchase. Though one might expect greater consensus on the value of performance, the reverse is the case. Typical measures of performance include the ratios of engine size to weight, or horsepower to weight, and acceleration time from 0 to $60 \mathrm{mph}$. Estimated values for an 0.01 cubic inch per pound change in the engine size/weight ratio (equivalent to about $0.004 \mathrm{HP} / \mathrm{LB}$, or about $10 \%$ of the mean) range from $\$ 6,787$ to negative $\$ 3,875$. Negative values for performance are not 
uncommon in the literature. A very recent study (McCarthy and Tay, 1989) values a 1 second decrease in acceleration time at between negative $\$ 630$ and negative $\$ 1004$.

Our rationale for attributing values to weight and performance is as follows. The principal value of weight to the consumer is its perceived effect on safety. We judge that weight, per se, has no value, and substitute for the value of weight an estimate of the c.nsumers' willingness to pay for an equivalent change in vehicle safety. For performance, we simply choose a positive value toward the middle of the range of available estimates, on the grounds that performance, per se, does have value to the typical consumer. The value we choose is $\$ 20$ per $1 \%$ change in the HP/WT ratio. That is, for a $20 \%$ increase in horsepower, ceteris paribus, the consumer is willing to pay $\$ 400$. This value, crude as it is, is at least in line with the cost to the consumer of larger, more powerful engine options.

Much has been written and said about the effect of vehicle weight on safety, but only recently has the National Highway Traffic Safety Administration (NHTSA) begun to carefully examine the evidence for passenger cars (e.g., U.S. DOT, NHTSA, 1989). To our knowledge, there are no estimates for light trucks. Early studies (e.g., Evans, 1982; 1984) found that occupants of smaller, lighter cars were substantially more likely to be killed or injured in a collision with a larger, heavier car than the occupants of the larger car. None of these studies, however, considered the total social effect on all traffic fatalities of weight reductions in an entire fleet. This would differ from the individual risk in that the probabilities of colliding with cars of different weights would change as the fleet downsized. This total social impact, including collisions with pedestrians and trucks, is the measure one would want to use.

The best available quantification of the impacts of size and weight changes on traffic fatalities comes from recent studies by NHTSA of single-vehicle accidents (U.S. DOT, 
NHTSA, 1990). With respect to single vehicle accidents in which cars did not roll over (about $57 \%$ of single vehicle fatalities), this study concluded,

"In nonrollover crashes, car weight reductions have had little or no effect on fatality risk, but a small increase in the risk of nonfatal injury." (p. 1)

With respect to rollover crashes, the study found a significant relationship of fatality risk to size and weight, but could not conclusively determine whether size or weight was the key factor.

"In rollover crashes, on the other hand, car-size has a major effect on fatality risk - not because small cars are less crashworthy, but because they are more rollover prone.... The net effect of the $1970-82$ car size changes is an increase of approximately 1340 additional rollover fatalities per year in the United States. (6,300 additional serious injuries, ed.) The analysis methods do not identify which individual vehicle size parameter (track width, curb weight, wheelbase, etc.) is the principal 'cause' of this added rollover proneness." (p. 1)

As a caution to studies such as this one the NHTSA authors observe,

"While the methods of this report are appropriate for estimating the effect of historical changes in car size on rollover fatality risk, it would be inadvisable to use them to predict what might happen in the future if a single parameter (say, curb weight) is changed while all others are held constant." (p. 40) 
This, of course, is precisely what we mean to do. Nonetheless, it is an important point to bear in mind since the effect of future weight reduction is sure to depend on precisely how weight is reduced. All the weight reductions assumed in this study are due to substituting lightweight materials, such as aluminum and plastics, for conventional materials. Putting bricks in one's trunk will not make one's car safer. Similarly, it is not clear that substituting lightweight materials will make it less safe.

NHTSA's study does make an attempt to attribute the increase in fatalities to downsizing within domestic car lines versis market shifts from full-sized cars to imports and subcompacts. The estimates, which are bracketed by caveats warning against cavalier use, attribute $74 \%$ of the observed increase in fatalities to market sales shifts among vehicle size classes (U.S. DOT, NHTSA, 1990, p. 40). Since $\$ 6 \%$ of the weight reduction in automobiles between 1975 and 1982 is attributable to within size class weight reduction (Heavenrich and Murrell, 1990), very little of the observed increase in fatalities is likely due to weight. If one accepts all of the above, on the order of one tenth to one third of the estimated 1340 fatalities inight be attributable to weight reduction alone.

Thus far, NHTSA's studies have focussed on single vehicle accidents which account for only about half of vehicle occupant fatalities. Estimates for multivehicle accidents may soon be available but were not published at the time this report was written. Until these become available, we have only the single-vehicle accident estimate to work with. Even when the latter study is complete, a great deal will remain unknown. NHTSA's studies have not considered the impact of vehicle downsizing on pedestrians, for example. It seems clear to us that pedestrians would benefit from narrower cars at the very least, and might benefit from lighter cars, especially if stopping distance were reduced with vehicle mass. Pedestrian and bicycle fatalities accounted for $20 \%$ of all traffic fatalities in 1988 . Conceivably, motorcyclists 
might also benefit. Collisions with heavy trucks, on the other hand, could be worse. The bottom line is that our knowledge of this issue is woefully inadequate.

In making our estimates we wish to recognize that, on the one hand, there is evidence that weight and safety are related but, on the other, our quantitative knowledge of what the total social effects of fuel economy-related weight reduction will be is weak almost to the point of being nonexistent. We must also acknowledge that NHTSA's analysts have warned against misusing their numbers in the very way we intend to use them. Recognizing that estimates useful for making the kind of calculations we want to make are not yet available, we adopt the following convention, solely to obtain a rough indication of how big a safety impact might be. We do not believe we are estimating the true safety impact of fuel economy improvement. As a reference assumption, we adopt the NHTSA estimate of 1,340 fatalities and 6,300 injuries per $1,000 \mathrm{lbs}$. as the impact on safety of future weight reductions to improve fuel economy. We assume an equal effect for light trucks proportionate to the numbers of vehicles on the road. Since there are roughly one-third as many light trucks as passenger cars, we divide the numbers for cars by three.

Safety impact estimates are used in two ways. First, we use them to compute hedonic price effects. As weight is reduced, the perceived value of the car is reduced, cost held constant, presumably because the consumer perceives it to be less safe. We know of no empirical evidence to support this, but we include it anyway because much has been made of the safety and fuel economy issue and we want to see how significant it might be in comparison with other factors. Second, the estimated safety cost is used for computing social costs and benefits. Here we are treating the safety impact as a particular component of a loss of consumers' surplus. Safety is not a true externality because it is essentially a private cost borne by the car owner. 
Translating lives into dollars is a distasteful task, and there is no correct way to do it. The ideal approach would be to determine the cost of safety improvements that might save as many lives as weight reduction might lose and add that cost to the vehicle price, under the assumption that the government would coordinate its safety and fuel economy regulations. Unfortunately, we have no such estimate. As a second best approach, we use estimates provided by NHTSA (Shelton, 1990) of consumers' willingness to pay for increased safety. These are $\$ 2,000,000$ per fatality and $\$ 95,000$ per serious injury.

To translate the increased risk of fatalities into the hedonic cost of weight reduction, we capitalize it as an effective vehicle price increase. As such, it affects both vehicle sales and scrappage. This is accomplished as follows. If we assume 1,340 fatalities at $\$ 2,000,000$ each and 6,300 fatalities at $\$ 95,000$ each, we obtain a total cost of $\$ 3.2785$ billion per year, per 1,000 lbs., or $\$ 3.2785$ million per $\mathrm{lb}$. In 1982 , the reference year for NHTSA's estimaies, there were 122.77 million automobiles in the U.S., for a per vehicle cost of $\$ 0.0267 / \mathrm{lb}$. Assuming a ten year vehicle life and discounting at $10 \%$, we derive a net present value per lb. of $\$ 0.16$.

The net change in the price of a new vehicle is the technology cost, plus the hedonic cost of performance changes ( $\$ 20$ per $1 \%$ ), plus the present value of safety impacts due to weight reduction $(\$ 0.16 / \mathrm{lb}$.), minus the present value of future fuel savings (always using a discount rate of $10 \%$ ). This net price change is used to estimate effects on vehicle sales and scrappage rates. For purposes of calculating costs and benefits, the components are treated individually, as described in Section 3.

In estimating social costs we vary our assumptions about the impact on safety to see how sensitive the total costs and benefits are to safety impacts. Varying this assumption in the last step, rather than redoing the entire analysis from the beginning, results in only a small 
loss of accuracy and reduces the computational burden enormously. NHTSA's analyses suggest to us that the impact of future fuel economy-related weight reductions will be considerably less than 1,340 fatalities per 1,000 lbs., and might even be nil. A reasonable assumption might be $10 \%$ of NHTSA's single vehicle fatality and injury estimates. One might reasonably double that estimate to recognize that multivehicle fatalities have yet to be heard from and are roughly equal in numbers. Including, pedestrians, cyclists, and heavy trucks, however, might counteract these extra fataities, to some extent. Since there are no comparable studies for light trucks, we might assume the same ratio of fatalities per pound as for cars, but for about a third as many vehicles. This gives 134 fatalities and 630 serious injuries per 1,000 lbs. for cars, and 45 and 210 for light trucks. We will use these numbers in addition to the NHTSA single vehicle estimate, in sensitivity analysis of costs and benefits.

\subsection{FUEL COST SAVINGS}

Fuel cost savings tend to offset the costs of fuel economy technology. Three factors determine the value of a given increase in MPG: 1) the future price of fuel in year $t\left(\mathbf{P}_{\mathbf{t}}\right)$, 2) the discount rate for future savings versus present costs ( $r$ ), and 3) the number of miles driven as a function of vehicle age $\left(M_{\mathrm{a}}\right)$. For the future price of fuel we use three National Energy Strategy fuel price projections: Low Oil Price, Reference Case, and High Oil Price (Figure 2). Data on miles driven as a function of vehicle age come from the Energy Information Administration's Residential Transportation Energy Consumption Survey (U.S. DOE, EIA, 1990a). In the Reference Case, which is used for most of the calculations below, gasoline prices rise from $\$ 0.98 /$ gal. in 1990 to only $\$ 1.07 /$ gal. in $1995, \$ 1.25$ in $2000, \$ 1.61$ by 2020 , and $\$ 1.71$ by 2030 (all prices are in 1989 dollars). 


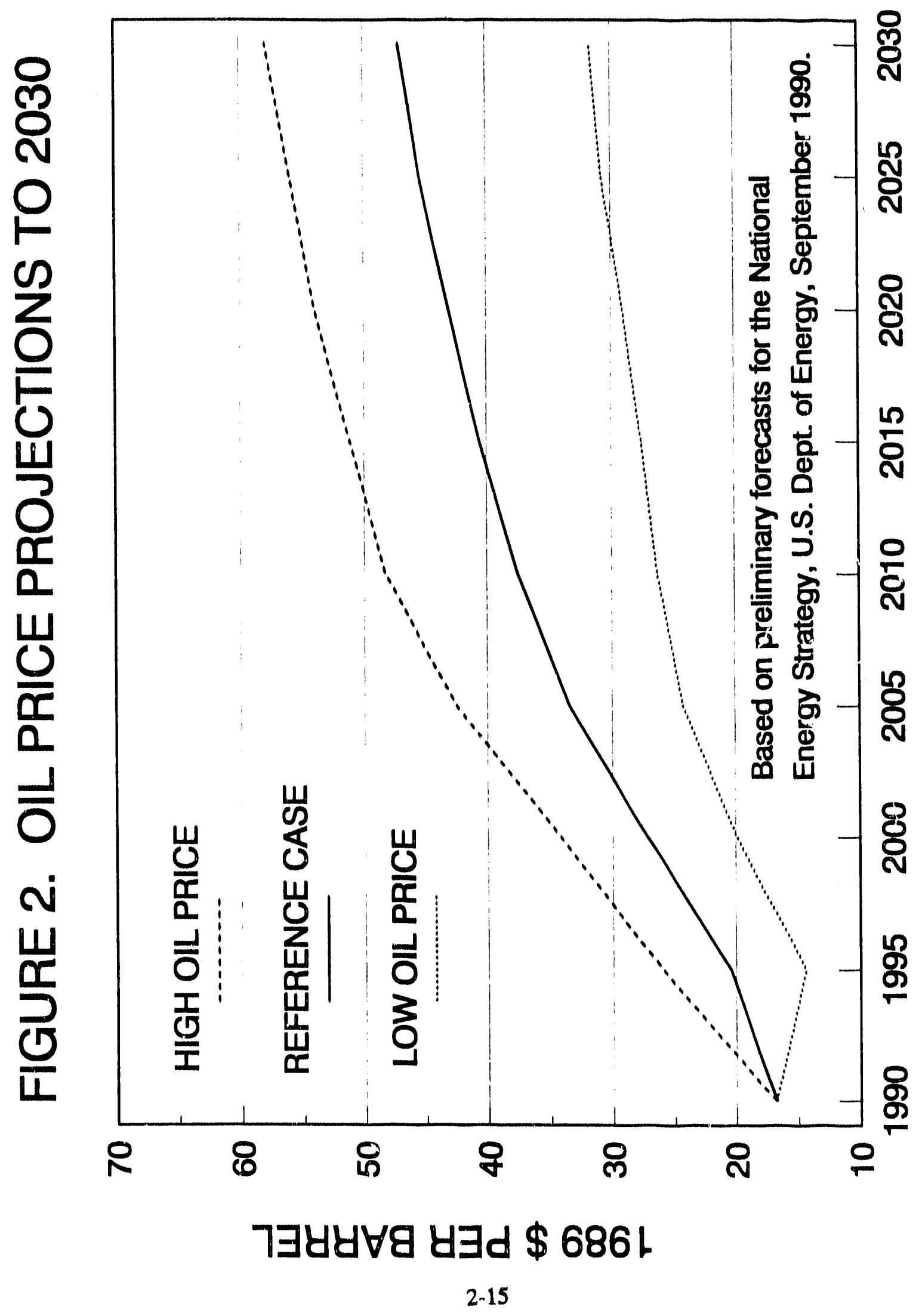


The present value of fuel savings $\left(S_{i}\right)$ of moving from fuel economy level $\mathrm{MPG}_{0}$ to $\mathrm{MPG}_{1}$ is computed for the purpose of estimating the vehicle price impact by,

$$
S_{i}=\sum_{a=0}^{L} \frac{M_{a} P_{t}}{(1+r)^{(a+0.5)}}\left[(1 / 0.85)\left(\left(1 / M^{\prime} G_{0}\right)-\left(1 / M^{\prime} G_{i}\right)\right)\right]
$$

State and federal gasoline taxes average $\$ 0.25 /$ gal. in 1989 , the base year of the forecast. Taxes are subtracted from gasoline price in computing the social value of fuel savings but not the private value to the consumer. The factor $(1 / 0,85)$ is intended to correct for an approximate $15 \%$ shortfall from EPA test MPG to on-road performance. In calculating the net price effects, $r$ is always 0.1 and $L=4$. This heavy discounting of fuel savings is intended to represent consumer perceptions, not social value. For the cost-benefit calculations, fuel savings are computed based on the projections of a vehicle stock model of energy use, as described below. Secondary effecti, such as the effect of higher new car prices (dollar and hedonic) on the scrappage rates of older vehicles, are captured by the stock model and reflected in somewhat lower total fuel savings for a given fuel economy improvement. Also, we vary discount rates and time periods in cumputing social costs to illustrate the sensitivity of costs and 'ienefits to key assumptions.

The observation that technological improvements in the efficiency of energy using consumer goods tends to increase their usage has been labeled the "take-back effect" or, alternatively, the "rebound effect" (Khazzoom, 1980). Improvements in MPG lower fuel costs perr mile and, therefore, should tend to increase total vehicle travel, ceteris paribus. This zubject has been recently reviewed by Greene (1991), who concluded that the elasticity of passenger car and light truck travel with respect to fuel cost per mile is probably in the range of -0.05 to -0.15 . In other words, a $10 \%$ increase in MPG would increase travel by $0.5 \%$ to $1.5 \%$. In this analysis we use an elasticity of -0.2 which is probably more in line with older sturies, but we test the sensitivity of our results to this assumption. We represent the 
rebound effect in year $t$, scenario $i\left(R_{t}\right)$ by adjusting the Base Case vehicle miles of travel (VMT) according to the improvement in fleet MPG over the base case:

$$
\mathbf{R}_{\mathrm{ti}}=\left(\mathrm{MPG}_{\mathrm{tBC}} / \mathrm{MPG}_{\mathrm{ti}}\right)^{-0.2}
$$

\section{OIL PRICE BENEFITS}

The U.S. is such a large consumer of oil (25\% of world oil use in 1989) that significant reductions in U.S. demand could affect world oil prices (see, e.g., Broadman, 1986). The ability of a single large consumer to affect market prices is referred to as "monopsony" power, and the change in prices resulting from a monopsonist's change in demand is termed the monopsony price effect. By unilaterally cutting back on consumption, the dominant consumer can lower the price of every barrel of oil it buys. If the U.S. were facing competitive world oil suppliers, the monopsony price effect would be certain, and relatively easily estimated. The existence of the OPEC cartel, however, removes the certainty. OPEC could counter a significant reduction in U.S. demand by cutting back on production to hold the line on prices, thereby eliminating the monopsony price benefit. However, Greene (1991) has argued that OPEC's resulting loss of market share would lead to a reduction of its monopoly power, forcing an eventual reduction in prices over what they would otherwise have been.

An interesting aspect of monopsony benefits generated by the U.S. is that the majority would accrue not to the U.S. but to other users of petroleum throughout the world. Three times as many benefits would be captured by consumers outside the U.S. If the rest of the world were to follow the U.S.'s lead and similarly reduce demand, even greater benefits would accrue to U.S. consumers. If on the other hand, the rest of the world took the opportunity 
to increase its consumption, lesser benefits would accrue to U.S. consumers. Thus, consuming nations have a mutual interest in cooperating to conserve oil. If they are successful, the monopsony benefits generated by one will be multiplied by the efforts of others. If they are not, the benefits may be reduced.

We estimated monopsony price benefits by counting only those benefits directly captured by U.S. consumers, and assuming that the rest of the world does not similarly reduce its oil demand. First we estimate the change in world oil price using an elasticity relating world oil price to U.S. oil demand, as explained below. We assume that all the reduced oil demand translates into reduced oil imports. In fact, to the extent that reduced demand lowers world oil prices there will be some reduction in U.S. oil production, resulting in a somewhat smaller import reduction. There would also be a gain in efficiency from not producing the higher cost U.S. oil, but we ignore this also. U.S. benefits are set equal to U.S. imports (after the reduction in demand) times the estimated price change. Again, all the reduction in demand translates into reduced imports for the purpose of this calculation. So long as the changes in quantity and price are relatively small and the U.S. supply and demand curves are relatively inelastic, this will be a reasonable approximation.

A decrease in U.S. demand for oil triggers a series of adjustments by oil suppliers and demanders via the oil market. The long-run response of world oil prices can be characterized by an elasticity of world oil price with respect to U.S. oil demand. ${ }^{2}$ In equilibrium, U.S. oil demand $\left(D_{U S}\right)$ equals net oil supply to the U.S. $\left(S_{U S, N}\right)$, and so the elasticity of world oil price with respect to U.S. demand is the inverse of the elasticity of net supply to the U.S. with respect to world oil price. Net supply comprises domestic supply $\left(\mathrm{S}_{\mathrm{US}}\right)$, OPEC supply $\left(\mathrm{S}_{\mathrm{OPEC}}\right)$,

\footnotetext{
${ }^{2}$ The exposition of world oil price elasticity with respect to U.S. demand offered here is based on a derivation due to my colleague, Dr. Paul Leiby (1990).
} 
rest-of-wurld nonOPEC supply $\left(\mathrm{S}_{\mathrm{ROWN}}\right)$, minus rest-of-world (including OPEC) demand ( $\left.\mathrm{D}_{\text {ROW }}\right)$.

$$
D_{U S}=S_{U S, N}=S_{U S}+S_{O P E C}+S_{\text {ROWN }}-D_{\text {ROW }}
$$

From equation (3) we can derive the fact that the elasticity of net supply to the U.S. is the weighted suin of elasticity of each of its components.

$$
\eta_{U S, N}=\frac{\eta_{U S} s_{U S}+\eta_{O P E C} s_{O P E C}+\eta_{R O W N} s_{R O W N}-\eta_{R O W} D_{R O W}(4)}{s_{U S}+s_{O P E C}+s_{R O W N}-D_{R O W}}
$$

Of all the terms in equation '?), the price elasticity of OPEC supply is the most difficult to determine. Perhaps the best one can do is to choose some plausible values and use them to identify a range of net supply elasticities. Leiby (1990) has done this using data from the International Energy Annual (U.S. DOE, EIA, 1990b) and the Energy Information Administration's Oil Market Simulation (OMS) model. The data and elasticities are shown in Table 3.

Reasonable elasticities of world oil price with respect to U.S. demand appear to range from $\mathrm{C.3}$ (assuming unitary elasticity of OPEC supply) to 1.1 (assuming perfectly inelastic OPEC supply and low values for all other elasticities). A value of about 0.5 is consistent with the DOE OMS model, and reasonable values for other parameters. This would imply that if U.S. demand decreased by 1 MMBD (about 5.3\%), then world price would decline by $\$ 0.75 / \mathrm{BBL}$ (about 2.6\%). Assuming an elasticity of 0.67, a 1 MMBD decline in demand would lead to a $\$ 1 / \mathrm{BBL}$ decrease in oil price, while an elasticity of 0.3 would imply a $\$ 0.45$ price decline. In the analyses below, we wil! use values of $0.3,0.5$, and 0.6 . We also calculate price impacts separately for the petroleum saved by passenger cars and light trucks. Given that the oil demand changes are small, this is not an unreasonable approximation. 
Table 3. Elasticity of World Oil Price with Respect to U.S. Oil Demand: Illustrative Calculations Based on Year 2000 Projections (Oil \$28/BBL in 1988\$).

\begin{tabular}{|c|c|c|c|c|c|}
\hline & $\begin{array}{l}\text { Quantities } \\
\text { (MMBD) }\end{array}$ & OMS90 & Case 1 & Case 2 & Case 3 \\
\hline$D_{\text {Us }}$ & 18.88 & -0.7 & -0.7 & -0.7 & -0.4 \\
\hline$S_{U S}$ & 8.45 & 0.4 & 0.3 & 0.3 & 0.1 \\
\hline $\mathrm{S}_{\mathrm{OPEC}}$ & 28.99 & 0.0 & 0.0 & 1.0 & 0.0 \\
\hline $\mathrm{S}_{\mathrm{ROWN}}$ & 17.41 & 1.0 & 0.3 & 0.3 & 0.1 \\
\hline$D_{\text {ROW }}$ & 35.97 & -0.5 & -0.7 & -0.7 & -0.4 \\
\hline$S_{U S, N}^{K U W}$ & 18.88 & 2.1 & 1.7 & 3.3 & 0.9 \\
\hline$n_{w}$ & & 0.5 & 0.6 & 0.3 & 1.1 \\
\hline
\end{tabular}

Source: Leiby, 1990, p. 2.

\section{TRANSFER OF WEALTH VIA MONOPOLY PRICING}

By using their monopoly power to increase world oil prices above competitive market levels, the OPEC producers increase the economic rent flowing from consumers to them (API, 1988, p. 3). Adelman (1989) estimated that in 1986 the long-run competitive equilibrium world oil price was about $\$ 5 / \mathrm{bbl}$. ( $\$ 5.50$ in 1989 dollars). The world price in 1971 72 , just before the OPEC Cartel flexed its muscles, was about $\$ 3.20 / \mathrm{bbl}$, or about $\$ 8.50$ in 1989 dollars. Every dollar over the competitive market price U.S. consumers pay for OPEC oil is U.S. wealth transferred to OPEC and other low-cost oil producers. We value it dollar for dollar, according to the precept that a penny saved is a penny earned. This transfer of wealth is sometimes neglected in analyses of the costs of imported oil, on the grounds that OPEC producers may use the money to buy U.S. products or to invest in the U.S., resulting in no loss of growth to the U.S. economy. Mork and Hall (1980) claim that this is not true, but that the primary effect is a decline in demand for U.S. goods and services and, hence, lower economic growth. However, even if all of the wealth transferred were invested in the U.S. economy, there would still be a change in ownership, and the returns to the capital would still go to foreign instead of domestic owners. The impact of this transfer on economic 
growth, inflation, or unemployment is not considered. The impact of potential price shocks on these factors is considered in the form of an energy security premium.

To the extent that it matters who owns the capital of the United States, the transfer of wealth via monopolistic oil prices may be considered important. We measure the avoided wealth transfer as the quantity of import reduction multiplied by the difference between the new estimated world oil price and the estimated competitive price.

By assuming that all demand reduction translates into reduced imports, we overestimate the transfer of wealth. Some of the reduction will come from reduced domestic production and some from marginal foreign sources. This will result in resource savings and efficiency gains but not reduced wealth transfer. The two are combined here. Two estimates of what the price of oil would be in the absence of the OPEC oil cartel are used. The estimate of $\$ 8.50 / \mathrm{bbl}$ is broadly consistent with but higher than estimates by Adelman (1989). It is also roughly equal, after accounting for inflation, to the price of oil prevailing before the OPEC-led price increases of 1973-4 (Greene, 1991). As a higher competitive world oil price we use $\$ 16 / \mathrm{bbl}$., about the lowest price observed in recent years. This may well be a controversial component of the costs and benefits. To our knowledge it has not been measured elsewhere and, thus, there is no convention about how to value it. Clearly, it deserves greater attention and more precise measurement.

\section{ENERGY SECURITY}

It is customary to divide the costs of oil dependency into economic and national security effects (Hogan and Broadman, 1988). On the economic side, we are primarily concerned with the impacts of sudden oil price changes (increases or decreases) on economic 
growth, inflation, and unemployment. These losses result from the sluggish adjustment of the economy to abrupt, important changes in commodity prices. We are not concerned here with the sustained increase in price due to the exercise of monopoly power, because this is included in the "monopsony price" and "transfer of wealth" effects described above. We are concerned, however, with the less tangible political and strategic costs of dependence on a politically unstable region for supplies of so critical a commodity as oil. It has also been argued that oil price uncertainty reduces capital investment, especially in energy-using equipment, leading to lower economic growth, but there appear to be no estimates of the magnitude of this effect.

The oil price shocks of 1973-74 and 1979-80 were the primary cause of subsequent recessions and extraordinary inflation (Hamilton, 1985; U.S. GAO, 1988, pp. 2 \& 16). Economic analyses of the oil price shocks of the 70s have shown that nearly all of the loss of GNP in the recessions that immediately followed can be attributed to them (Mork and Hall, 1980, p. 42; U.S. Congress, OTA, 1984). An oil price shock causes a sudden shift in energy prices, to which the economy must adjust in order to produce efficiently. The necessary adjustments to prices, capital, and technology take time, and during this time the economy is producing less efficiently than before the price shock. This adjustment cost is especially important for energy price shocks since energy-using processes typically require long-lived, expensive capital equipment. The stickiness of the adjustment process lowers GNP growth for several years.

Inflation and unemployment are key symptoms of the cost of adjustment to price shocks. Studies of the 1973-74 and 1979-80 oil price shocks indicate that they contributed to substantial increases in inflation. Although inflation was expected to rise by $3 \%$ between 1973 and 1974 , it actually rose $12 \%$. Similarly, a $7 \%$ inflation rate was anticipated for $1979-80$ 
but the actual rate was $14 \%$. Unemployment will also be affected, depending on the stickiness of wages and prices throughout the economy.

Estimates of the economic costs of vulnerability to supply shocks vary widely, from essentially nil to over \$20/BBL (Broadman, 1986, Table 1). One estimate of the economic costs of supply disruptions alone (Broadman and Hogan, 1988) put the gap between the social and private cost at \$7-\$8/BBL (1985\$, or \$8-\$9/BBL in $1989 \$)$. This view has been disputed by those who argue (inter alia) that the Strategic Petroleum Reserve (SPR) greatly reduces the potential cost of supply disruptions (Nesbitt and Choi, 1988; Goulder, 1985). Yet another study that explicitly considered the use of the SPR and allowed tariffs to be suspended during disruptions to mitigate the adverse economic impact, concluded that social costs of potential disruptions were essentially identical to those of Broadman and Hogan (Murphy, Toman, and Weiss, 1986). Even estimates by a single author range from $\$ 1$ to $\$ 20 / \mathrm{BBL}$ due chiefly to uncertainty about the size and duration of future oil price shocks (Broadman, 1986, Table 1). We use three estimates here: $\$ 1 / \mathrm{BBL}$ to capture the low end of the range, $\$ 5 / \mathrm{BBL}$ the middle, and \$10/BBL, representing a higher but still credible estimate.

Neither the \$1/BBL nor the \$10/BBL estimate includes strategic costs of imported oil. These costs exist, but are extremely difficult to quantify (API, 1988). Two thirds of the world's proven oil reserves lie in the Persian Gulf Region. The strategic vulnerability of this region and the costs of maintaining its stability have been made all too clear by the recent Persian Gulf War. But there are more subtle costs of oil dependency, as the 1987 Report to the President, "Energy Security" pointed out:

"Increased dependence on insecure oil supplies reduces flexibility in the conduct of U.S. foreign policy." (U.S. DOE, 1987, p. 68) 
The strategic vulnerability of Persian Gulf oil supplies could also create problems for military fuel supplies in a large scale conflict. Attempts to quantify these costs have been crude, at best. Nonetheless, they suggest that the costs could be substantial. Rather than including an arbitrary strategic cost component, we argue that the existence of significant strategic costs argues in favor of the higher (\$10/BBL) rather than the lower (\$1/BBL) energy security cost estimate.

\subsection{EMISSIONS COSTS AND BENEFITS}

It is commonly believed that more efficient vehicles will be cleaner and less polluting. It has also been argued that more efficient vehicles will be driven more and thus produce more pollution (Khazzoom and Shelby, 1990), and that the cost of higher fuel economy will slow scrappage rates keeping older, more polluting vehicles around longer (Gruenspecht, 1982). In fact, all of the above are true. More efficient vehicles will certainly reduce emissions of hydrocarbons (HC), mainly by reducing evaporative rather than tailpipe emissions (DeLuchi, Wang, Greene, 1991). On the other hand, more efficient vehicles will tend to be driven more because of the lower fuel cost per mile. Because current law sets tailpipe emission standards based on mass emitted per mile, more miles may mean more pollutants. ${ }^{3}$ Finally, older vehicles tend to pollute more because they have been designed to less stringent standards and because emissions performance tends to deteriorate with age. The vehicle stock model and the calculations based on its output, take all of these factors into account. The key question, of course, is how important is each of them?

\footnotetext{
${ }^{3}$ Whether more efficient engines permit the tightening of emissions standards has not heen carefully examined. If so it could mean that more efficient cars would pollute less even with an increase in vehicle use. Finally, since tailpipe emissions are greatest before a vehicle is fully warmed up and its catalyst lit, actual emissions should be more closely related to number of trips rather than total miles. This issue, however, has not be analyzed.
} 
We consider the three major criteria pollutants for motor vehicles: hydrocarbons (HC), carbon monoxicle (CO), and oxides of nitrogen $\left(\mathrm{NO}_{\mathrm{x}}\right)$. We also estimate emissions of carbon dioxide, the chief greenhouse gas produced by motor vehicles. To compute the effects of scrappage and vehicle use changes due to fuel economy improvements, we need estimates of miles driven by eacth vintage, together with vintage-specific emissions rates for each forecast year. The vehicle stock model provides estimates of miles driven that are sensitive to the age and efficiency of each vintage, as well as the price of gasoline in the forecast year. Tables of vintage-specific emissions rates for each forecast year were provided by the Environmental Protection Agency, based on forecasts of their MOBILE4 model (U.S. EPA, 1990). Emissions were obtained by multiplying predicted miles by the appropriate emission rate, for each vintage, and summing across vintages in each year. Thus, a shift towards older vehicles would be reflected in more miles by vehicles with higher ernissions rates and, therefore, greater total ernissions. Efficiency improvements would cause increased vehicle use and, therefore greater emissions. These effects, however, turn out to be relatively minor.

Higher MPG will reduce $\mathrm{HC}$ and $\mathrm{CO}_{2}$ emissions. DeLuchi, Wang, and Greene (1991) estimate that every 1 MPG improvement beyond the current new car fleet average level of $28 \mathrm{MPG}$ will result in approximately $0.0229 \mathrm{gpm}$ reduction in total hydrocarbon emissions. This estimate takes into account emissions controls and fuel volatility reductions mandated by the clean air act, and includes total system emissions from crude oil production to the tailpipe.

Carbon dioxide emissions are directly proportional to fuel consumption. The EPA estimates that $19.7 \mathrm{lbs}$. of carbon dioxide are produced per gallon of gasoline consumed. The amount may vary slightly due to variations in the composition of gasoline. Given the atomic weights of carbon (12.011) and oxygen (15.9994), this is equivalent to $[12.011 /(12.011+31.988)] 19.7=5.38 \mathrm{lbs}$. of carbon per gallon. Except for the small increase 
in travel with increased efficiency, fuel consumption will be directly proportional to fuel efficiency.

Ideally, one would like to value emissions reductions based on the environmental and health costs they impose. Of course, these are very difficult to determine because there are tremendous scientific uncertainties about impacts and enormous economic and ethical arguments about the value of a clean environment and the value of life, for exampic. A simpler alternative is to use the avoided cost of other emission control technologies in use or required to be implemented in the future. The reasoning is that society has implicitly valued emission reductions at least the cost of the most expensive measure it is using to control them. For criteria pollutants, typical avoided costs per ton are: 1) $\$ 300$ for $\mathrm{CO}, 2) \$ 2,000$ for NOx, 3) $\$ 2,900-\$ 3,800$ for HC. In our calculations we use $\$ 3,350 /$ ton for HC.

Since there currently is no regulation of $\mathrm{CO}_{2}$ emissions, there is little basis for judging what the society is willing to pay to reduce them. There have been several studies, however, of the costs of reducing $\mathrm{CO}_{2}$ emissions. Considering a variety of strategies, Nordhaus (1991, Table 9) concluded that a $5 \%$ reduction in $\mathrm{CO}_{2}$ emissions by the U.S. could be obtained for $\$ 2.6 /$ ton of $\mathrm{C}$, a $10 \%$ reduction for $\$ 5.3 /$ ton, $25 \%$ for $\$ 40.2 /$ ton, and $50 \%$ for $\$ 119.9 /$ ton. Since there are 0.273 tons of $\mathrm{C}$ per ton of $\mathrm{CO}_{2}$, in terms of $\$ /$ ton of $\mathrm{CO}_{2}$, these costs are: $5 \%$ for $\$ 9.50,10 \%$ for $\$ 19.50,25 \%$ for $\$ 150$, and $\$ 440$ for $50 \%$. Some studies indicate that costs could be considerably higher than these estimates (e.g., Manne and Richels, 1990a, 1990b, find a carbon tax of over $\$ 100$ and possibly as high as $\$ 250$, would be necessary to achieve a $20 \%$ reduction in $\mathrm{CO}_{2}$ over 1990 levels in 2020), while others have suggested costs will be lower and perhaps negative up to some point (e.g., Williams, 1990). The report of the National Academy of Sciences (1991) on policy implications of global warming characterized options costing from $\$ 0-\$ 9 /$ ton $\mathrm{CO}_{2}$ as "low-cost" and those from $\$ 10-\$ 99 /$ ton as "moderate cost." The report emphasized the wide range of uncertainty in costs, but concluded that much 
could be done (perhaps as much as a $25 \%$ reduction in $\mathrm{CO}_{2}$ emissions) at low cost. It seems to us that $\$ 10 /$ ton of $\mathrm{C}$ is a reasonable low cost estimate for a significant but not drastic reduction in $\mathrm{CO}_{2}$ emissions. As a higher but still plausible estimate we will use $\$ 100 /$ ton of $\mathrm{C}$, and $\$ 50 /$ ton of $\mathrm{C}$ as a middle estimate. Costs per ton of $\mathrm{CO}_{2}$ are roughly one fourth as large.

\section{CONSUMERS' SURPLUS EFFECTS}

By changing the prices of cars, vehicle travel, and petroleum, fuel economy standards do affect consumers' surplus. Changes in vehicle design to achieve higher MPG can also reduce consumers' surplus if they are perceived as undesirable by consumers. However, since we directly account for the "hedonic" costs of performance reductions in computing the cost of fuel economy technology and the effect of reduced weight on safety, these should not be included in calculating the remaining consumers' surplus effect. Other design changes may be made, such as more aerodynamic styling, that could well affect consumers' satisfaction, but in ways that we think are impossible to predict and as likely to be favorable as unfavorable. This leaves vehicle price, fuel cost per mile, and petroleum prices.

We assume that demand equations are approximately log-linear over the range of interest, with price elasticity of $\alpha$,

$$
Q(p)=Q_{0} \cdot\left(p / p_{0}\right)^{\alpha}
$$

Given a price increase from $p_{0}$ to $p_{1}$, consumers' surplus can be approximated by the integral under

the demand curve minus the change in expenditure, $\left(p_{1}-p_{0}\right) \cdot Q\left(p_{1}\right)$. 


$$
\begin{aligned}
C S & =\int_{p_{0}}^{p_{1}} Q_{0}\left(p / p_{0}\right)^{\mu} d p-\left(p_{1}-p_{0}\right) Q\left(p_{1}\right) \\
& =Q_{0}\left[p_{1}\left(p_{1} / p_{0}\right)^{\prime \prime}(\{1 /(\alpha+1)\}-1) \cdot p_{0}\left(\{1 /(\alpha+1)\}-\left(p_{1} / p_{0}\right)^{a}\right)\right\}
\end{aligned}
$$

Equation (6) ignores the changes in demand for other products that will oecur when the price of vehicles or travel changes. Given that price changes are relatively small, as they are here, this should not create serious errors.

The vehicle price increase includes the cost of fuel economy technology, minus the value to the consumer of future fucl cost savings. As a result, the effective price increase, and consequently the consumers' surplus loss is not as great as one might expect. Higher MPG reduces the fuel cost per mile of travel, thereby reducing the price of vehicle travel. This reduction in the price of travel yields a consumers' surplus gain, offsetting part of the CS surplus loss due to higher vehicle prices. Finally, the reduction in world oil prices will result in consumers' surplus gains for all other users of oil in the U.S. and the world. We assume a new car prices elasticity of -1.0 , an oil price clasticity of demand of -0.7 , and three fuel cost per mile elasticities: $-0.05,-0.1$, and -0.2 . 


\section{MODELING AND ESTIMATION}

Costs and benefits of fuel economy improvements depend on the size and timing of MPG increases, and on the use and turnover of the vehicle stock. The fundamental fact of fleet fuel economy improvement is that greater energy efficiency is embodied in new vehicles and that the returns (fuel savings) are realized over time as the vehicle stock turns over. For this reason, calculating future costs and benefits rcquires the use of a model of vehicle stock turnover and use. The model must not only be able to retire vehicles as they age, but it should predict how their usage will change with age and with changes in the cost of fuel and vehicle fuel economy. It must predict the numbers of vehicles by age for each forecast year so that changes in fleet average weight can be computed for safety calculations. It must also produce forecasts of vehicle miles by vintage for use in computing fleet average emissions rates. Finally, we must have a framework for integrating all of the components of costs and benefits, and for analyzing their sensitivity to key assumptions.

Figure 3 illustrates the cost-benefit calculation process. At its heart is a model of the motor vehicle stock, the Alternative Motor Fuel Use Model (Greene and Rathi, 1990) developed by Oak Ridge National Laboratory for the U.S. Department of Energy. (I) The combined imported and domestic vehicle characteristics, shown in Table 1, are used to compute the net change in new car and light truck prices, and the resulting change in sales. (II) Sales, fuel economies, and new car and truck prices are inputs to the AMFU model,

which predicts the evolution of the vehicle stock over time and its fuel use. One output of the AMFU model is a detailed accounting of vehicle miles by vintage, for each forecast year. (III) These estimates, together with EPA projections of emissions per mile by vehicle vintage 


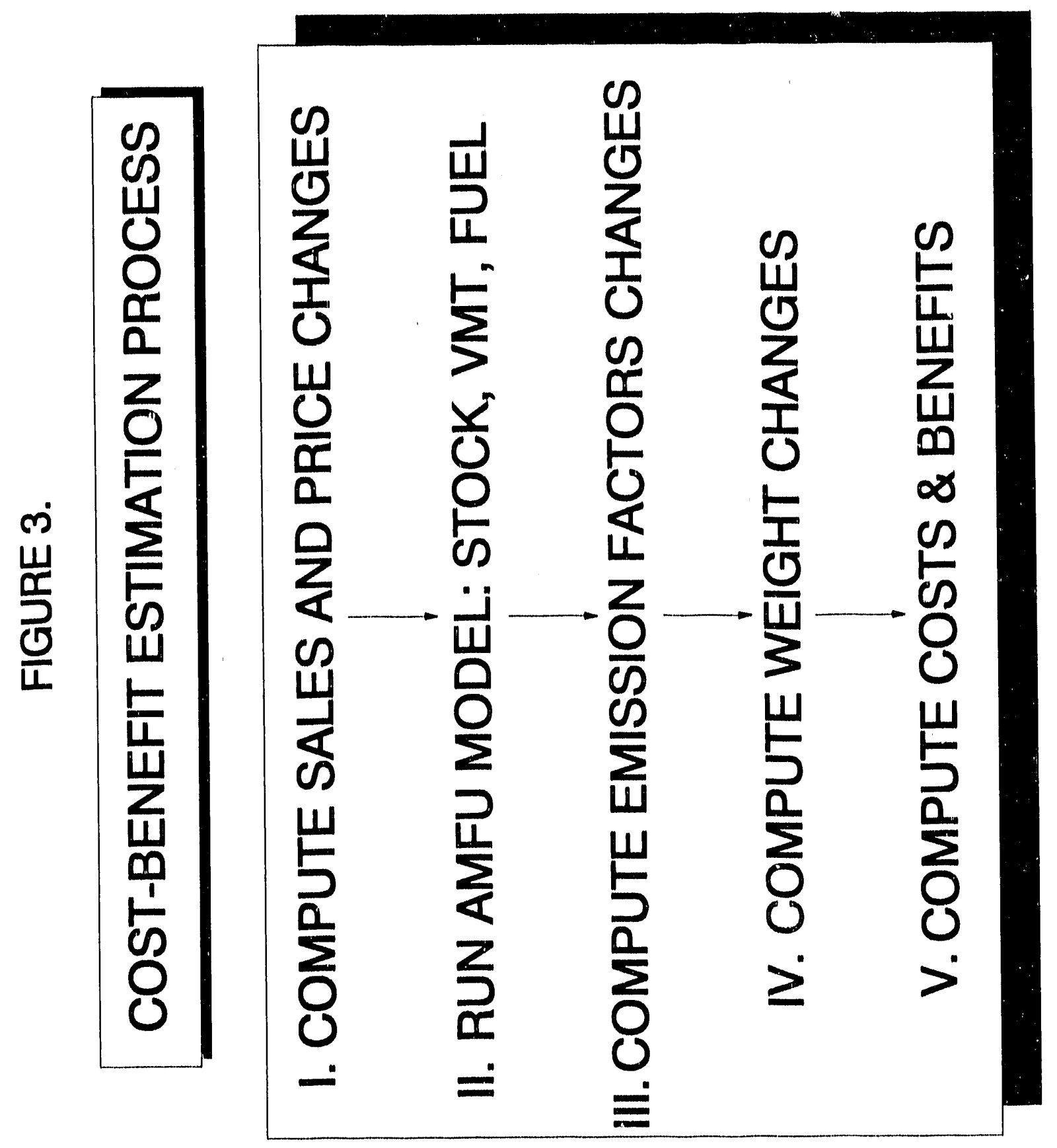


are used to estimate the total fleet average emissions rate. Another output of the AMFU model is the number of vehicles by vintage for each forecast year. (IV) These detailed vehicle stock projections are used to estimate changes in the average weight of the vehicle fleet. (V) Finally, fuel use and vehicle use projections, together with emissions and weight changes are combined in an integrating spreadsheet to estimate the streams of costs and benefits over time and discount them to present value. Combining all these computations in a single worksheet facilitates testing the sensitivity of the results to key assumptions.

\subsection{VEHICLE PRICE AND SALES}

The price changes computed in step (I) engender adjustments in passenger car and light truck sales and, later in the AMFU model, changes in the rates of vehicle scrappage. The components of price changes are: 1) the cost to the consumer of fuel economy technology, plus 2) the present value of changes in performance and weight, minus 3) the present value of future fuel cost savings. Including the value of fuel savings greatly reduces the effective price increase and, therefore, its impact. Average 1989 new car and light truck prices are assumed to be $\$ 15,403$ and $\$ 13,5(0)$, respectively (MVMA, 1990, pp. 40 and 47). Price changes are added to these base prices. Next, we adjust the baseline sales forecasts to account for the higher cost of more efficient vehicles using a price elasticity of $\mathbf{- 1 . 0}$. This is both a conveniently round number and one with empirical support (e.g., Irvine, 1983). The initial sales forecasts are based on the Energy Information Administration's 1990 Annual Energy Outlook forecasts (Cohen, 1990), extended to 2030. 


\subsection{VEHICLE STOCK MODEL}

The vehicle stock model: 1) adds new vehicles to the existing fleet, 2) scraps older vehicles, 3) computes vehicle use by multiplying the number of vehicles by a computed miles per year for vehicles of that age and type, and 4) computes fuel consumption by dividing vehicle miles for each vintage by the estimated on-road efficiency of vehicles of that vintage and type. Since all of these are computed at the level of vehicle type and vintage, the model can produce vintage-specific output for use in computing emissions and weight changes.

\subsection{EFFECTS OF NEW CAR PRICE ON SCRAPPAGE}

Reducing the saies of newer, more efficient vehicles retards the rate of fleet fuel economy improvement. ${ }^{4}$ Higher new car prices reduce the scrappage rates of older vehicles further retarding MPG gains. In the original version of AMFU, scrappage is accomplished via a logistic scrappage curve, in which the rate of scrappage depends on used car prices which are, in turn, a function of new car prices. For this analysis, we replaced the logistic scrappage function for passenger cars with a scrappage function developed by Gruenspecht (1982). ${ }^{5}$ Gruenspecht's price elasticities are shown in Table 4. We used the AMFU logistic scrappage function for light trucks.

${ }^{4}$ In the AMFU model, reduced sales would also depress vehicle travel and fuel use. This may be realistic but if it is not, it will lead to an overstatement of fuel savings. Instead, we assume that the intensity of vehicle use will increase so that vehicle miles remain at the same level as in the Base Case.

${ }^{5}$ The mathematical form of the logistic function requires that scrappage elasticities decline with vehicle age, although the sensitivity of scrappage rates to a dollar change in price increases. In Gruenspecht's model the data determine the pattern of scrappage elasticities with age and his empirical results show that elasticities increase with age, an intuitively satisfying result. As it turned out, the quantitative tesults differed little between the two models because scrappage rates for newer vehicles are almost negligible. 
Recent evidence suggests that vehicle scrapping rates have slowed and that expected lifetimes have increased since the 1970's (Davis and Hu, 1991, Table 3.6). Thus, using Gruenspecht's rates may tend to overestimate the rates of scrappage, le iding to an underestimate of the growth of vehicle stock. On the one hand, this will accelerate the rate of stock turnover and efficiency improvement, but only slightly. On the other, it will result in slow growth in the vehicle stock, reducing total vehicle travel and fuel use. These two effects will tend to counterbalance each other in terms of their effects on future fuel savings.

Table 4. Elasticities of Scrappage with Respect to Price.

\begin{tabular}{lcc} 
Age & Elasticity & $\begin{array}{c}\text { Average } \\
\text { Scrapping }\end{array}$ \\
\cline { 3 - 3 } 5 & -1.36 & 0.0154 \\
6 & -1.57 & 0.0237 \\
7 & -1.48 & 0.0378 \\
8 & -0.99 & 0.0677 \\
9 & -0.80 & 0.1109 \\
10 & -0.72 & 0.1654 \\
11 & -0.88 & 0.2133 \\
12 & -0.98 & 0.2518 \\
13 & -1.19 & 0.2741 \\
14 & -1.52 & 0.2849 \\
$15+$ & -1.52 & $0.2849^{\circ}$
\end{tabular}

- Assumed equal to 14-year-old vehicles.

Source: Memorandum from Howard Gruenspecht, Council of Economic Advisors, August 8, 1990. Rates estimated using 1967-78 vehicie registration data.

Gruenspecht's scrappage rates and elasticities were estimated using data from 1967-78. 


\subsection{VEHICLE USE}

Vehicle use tends to decline with vehicle age and is also sensitive to fuel cost per mile (price per gallon divided by miles per gallon), and the economy. In the AMFU model, vehicle use is assumed to decline exponentially with age, at a rate estimated using data in the Department of Energy's Residential Transportation Energy Consumption Survey (U.S. DOE, EIA, 1990). Although this survey covers only vehicles domiciled at residences, this includes over $90 \%$ of passenger cars and three-fourths of light trucks (Davis and Hu, 1991, Table 3.31). Furthermore, fleet vehicles tend to receive greater annual use and are typically held for only $2-4$ years before being sold to the household sector. The rate of decline in vehicle use with age is $4.6 \%$ for automobiles and light trucks. The usage rate of a new vehicle is calibrated so that fuel use in the base year matches fuel use reported by the Federal Highway Administration for passenger cars and 2-axie, 4-tire trucks, in Table VM-1 of Highway Statistics (U.S. DOT, 1989).

In future years, usage is adjusted according to changes in economic factors. An income elasticity of travel of 0.4 is used for both passenger cars and light trucks (a 10\% increase in income produces a $4 \%$ increase in travel). The elasticity of travel with respect to cost-per-mile used in the AMFU model is -0.2 , although recent investigations suggest that it is probably lower, in the range of -0.05 to -0.15 (Greene, 1991). The effect of fuel costs on travel is computed using vintage-specific, rather than fleet average, efficiencies. That is, usage by each age category of vehicle is adjusted as efficiencies improve, as well as when fuel prices change. For example, if the MPG of 15-year-old cars in 2020 is twice that of 15 -year-old cars in 1989 (base year), then they will be driven $20 \%$ more at the same fuel price (100\% reduction in cost per mile, -0.2 elasticity). Finally, the projections of new car fuel economy based on the EPA test cycle are adjusted to reflect real world driving conditinns. We begin with an on-road/test-cycle MPG ratio of 0.85 , which declines to 0.70 by the year 2025 , 
reflecting the impacts of increased urbanization and congested driving conditions. This assumption has a relatively minor impact on the cost-benefit calculations because it is assumed to hold in all three scenarios.

The equation for vehicle miles is:

$$
\begin{aligned}
& \left.M_{t}=\sum M_{t v}=\sum N_{w} \cdot R_{a} \cdot\left(I_{v} I_{0}\right)^{0.4} \cdot\left(\left[P J / M P G_{v} \cdot C F_{v}\right\}\right]+\left[P_{0} /\left\{M P G_{0, a} \cdot C F_{0 .}\right\}\right]\right)^{-0.2} \\
& \text { v v }
\end{aligned}
$$

$\mathbf{M}$ is miles, $\mathbf{N}$ the number of vehicles, $\mathbf{R}$ the relative use of a vehicle of age a compared to a new vehicle, I is income (or GNP for trucks), P the price of gasoline, and CF is the MPG correction factor. The indexes are $\mathrm{v}$ for vintage (model year), $\mathrm{t}$ for calendar year, and a for vehicle age $(a=t-v)$. The subscript 0 in place of $t$ indicates base year values.

The equation for fuel use is:

$$
F_{t}=\sum_{v} F_{t v}=\sum_{v} M_{t v} /\left(M P G_{v} \cdot C F_{v}\right)
$$

\subsection{FLEET AVERAGE WEIGHT AND EMISSIONS CHANGES}

For each forecast year $(t)$ the AMFU model produces two matrices of vehicles $\left(N_{t w}\right)$ and vehicle miles $\left(\mathrm{M}_{\mathrm{tv}}\right)$ by vintage $(v)$. The fleet average weight change is computed as the weighted average of the vintage (model year) weight changes $\left(\Delta w_{v}\right)$ shown in Tables 1 and 2, above. We calculate the fleet average emissions per mile $\left(\mathrm{gpm}_{\mathfrak{t}}\right)$ as the average EPAestimated year-and-vintage emissions rates $\left(e_{\mathrm{tv}}\right)$, weighted by the appropriate vehicle miles $\left(\mathrm{M}_{\mathrm{tv}}\right)$. 


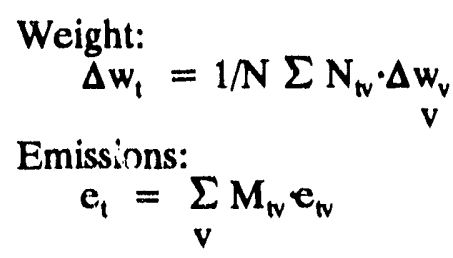

EPA emissions factors are a combination of several types of emissions sources in addition to tailpipe emissions. HC emissions rates include: 1) basic exhaust (tailpipe) emissions, 2) the effect of tampering with emissions control equipment on tailpipe emissions, 3) evaporative emissions, 4) refueling emissions, and 5) running losses, all expressed on a grams per mile basis. $\mathrm{CO}$ and $\mathrm{NO}_{\mathrm{x}}$ emissions include basic exhaust emissions and tampering effects. The factors developed by EPA for this study (U.S. EPA, 1990) include the impact of the new Clean Air Act on emissions by gasoline-powered vehicles. For example, enhanced inspection and maintenance, onboard refueling controls, and gasoline vapor pressure reduction to $9.0 \mathrm{psi}$ RVP in 1992 and beyond, are all included. As a result, emissions rates are expected to decline significantly over time, especially for older cars (Figure 4). Separate tables of factors were used for passenger cars and light trucks.

\subsection{CAICULATION OF COSTS AND BENEFTTS}

Using the vehicle stock model, we produced forecasts to the year 2030 of fuel use, numbers of vehicles, and vehicle travel (see Appendix B, Tables 1-6). These form the basis of the cost and benefit calculations. We took forecasts at five-year intervals beginning with 1990, and computed costs and benefits for each. We then linearly interpolated costs and benefits for the intervening years. This greatly reduced the amount of data to be handled and the size of the spreadsheet used for computing costs and benefits, without any serious loss 


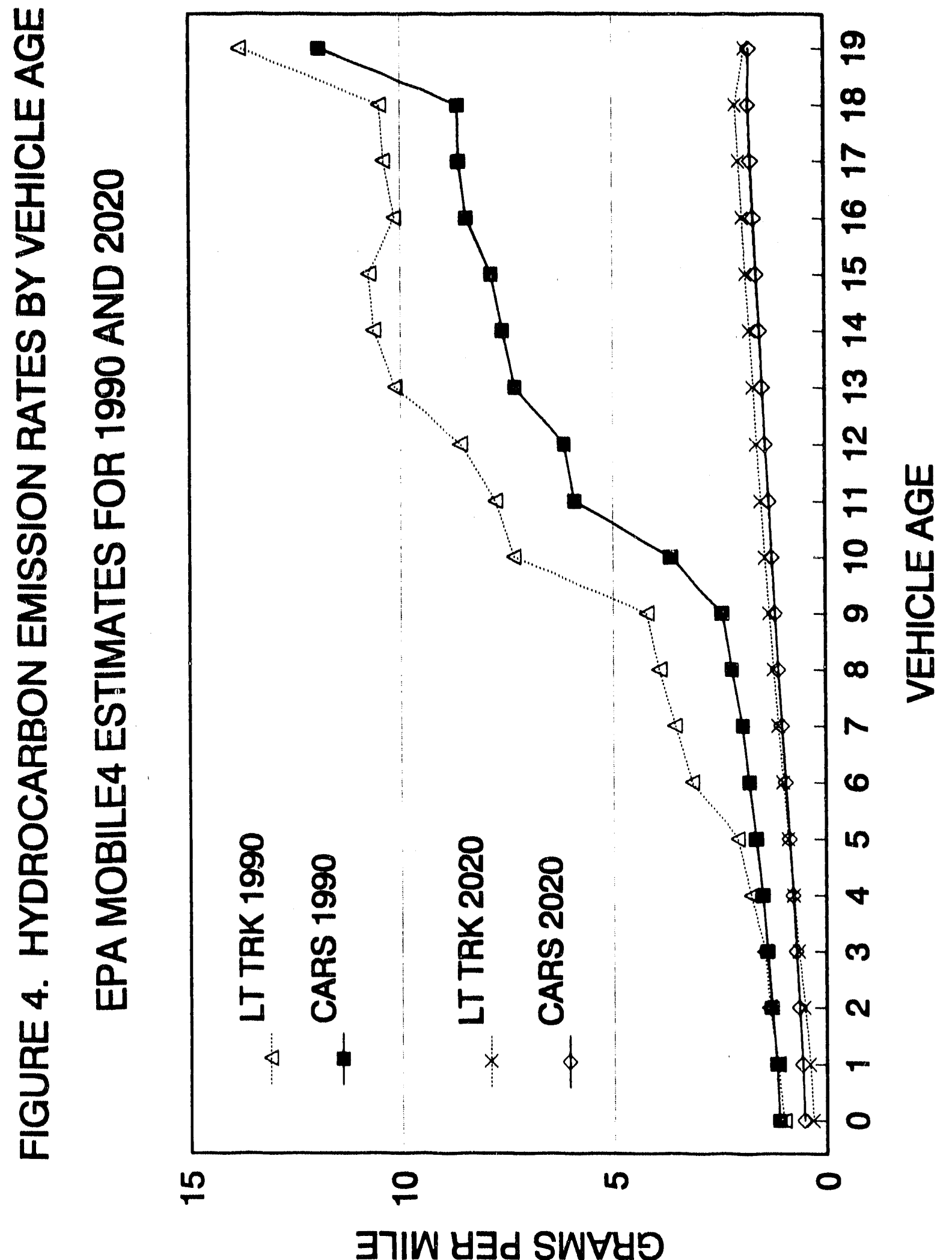


of accuracy. All costs are discounted back to 1990 , in 1989 dollars. Calculations were carried out independently for passenger cars versus light trucks so that the respective fuel economy improvements could be evaluated separately.

Vehicle use forecasts by the AMFU model were adjusted to reflect the assumption that vehicle travel would not decrease as a result of the reduced size and greater age of the vehicle fleet. Other things equal, the vehicle stock model would predict that a smaller, older fleet would result in less vehicle travel. The adjustment made here assumes that the intensity of vehicle use will increase such that there is no loss of vehicle travel at constant fuel econciny. In fact, vehicle use increases as a result of the fuel economy improvement. This increase depends on the elasticity of vehicle use with respect to fuel cost per mile: the "rebound effect." While it is clear that a smaller, older fleet will produce somewhat fewer miles of travel, it is not clear that the effect will be directly proportional to the number of vehicles, as shown in equation (4). Making a complete restoration of vehicle miles, as we do here, is sure to overstate the negative impacts of fuel economy due to increased vehicle travel.

Costs and benefits are counted up to a certain future year and ignored beyond that point. Because vehicle costs are borne up front, while fuel savings and other costs and benefits accrue in the future, this intruduces a minor accounting problem. Clearly, we do not wish to count the full capital cost of vehicles sold in the end year when we will be counting only one year of their other lifetime costs and benefits. The median age of an automobile sold in the U.S. is about 12 years. Thus, more than half the vehicles sold in 2010 will still be on the road in 2020. If we count the full capital cost of those vehicles but not their full fuel savings (as well as other costs and benefits) we will make a nontrivial accounting error. To 
avoid this, we use a discounted user cost of capital method to amortize the initial cost of fuel economy improvements over the vehicle's lifetime. ${ }^{6}$

Nearly all the key parameters can be varied in the cost-benefit calculation spreadsheet. Those that may be readily changed include:

1. The discount rate.

2. The future limit of costs and benefits (up to 2030).

3. The elasticity of travel with respect to fuel cost per mile.

4. The elasticity of world oil price with respect to U.S. demand.

5. The energy security value of reduce oil demand (per BBL).

6. The value of one ton $\mathrm{C}$ emissions reduction.

7. The numbers of fatalities and injuries per $1,000 \mathrm{lbs}$. weight reduction.

Thus far, we have consistently assumed $10 \%$ real private discount rate. We are free now to assume a different social discount rate for valuing costs and benefits to society. We introduce a small inconsistency by varying the fuel-cost-per-mile elasticity of travel in the final costbenefit calculations without rerunning the vehicle stock model. As long as the elasticities are

${ }^{6}$ The user cost of capital method assumes that the sale of a car at some future time will return a fraction of its initial cost. Thus, the cost of a car over its lifetime would be,

$$
\mathrm{C}=\Sigma\left\{\left[\left(\mathrm{k}^{\mathrm{i}-1} \mathrm{P}_{0}\right) /(1+\mathrm{r})^{\mathrm{i} \cdot \mathrm{1}}\right]-\left[\left(\mathrm{k}^{\mathrm{i}} \mathrm{P}_{0}\right) /(1+\mathrm{r})^{\mathrm{i}}\right]\right\} \text {, }
$$

where $\mathrm{k}$ is one minus the depreciation rate (we assume $\mathrm{k}=0.85$ ), $\mathrm{P}_{0}$ is the purchase price, $\mathrm{r}$ the discount rate $(0.1)$, and $i$ indexes time periods that the vehicle is held. The capital cost of a vehicle held up to $\mathrm{T}$ time periods would be, the sum up to period $\mathrm{T}$ of $\mathrm{C}$, rather than the sum over the entire vehicle's lifetime. We use this equation to estimate the share of lifetime vehicle cost borne in each year. It is easy to show that the equation for $\mathrm{C}$ has the form,

$$
C=A \cdot \Sigma\left[k^{i} /(1+r)^{i}\right],
$$

so that the fraction of total cost in year $\mathrm{t}$ is,

$$
f_{t}=\left[k^{1} /\left((1+r)^{t}\right] / \sum\left[k^{i} /(1+r)^{i}\right]\right. \text {. }
$$

The expected cost share for the first $T$ years is the sum of cost shares for each of the first $T$ years times the probability of surviving for $\mathrm{T}$ years, or more, plus the probability of being scrapped during the first $\mathrm{T}$ years, times the sum of all cost shares. The first ten year's shares computed in this way are $23 \%, 41 \%, 55 \%, 65 \%, 74 \%, 80 \%, 86 \%, 90 \%, 93 \%$, and $96 \%$. These shares are used to scale down the last 10 years' technol agy costs (e.g., from 2020 to 2030). 
small, however, this inconsistency will be of no quantitative importance. Since we readjust the VMT in the cost-benefit spreadshect to counteract the effect of smaller, older vehicle fleets, and then to add the "rebound effect", as described above, these effects will be consistent with the elasticities we choose for sensitivity analysis. The only inconsistency will be in the minor adjustments in the distribution of vehicle miles across vintages that take place in the vehicle stock model. These will be consistent with an elasticity of -0.2 . We use this simplification to avoid the considerable effort involved in redoing the entire set of calculations beginning with the AMFU model. 


\section{ENERGY DEMAND SCENARIOS}

Projections of economic and population growth, and energy prices were taken from analyses done for the National Energy Strategy. Because this study was carried out at the same time the NES was under development, some of the projections are not the final NES projections, but they are quite close to the final NES projections. We carried out cost/benefit calculations for three scenarios: 1) Reference Case, 2) Low Energy Prices, and 3) High Energy Prices. In the Reference Case, oil prices increase from $\$ 16.70 / \mathrm{BBL}$ in 1990 to $\$ 20 / \mathrm{BBL}$ by 1995 , and reach $\$ 43 / \mathrm{BBL}$ in 2020 (Table 5). In the Low Oil Price Case, prices actually decline to $\$ 14 / \mathrm{BBL}$ in 1995 and reach only $\$ 29 / \mathrm{BBL}$ in 2020 . In the High Oil Price Case, prices jump to $\$ 26 / \mathrm{BBL}$ in 1995 and climb to $\$ 54 / \mathrm{BBL}$ by 2020 .

These prices span a considerable range of possibilities but do not allow for continued low or declining prices through 2030 nor do they contain significant price shocks. Their principal effect will be to lower or raise the value of fuel saved by higher fuel economy.

The rate of economic growth is affected only slightly by oil prices (Table 6.). In the year 2020, GNP is $2.3 \%$ higher in the Low Oil Price Case than in the High Oil Price Case. Vehicle sales have not been adjusted to take into account this change in economic growth. In general, vehicle sales are quite sluggish throughout the period, growing at an average annual rate of only $0.7 \%$, just slightly above the rate of population growth, $0.5 \%$. This slow

rate of growth in population and vehicle sales leads to slow growth in the vehicle stock and vehicle travel (about 1\%/yr.) in all forecasts. Were the growth of vehicle stock and, thus, 
Table 5. Energy Price Projections (1989\$ per barrel for oil, per gallon for gasoline).

\begin{tabular}{|c|c|c|c|c|c|c|}
\hline \multirow{3}{*}{$\begin{array}{l}\frac{\text { Year }}{\text { Historical }} \\
\frac{1987}{\text { Projected }}\end{array}$} & \multicolumn{2}{|c|}{$\frac{\text { Low Oll Price }}{\text { Oil Gasoline }}$} & \multicolumn{2}{|c|}{ Reference Case } & \multicolumn{2}{|c|}{ High Oil Price } \\
\hline & & & & & & \\
\hline & 18.16 & 0.96 & & & & \\
\hline 1990 & 16.68 & 0.98 & 16.70 & 0.98 & 16.78 & 0.98 \\
\hline 1995 & 14.37 & 0.93 & 20.45 & 1.07 & 26.02 & 1.20 \\
\hline 2000 & 19.92 & 1.06 & 28.06 & 1.25 & 34.23 & 1.40 \\
\hline 2005 & 24.25 & 1.16 & 33.34 & 1.30 & 42.59 & 1.60 \\
\hline 2010 & 26.33 & 1.21 & 37.39 & 1.43 & 48.25 & 1.74 \\
\hline 2015 & 27.54 & 1.24 & 40.47 & 1.55 & 51.20 & 1.81 \\
\hline 20 & 29.06 & 1.28 & 42.97 & 1.61 & 53.99 & 1.87 \\
\hline 2025 & 30.77 & 1.32 & 45.34 & 1.67 & 55.98 & 1.92 \\
\hline 2030 & 31.59 & 1.34 & 47.14 & 1.71 & 57.90 & 1.97 \\
\hline
\end{tabular}

Source: Table 1-2, supplied by Mr. Eric Peterson, preliminary model runs for National Energy Strategy, Office of Pollicy, Planning, and Analysis, U.S. Department of Energy, Washington, D.C., October 5 and 7, 1990.

Table 6. Economic Growth, Population, and Veinicle Sales Projections.

\begin{tabular}{|c|c|c|c|c|c|c|}
\hline \multirow{3}{*}{ Year } & \multirow{2}{*}{$\frac{\text { Population }}{(0000,000 \mathrm{~s})}$} & \multicolumn{3}{|c|}{ Gross National Product (billions) } & \multicolumn{2}{|c|}{ Vehicle Sales $(000 \mathrm{~s})$} \\
\hline & & Low Oil & Reference & High Oil & Automobile & 1 Trucl \\
\hline & 251 & 5331 & 5331 & 5331 & 10,037 & $4, \because 70$ \\
\hline 1995 & 261 & 6262 & 6220 & 6177 & 10,763 & 5,120 \\
\hline 2000 & 269 & 7256 & 7181 & 7141 & 11,319 & 5,380 \\
\hline 2005 & 276 & 8343 & 8264 & 8200 & 12,005 & 5,710 \\
\hline 2010 & 283 & 9473 & 9375 & 9288 & 12,348 & 5,870 \\
\hline 2015 & 289 & 10519 & 10386 & 10295 & 12,534 & 5,960 \\
\hline 2020 & 294 & 11523 & 11368 & 11262 & 12,724 & 6,050 \\
\hline 2025 & 298 & 12539 & 12367 & 12261 & 12,916 & 6,140 \\
\hline 2030 & 301 & 13583 & 13383 & 13264 & 13,311 & 6,230 \\
\hline
\end{tabular}

Sources: Table 1-1, Mr. Eric Peterson, op. cit., Table 5. Memorandum from Mr. Barry Cohen, Office of Energy Markets and End Use, Energy Information Administration, U.S. Department of Energy, Washington, D.C., August 30, 1990. 
travel more consistent with recent history (about 3\%/yr.) or recent forecasts by others for this time period (2-3\%/yr.), the value of fuel savings and vehicle costs, as well, would be greater (see, e.g., U.S. DOT, FHWA, 1990).

Under the Reference Caso economic assumptions and Base Case fuel economy projection, fuel use by automobiles and light trucks increases from 98.7 billion gallons annually in 1990 to 101 billion in $2000,110.1$ in 2010 , and 117.0 by 2020 . This relatively low rate of growth (just over $0.5 \% / y r$ ) is attributable to the slow rate of growth in the vehicle stock and vehicle travel. Automobile stock actually declines by $1 \%$ between 1990 and 1995 , probably due to the fact that the historical average scrappage rates used are not consistent with the low rate of sales growth projected.

However, it is also due to a continued switch from passenger cars to light trucks that is inherent in the sales projections. Total light duty vehicle stock increases by $2 \%$ from 1990 to 1995 . Still, both stock growth $(0.75 \% / y r$.$) and the growth of vehicle travel (0.86 \% / y r$.) from 1990 to 2020 are quite low relative to recent history. Even given the likelihood that the growth of travel will slow in the future, these rates still appear low and imply lower amounts of future fuel use and lower values for future fuel savings. Fuel economy increases from 20.6 to 23.0 MPG for automobiles and 15.9 to 16.9 for light trucks. These relatively low values reflect on-road fuel economy and embody an assumption of an increasing gap between the EPA test-values of MPG and those actually achieved by motorists. The assumed shortfall in 2020 and thereafter is $30 \%$ (on-road MPG is $70 \%$ of the EPA test value), so that an on-road MPG of 23 corresponds to a test value of 32.9 MPG. If on-road performance were better, fuel use would be reduced and consequently the value of fuel savings would also. However, analysts expect on-road performance to continue to decline from its early 1980 s level of 0.85 , due to increasing urbanization and traffic congestion (Westbrook and Patterson, 1989). 
The slightly higher rate of income growth and lower rate of fuel price increases in the Low Oil Price scenario produce slightly higher levels of VMT and fuel use. Passenger car and light truck fuel use reach 75.3 and 38.7 billion gallons per year, respectively, by 2010 . Year 2030 combined light duty vehicle fuel use hits 128.4 billion gallons, with VMT at 2.69 trillion, 5\% higher than the Reference Case. The higher prices and lower economic growth of the High Oil Price scenario produced correspondingly lower rates of growth (Figure 5). Fuel use is also correspondingly lower: $105.7 \mathrm{BGAL}$ in 2010 and 118.4 in 2030. Vehicle travel is down about 3\% over the Reference Case. Since vehicle sales and scrappage are not sensitive to income in the vehicle stock model, the size and composition of the vehicle fleet is unaffected. The lower fuel use of the High Oil Price Case tends to reduce the impact of fuel economy improvements, but this is more than offset by the increased value of the fuel saved, as will be seen below.

The higher fuel economies of Level 2 and Level 3 not only reduce fuel use and increase MPG, but also have small impacts on vehicle travel and the number of vehicles. Level 3 passenger car VMT is $2.1 \%$ higher in 2020 than in the Base Case. The size of the car fleet, however, is $1.3 \%$ smaller. Although noticeable, these differences are obviously quite small. A total increase in VMT of $2.1 \%$ over a 30 -year period amounts to an annual growth rate of only $0.07 \%$. And this is assuming an elasticity value which is probably a bit high (-0.2 versus less than -0.15). We conclude that although fuel economy improvements do induce a measurable rebound effect and do influence vehicle sales and scrappage, at least for the fuel economy improvements considered here, these effects are relatively small. We will examine further the impact of the rebound effect on the value of fuel savings and other costs and benefits below. 


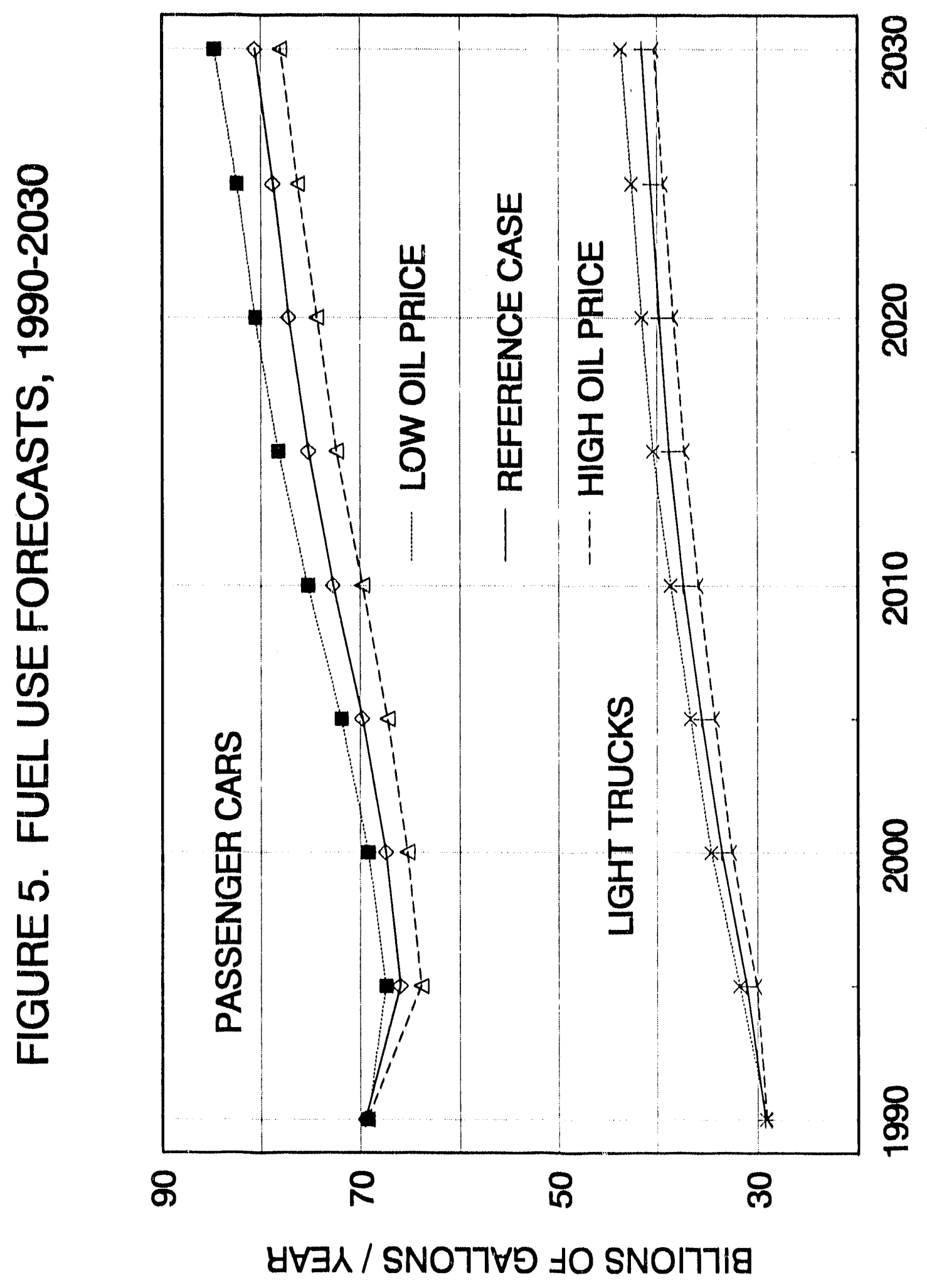


Projected fuel use actually declines from 1990 to 1995, in part due to the continuing improvement in new car and truck MPG, but also due to sluggish sales and relatively high ratcs of scrappage, resulting in low growth in vehicle travel. Note that the projected automobile stock also declines slightly from 1990 to 1995 . Because the light truck market continues to expand, light truck fuel use grows more than passenger car fuel sse, absolutely as well as relatively. By 2020 light truck fuel use is up 10.6 billion gallons in the Base Case, while automobile use increases by only 7.7 billion gallons.

Increasing new car fuel economy to $35 \mathrm{MPG}$ and light truck fuel economy to $26 \mathrm{MPG}$ cuts 2030 fuel use by 6.5 to 7.1 billion gallons annually, depending on the fuel cost elasticity of travel. Projected 2030 automobile gasoline use drops from 80.6 BGAL to 76.4 BGAL, and light truck fuel sse falls to 39.3 from 41.6 (assuming an elasticity of -0.2). Level 3 fuel economies are 36.5 MPG for passenger cars and 27.5 for light trucks. These push projected 2030 fuel use down to 74.2 BGAL and 37.5 BGAL for passenger cars and light trucks, respectively. As Figure 6 shows, maximum fuel savings are approached by 2015 because the stock turnover process is nearly complete by then. Again, depending on the elasticity assumed, Level 3 fuel savings range from 10.5 to $12.4 \mathrm{BGAL}$, annually. This translates into 0.7 to 0.8 MMBD less oil consumption. 


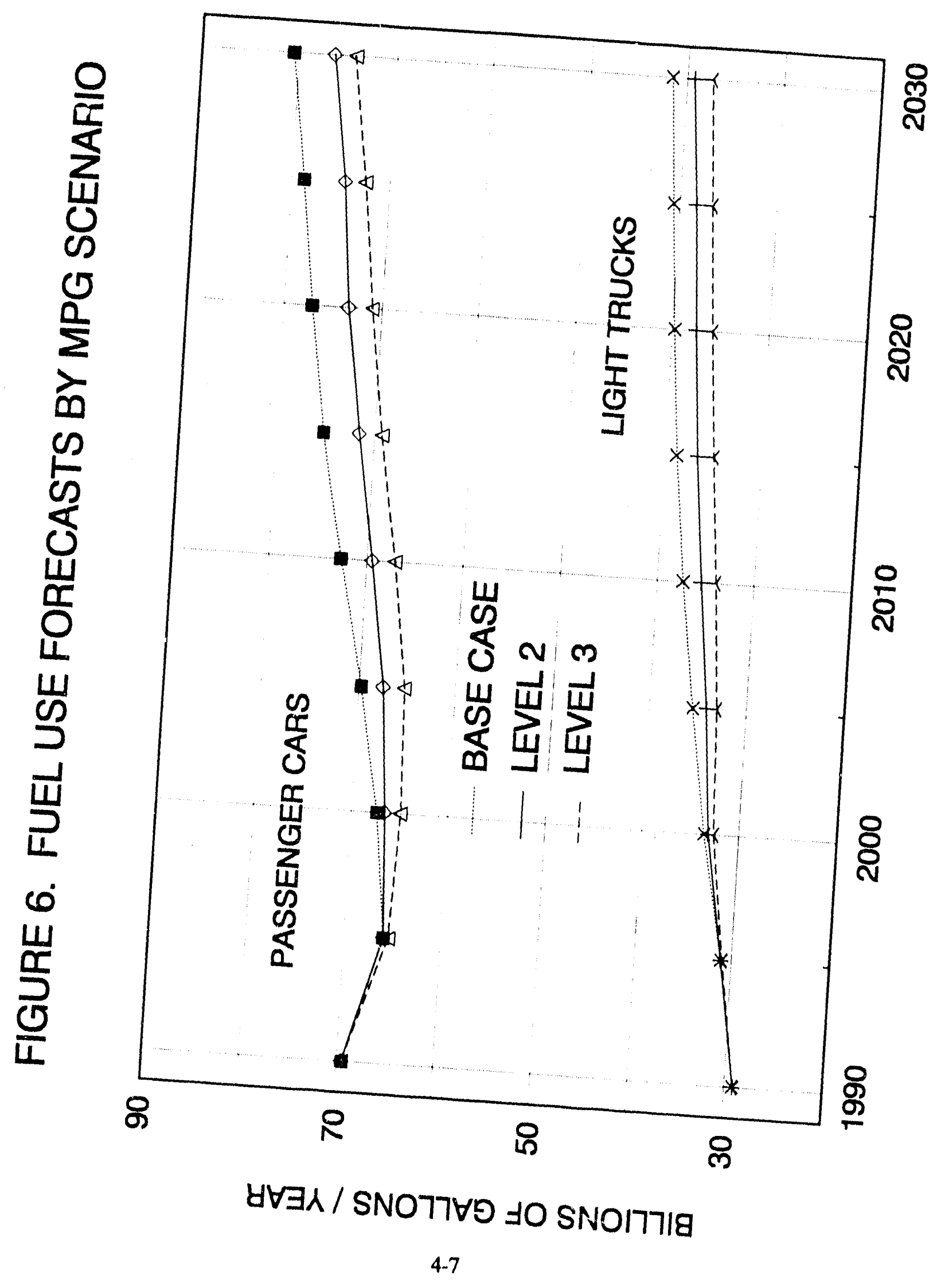




\section{COSTS AND BENEFTIS: RESULTS}

All things considered, fuel economy improvements appear to yield substantial, positive social benefits. In the Reference Case scenario, using middle-of-the-range assumptions, the Level 2 fuel economy improvement (35 MPG cars, 26 MPG light trucks) produces an estimated social benefit of $\$ 41$ billion (\$28 B for cars, \$13 B for light trucks) net present value (NPV), excluding the avoided transfer of wealth to oil exporting countries. Level 3 benefits, again excluding the transfer of wealth, are somewhat smaller due to the fact that the present value of direct technology costs exceed those of direct fuel savings (Table 7). Using less favorable assumptions for the values of externalities and for appraising future benefits, the NPV of Level 2 fuel economy increases drops to $\$ 4 \mathrm{~B}$, and the value of Level 3 becomes negative $\$ 10.5 \mathrm{~B}$. On the other hand, more favorable but still plausible assumptions lead to very large benefits. The NPV of Level 2 benefits could be as large as $\$ 130 \mathrm{~B}$, or $\$ 197 \mathrm{~B}$, counting the avoided transfer of wealth. Under the same favorable assumptions, Level 3 benefits jump to $\$ 173 \mathrm{~B}$ to $\$ 286 \mathrm{~B}$.

It is useful to review the key assumptions affecting the present value of externalities and other social costs (Table 8). Next we examine the costs components, social and private, to determine which appear to be the most important. Finally, we consider how the energy price assumptions affect expected benefits and costs. More detailed data used in computing costs and benefits can be found in Appendix A of this report.

Conclusions about net costs and benefits strongly depend on the discounting of future benefits and the values attached to social costs. Because vehicle technology costs are born 
Table 7. Summary of Fuel Economy Costs and Benefits (Billions 1989\$).

LEVEL 2

Cost Benefit

Fuel Savings

Vehicle Costs

Oil Costs

Consumers' Surplus

Safety

Energy Security

Emissions

$\mathrm{CO}_{2}$

Wealth Transfer

Total (Exl. Transfer)

Grand Total

$\frac{\text { Moderate }}{\text { Cars Light Trk }} \frac{\text { Unfavorable }}{\text { Cars Light Trk }}$

$\begin{array}{rr}33.5 & 19.5 \\ -21.2 & -15.4 \\ 8.3 & 4.8 \\ 0.1 & 0.1 \\ 0.0 & -0.2 \\ 3.2 & 1.9 \\ 0.9 & 0.2 \\ 3.6 & 2.1\end{array}$

$19.0 \quad 11.1$

$28.3 \quad 13.0$

47.4
11.1

$-9.7$

1.5

0.1

0.0

0.2

0.2

0.2

4.3

3.5

7.8
6.5
-7.0

0.9

0.1

$-0.1$

0.1

$-0.0$

0.1

1.2

0.6

3.2
24.1 $\frac{\text { Favorable }}{\text { Cars Light Trk }}$

$\begin{array}{ll}72.0 & 41.6\end{array}$

$-37.8 \quad-27.3$

$21.9 \quad 12.7$

$0.2 \quad 0.1$

$0.0 \quad-0.0$

$13.3 \quad 7.7$

0.6

8.7

$41.5 \quad 24.0$

$86.9 \quad 44.2$

128.4

\section{UNDISCOUNTED TOTALS}

$\begin{array}{lrrrrrr}\text { Fatalities } & 0 & 37 / 2 & 0 & 372 & 0 & 37 \\ \mathrm{CO}_{2} \text { (Millions of tons) } & -245 & -141 & -218 & -125 & -258 & -148\end{array}$

LEVEL 3

Fuel Savings

Vehicle Costs

Oil Costs

$-218$

Consumers' Surplus

Safety

Energy Security

Emissions

$\mathrm{CO}_{2}$

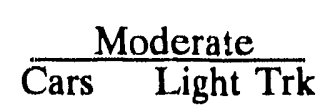

$\frac{\text { Unfavorable }}{\text { Cars Light Trk }}$

$\frac{\text { Favorable }}{\text { Cars Light Trk }}$

\section{0.}

$60.9-35.8$

22.3

12.5

124.8

$-106.6$

74.8

$-63.2 \quad-36.9$

$-32.3$

$-17.6$

1.7

36.9

$\begin{array}{rr}14.5 & 0.7\end{array}$

3.0

0.1

$-3.3$

$-1.6$

$-1.4$

$-0.6$

0.3

$-0.6$

$-64.4$

22.5

$6.0 \quad 3.5$

0.5

0.3

23.8

1.4

0.1

$-0.1$

3.5

0.1

6.8

3.9

0.5

0.3

26.9

14.1

$33.7 \quad 20.1$

8.2

4.8

70.5

0.9

Wealth Transfer

23.4

57.1

13.7

$-7.1$

$-3.5$

109.1

179.6

42.8

Grand Total

33.8

1.2

1.3

63.6

106.4

\section{UNDISCOUNTED TOTALS}

$\begin{array}{lrrrrrr}\text { Fatalities } & 5,342 & 2,681 & 5,342 & 2,681 & 534 & 268 \\ \mathrm{CO}_{2} \text { (Millions of tons) } & -415 & -251 & -371 & -225 & -437 & -264\end{array}$


up front and fuel savings realized in the future, benefits and costs are sensitive above all to the assumed discount rate. At a high social discount rate of $10 \% / y r$. , a real dollar of fuel saved ten years from now is worth only 39 cents. Discount rates of $6 \%$ and $3 \%$ make that dollar worth 56 cents and 74 cents, respectively. How far we look into the future also matters, depending on the discount rate. The last dollar of cost or benefit in 2030 is worth 31 cents at a $3 \%$ discount rate, but only 2 cents at 10\%. When we count through 2030 and discount at lower rates, costs and benefits increase. At discount rate of $3 \%$, fuel savings outweigh direct vehicle costs, even for Level 3 fuel economy. At higher discount rates, direct costs outweigh direct fuel savings in Level 3.

The values we assign to energy security and reducing carbon dioxide emissions obviously directly influence those costs and benefits. Similarly, the assumed competitive market price of oil raises or lowers the estimated transfer cf wealth. Less obvious, but equally direct, is the impact of the elasticity of world oil price with respect to U.S. demand. Level 3 passenger car fuel economy lowers oil demand by about 0.5 MMBD. This will produce a $\$ 0.55 / \mathrm{BBL}$ reduction in price, assuming an elasticity of 0.6 , but only a $\$ 0.23 / \mathrm{BBL}$ reduction if the elasticity is put at 0.3 (in 2030, assuming U.S. demand at 25.6 MMBD and the world oil price at $\$ 47 / \mathrm{BBL}$ ). The "rebound" elasticity of travel with respect to fuel cost per mile has several effects. First, it directly affects fuel savings and, thereby oil demand. By affecting oil demand, it influences the price of oil and oil cost savings. A high elasticity diminishes the oil import reduction, reducing both energy security benefits and the avoided transfer of wealth. A larger rebound effect also lessens $\mathrm{CO}_{2}$ emissions reductions. Finally, by increasing vehicle miles, it increases emissions of criteria pollutants. Individually, each of these effects is relatively small. The cumulative effect, however, is substantial, making this a key parameter. 
Table 8. Key Assumptions Affecting Costs and Benefits.

\begin{tabular}{|c|c|c|c|}
\hline Parameter & Moderate & Unfavorable & Favorable \\
\hline Discount rate & $6 \%$ & $10 \%$ & $3 \%$ \\
\hline Horizon & 2030 & 2020 & 2030 \\
\hline Rebound elasticity & -0.10 & -0.20 & -0.05 \\
\hline World Oil Price elasticity & 0.5 & 0.3 & 0.6 \\
\hline Energy Security Premium & $\$ 5 / \mathrm{BBL}$ & $\$ 1 / B B L$ & $\$ 10 / \mathrm{BBL}$ \\
\hline Value of $C(\$ /$ ton $)$ & $\$ 50$ & $\$ 10$ & $\$ 100$ \\
\hline Fatalities $/ 1,000 \mathrm{lbs}$ & $1,340 / 447$ & $1,340 / 447$ & $134 / 45$ \\
\hline $\begin{array}{l}\text { Injuries } / 1,000 \mathrm{lbs} . \\
\text { (Cars/Light Trucks) }\end{array}$ & $6,300 / 2,100$ & $6,300 / 2,100$ & $630 / 21$ \\
\hline
\end{tabular}

By far the largest individual cost-benefit components are direct fuel savings and direct vehicle costs. In every scenario and under all sets of assumptions, these two factors are the biggest (Figure 7). This leads to two observations. First, these are both internal, market costs. The consumer bears all the cost of fuel economy technology and reaps the fuel cost savings (the consumers' direct fuel savings are actually larger than the social savings by the value of the motor fuel tax). Second, these two costs tend to substantially offset each other in essentially all cases. This means that the externalities and other social costs and benefits come at the price of the difference between the two. This may seem like a trivially obvious observation, but it is not. Consider what would happen if a level of fuel economy had been chosen at which vehicle costs were $50 \%$ greater than fuel savings (e.g., Level 3, given unfavorable assumptions). Given the size of costs relative to other benefits, a large social loss would result. Put another way, for net benefits to be positive, the direct value of fuel savings must be approximately equal to vehicle costs. Thus, fuel economy improvements that are not close to being financially cost-effective in terms of direct costs and benefits, are not likely to be socially cost effective either.

The effects of alternative oil price projections are primarily to raise (or lower) the baseline fuel use and, in the opposite direction, decrease or increase the value of the fuel 


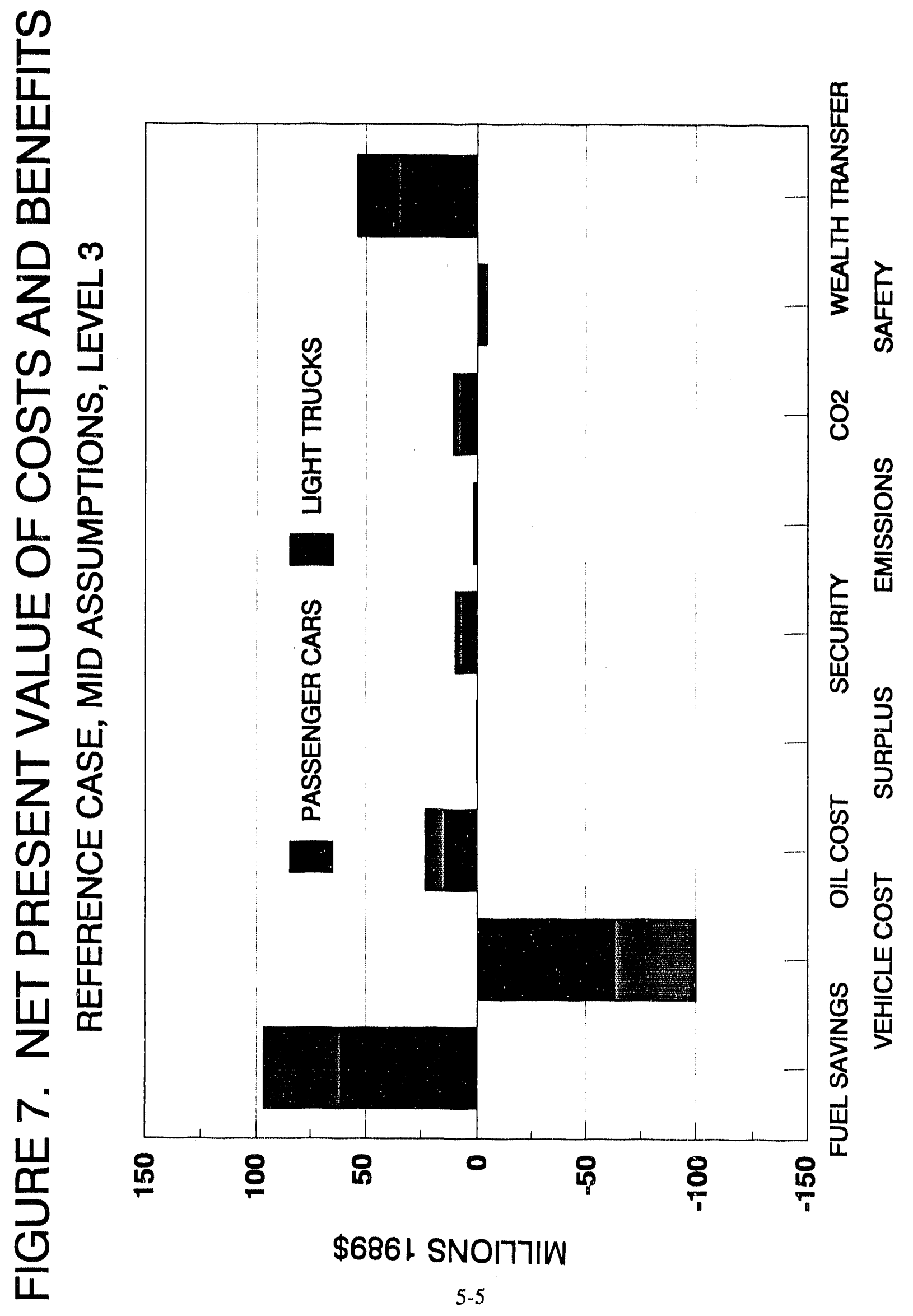


saved. For example, in the High Oil Price Case less fuel is used and fewer miles are travelled (Figure 8). As a result, NiPG improvements save fewer gallons of fuel, fewer tons of $\mathrm{CO}_{2}$, and have a smaller impact on energy security. But the value of the fuel saved is much greater and the cost of oil is higher, which gives a greater price impact per MMBD reduction in demand. The net result is favorable for fuel economy improvements, as might be expected. Using the "moderate" parameter assumptions, combined car and truck net social benefits for Level 2 fuel economy increases are $\$ 27.9 \mathrm{~B}$ in the Low Oil Price Case, and \$48.7 B in the High Oil Price Case (Table 9). Level 3 net benefits for the two extreme price projections are $\$ 14.5 \mathrm{~B}$ and $\$ 52.5 \mathrm{~B}$, respectively. The lion's share of the differences stem from the value of fuel savings and oil cost savings.

Oil prices affect the socially "optimal" level of fuel economy, as we can illustrate using the data in Table 9. It is not optimal to increase fuel economy until social costs equal social benefits and the net benefit becomes zero. The maximum net benefit will be obtained where the marginal social cost equals the marginal social benefit. By using small increments in fuel economy to define our Levels, we are now able to shed some light on where the social optimum might lie. Note that the total (Total and Grand Total) net benefits under the High Oil Price assumptions are higher for Level 3 than Level 2. Under the Low Oil Price assumptions, total social benefits are lower for Level 3. With low oil prices, the marginal net benefit of going from Level 2 to Level 3 is negative (total benefits decrease). Given high oil prices, the marginal net benefits increase, if only by a little. This indicates that, for low oil prices, the point at which marginal social costs equal marginal social benefits (the social optimum because the maximum social benefit is obtained there) is certainly less than Level 3, and could be less than Level 2. This is certainly true if one excludes the wealth transfer: benefit. Under high (and Reference Case) oil prices, net social benefits increase for Level 


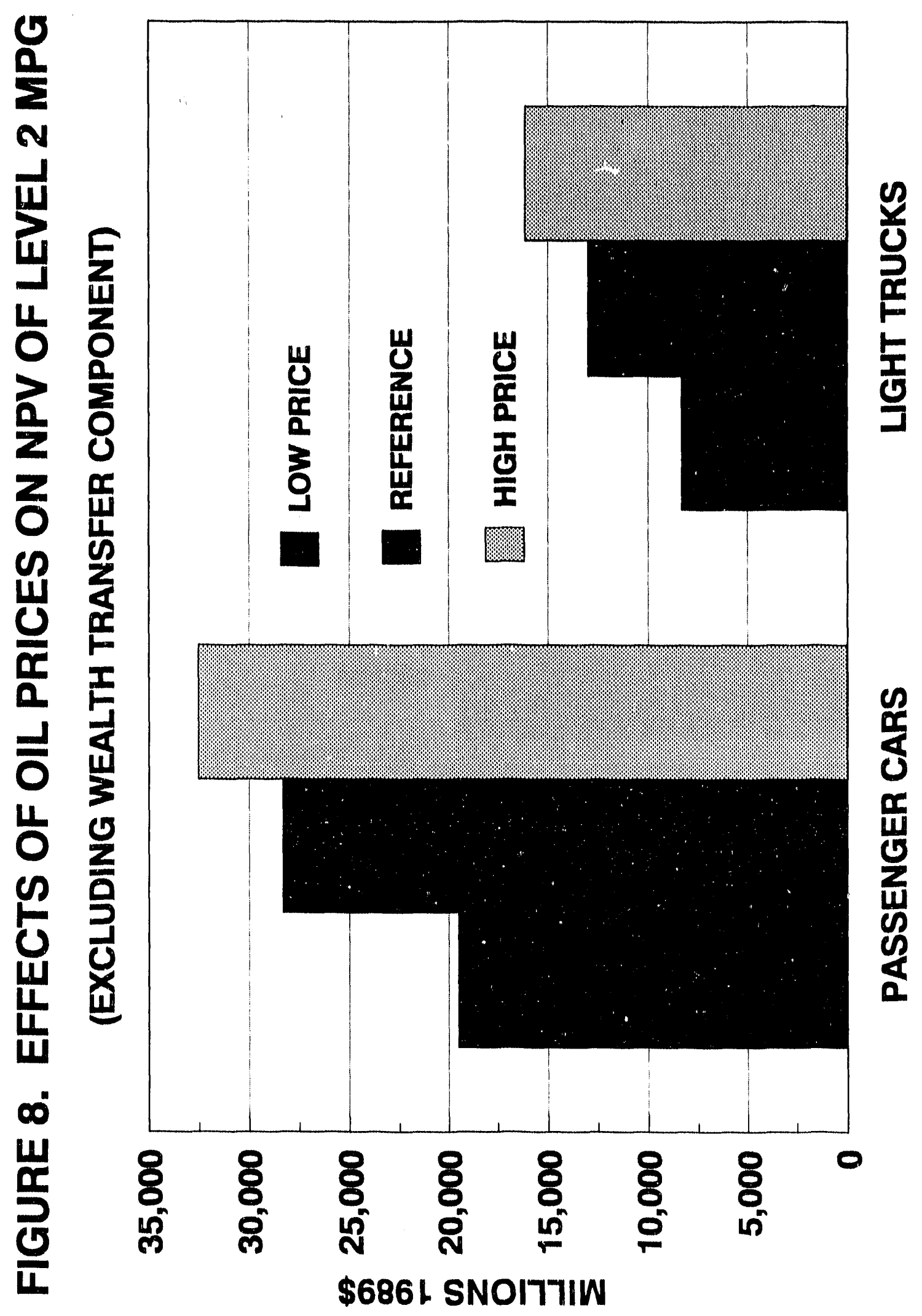


Table 9. Summary of Fuel Economy Costs and Benefits (Billions 1989\$) Using Moderate Parameter Values.

Cost Benefit

Fuel Savings

Vehicle Costs

Oil Costs

Consumers' Surplus

Safety

Energy Security

Emissions

$\mathrm{CO}_{2}$

Wealth Transfer

Total (Exl. Transfer)

Grand Total

\section{LEVEL 2}

$\frac{\text { High Oil Price }}{\text { Cars Light Truck }} \quad \frac{\text { Low Oil Price }}{\text { Cars Light Truck }}$

$\begin{array}{rrrr}37.7 & 22.4 & 26.4 & 15.7 \\ -21.2 & -15.4 & -21.2 & -15.4 \\ 8.7 & 5.2 & 6.5 & 3.9 \\ 0.2 & 0.1 & 0.1 & 0.1 \\ 0.0 & 0.2 & 0.0 & -0.2 \\ 3.0 & 1.8 & 3.2 & 1.9 \\ 0.8 & 0.2 & 0.9 & -0.2 \\ 3.4 & 2.0 & 3.7 & 2.2 \\ 23.9 & 14.2 & 11.7 & 7.0 \\ 32.5 & 16.2 & 19.5 & 8.4 \\ 56.4 & 30.4 & 31.2 & 15.3\end{array}$

\section{LEVEL 3}

Cost Benefit

Fuel Savings

Vehicle Costs

Oil Costs

Consumers' Surplus

Safety

Energy Security

Emissions

$\mathrm{CO}_{2}$

Wealth Transfer

Total (Exl. Transfer)

Grand Total

\begin{tabular}{|c|c|c|c|}
\hline \multicolumn{2}{|c|}{ High Oil Price } & \multicolumn{2}{|c|}{ Low Oil Price } \\
\hline$\overline{\text { Cars }}$ & Light Truck & Cars & Light Truck \\
\hline 69.7 & 41.2 & 49.1 & 28.8 \\
\hline-63.2 & -36.9 & -63.2 & -36.9 \\
\hline 15.6 & 9.4 & 11.7 & 7.0 \\
\hline 0.4 & 0.2 & 0.2 & 0.1 \\
\hline 3.3 & 1.6 & -3.3 & -1.6 \\
\hline 5.8 & 3.4 & 6.2 & 3.6 \\
\hline 1.3 & 0.2 & 1.4 & -0.2 \\
\hline 6.6 & 3.8 & 7.0 & 4.1 \\
\hline 43.4 & 25.9 & 21.1 & 12.6 \\
\hline 32.9 & 19.7 & $\begin{array}{r}9.2 \\
\end{array}$ & $\begin{array}{r}5.3 \\
179\end{array}$ \\
\hline 76.2 & 45.6 & 30.3 & 17.9 \\
\hline
\end{tabular}


3 fuel economy, indicating that marginal social benefits are still positive. This implies that the optimum must be higher than Level 2 and could possibly be higher than Level 3. Of course, all of this depends on the use of the "moderate" parameter values, and different conclusions could be reached with a different choice of parameters. 


\section{CONCLUSIONS}

The value of higher passenger car and light truck fuel economy varies widely, depending on several key assumptions. Within the range of assumptions used here, the net present social value of higher MPG varies between $-\$ 11$ billion and $+\$ 286$ billion. Where one falls within this range depends primarily on the social discount rate chosen, and the value one attaches to key external benefits. The fact that the greater part of the range falls in the realm of positive benefits suggests that moderate fuel economy improvements on the order of $36 \mathrm{MPG}$ for cars and 27.5 MPG for light trucks are probably justifiable on the basis of energy market, energy security, and global climate benefits.

The values assigned to energy security and $\mathrm{CO}_{2}$ emission reductions are critical, as is the presumed effect of U.S. petroleum demand reductions on world energy prices. These are highly conjectural quantities about which reasonable people may hold a wide range of opinions. Although we have captured much of that range in this analysis, we have by no means characterized all possible defensible positions. For example, if one believes that energy prices are likely to decline rather than increase, that OPEC supply is elastic with respect to price, that global climate change is not a serious threat, and discounts future benefits and costs at $10 \%$, one could well deem the fuel economy levels considered here too high. Others might consider them too low. The point is simply that value judgments and beliefs are absolutely critical.

Despite the uncertainties, the relative magnitudes of several key components of costs and benefits seem robust to a wide range of assumptions. The two largest components are 
vehicle costs and fuel savings. Major factors are the transfer of wealth from consumers of oil to the owners of oil via monopoly pricing, the reduced cost of oil imports, the value of reductions in $\mathrm{CO}_{2}$ emissions, and energy security benefits. Changes in emissions of $\mathrm{HC}, \mathrm{CO}$, and $\mathrm{NO}_{\mathrm{x}}$, consumers' surplus effects (apart from performance and safety), and safety impacts (although there is greater uncertainty), are all relatively minor factors. Although vehicle costs and fuel savings tend to largely offset one another under most assumptions, their relative size indicates that fuel economy improvements that are decidedly not cost-effective to the consumer, are not likely to be socially cost effective either. 


\section{REFERENCES}

1. Adelman, M.A., 1989. "Mideast Governments and the Oil Price Prospect," The Energy Journal, vol. 10, no. 2, pp. 15-24, April.

2. American Petroleum Institute, 1988. "Energy Security White Paper," Washington, D.C., November.

3. Broadman, H.G., 1986. "The Social Cost of Imported Oil," Energy Policy, vol. 14, no. 4, pp. 242-252.

4. Broadman, H.G. and W.W. Hogan, 1988. "Is an Import Tariff Justified: The Numbers Say Yes," The Energy Journal, vol. 9, no. 3, pp. 7-29.

5. Cohen, B., 1990. Memorandum, Office of Energy Markets and End Use, Energy Information Administration, U.S. Department of Energy, Washington, D.C., August 30, 1990.

6. Davis, S.C., and P. Hu, 1991. Transportation Energy Data Book, Edition 11, ORNL6649, Oak Ridge National Laboratory, Oak Ridge, Tennessee, January.

7. DeLuchi, M.A., Q. Wang and D.L. Greene, 1991. Motor Vehicle Fuel Economy. The Forgotten HC Control Strategy? Draft report prepared for the U. S. Department of Energy, Office of Environmental Analysis, Washington, D.C., May 1991.

8. Duleep, K.G., 1990. Memorandums and tables prepared for the U.S. Dept. of Energy, National Energy Strategy / Economic Policy Council Working Group on Fuel Economy Standards, by Energy and Environmental Analysis, Inc., Arlington, Virginia, September and October 1990.

9. EEA "Documentation of the Attributes of Technologies to Improve Fuel Economy" Report to Martin Marietta Energy Systems by Energy and Environmental Analysis, Inc., Arlington, Virginia, October 1991.

10. Energy and Environmentaı Analysis, Inc., 1989. "Domestic Manufacturers' Fuel Economy Capability to 2001: An Update," report prepared for the Center for Transportation Analysis, Dak Ridge National Laboratory, Oak Ridge, Tennessee, November 19.89.

11. Energy and Environmental Analysis, Inc., 1988a. "Forcign Manufacturers' Technology Development and Fuel Economy 1980-2000," report prepared for the Center for Transportation Analysis, Oak Ridge National Laboratory, Oak Ridge, Tennessee, December 1988.

12. Energy and Environmental Analysis, Inc., 1988b. "Light Duty Truck Fuel Economy: Review and Projections 1980-1995," DOE/OR/21400-H0, U.S. Department of Energy, Office of Policy; Planning, and Analysis, Washington, D.C., November 1988. 
13. Energy and Environmental Analysis, Inc., 1986. "Analysis of the Capabilities of Domestic Auto-Manufacturers to Improve Corporate Average Fuel Economy," DOE/RL/01830-H1, Office of Policy, Planning, and Analysis, U.S. Department of Energy, April 1986.

14. Evans, L., 1984. "Driver Fatalities Versus Car Mass Using an New Exposure Approach," Accident Analysis and Prevention, pp. 19-36.

15. Evans, L., 1982. "Car Mass and Likelihood of Occupant Fatality," SAE Technical Paper Series 820807, Society of Auiumotive Engineers, Warrendale, Pennsylvania.

16. Goulder, L., 1985. "Short- and Long-Run Effects of Oil Supply Disruptions: An Integrative Assessment, "Energy and Environmental Policy Center, John Kennedy School of Government, Harvard University, Cambridge, Massachusetts.

17. Greene, D.L., 1991. "A Note on OPEC Market Power and Oil Prices," Energy Economics, vol. $x$, no. x, pp. 123-129, April.

18. Greene, D.L., 1991. "Vehicle Use and Fuel Economy: How Big is the Rebound Effect?", draft report, Center for Transportation Analysis, Oak Ridge National Laboratory, Oak Ridge, Tennessee, March.

19. Greene, D.L. and A. Rathi, 1990. "Alternative Motor Fuel Use Model: Model Theory and Design and User's Guide," ORNL/TM-11448, Oak Ridge National Laboratory, Oak Ridge, Tennessee, March.

20. Greene, D.L. and J.T. Liu, 1988. "Automotive Fuel Economy Improvements and Consumers' Surplus," Transportation Research, vol 22A, no.3, p. 203-218.

21. Gruenspecht, H. K. 1982. "Differentiated Regulation: The Case of Auto Emissions Standards," The American Economic Review, Papers and Proceedings of the NinetyFourth Annual Meeting of the American Economic Association, vol. 72, no. 2, pp. 328331, May.

22. Hamilton, J.D., 1985. "Historical Causes of Postwar Oil Shocks and Recessions," The Energy Journal, vol. 6, no. 1, pp. 97-116, January.

23. Heavenrich, R.M. and J.D. Murrell, 1990. "Light-Duty Automotive Technology and Fuel Economy Trends Through 1990," EPA/AA/CTAB/90-03, U.S. Environmental Protection Agency, Office of Mobile Sources, Ann Arbor, Michigan.

24. Hogan, W.W. and H.G. Broadman, 1988. "Oil Tariff Policy: An Overview," Energy Systems and Policy, vol. 12, pp. 63-68.

25. Irvine, F.O. Jr., 1983. "Demand Equations for Individual New Car Models," Southern Economic Journal, vol. 49, no. 3, pp. 764-782, January.

26. Khazzoom, J.D., 1980. "Economic Implications of Mandated Efficiency Standards for Household Appliances," The Energy Journal, vol. 1, no. 4, pp. 21-40.

27. Leiby, P., 1990. "The Effect of a Decrease in U.S. Oil Demand on World Oil Price," memorandum to Mr. Abe Haspel, Office of Policy, Planning and Analysis, U.S. Department of Energy, Washington, D.C., October 23, 1990. 
28. Lindgren, L. H., Jones, D., "Automotive Technologies and Manufacturing Investment Costs" Report to the DOE, May 1986.

29. Manne, A., and R. Richels, 1990. "CO 2 Emission Limits: and Economic Cost Analysis for the USA," The Energy Journal, vol. 11, no. 2, pp. 51-74.

30. McCarthy, P.S. and R. Tay, 1989. "Consumer Valuation of New Car Attributes: An Econometric Analysis of the Demand for Domestic and Japanese/Western European Imports," Transportation Research, vol. 23A, No. 5.

31. Mork, K.A., and R.E. Hall, 1980. "Energy Prices and the U.S. Economy in 1979-80," The Energy Journal, vol. 1, no. 2, pp. 41-51, April.

32. Motor Vehicle Manufacturers Association, 1989. "MVMA Motor Vehicle Facts and Figures '89," Motor Vehicle Manufacturers' Association of the United States, Inc., Detroit, Michigan.

33. Murphy, F.H., M.A. Toman, and H.J. Weiss, 1986. "An Integrated Analysis of U.S. Oil Security Policies," The Energy Journal, vol. 7, no. 3, pp. 67-82.

34. National Academy of Sciences, Committee on Science, Engineering, and Public Policy, 1991. Policy Implications of Greenhouse Warming, Chapter 6, "Mitigation," National Academy Press, Washington, D.C.

35. National Research Council, Committee on Automobile and Light Truck Fuel Economy, 1992. Automotive Fuel Economy: How Far Can We Go?, forthcoming, National Academny Press, Washington, D.C.

36. Nesbitt, D.M. and T.Y. Choi, 1988. "Is an Import Tariff Justified: The Numbers Say No," The Energy Journal, vol. 9, no. 3, pp. 31-59.

37. Nordhaus, W.D., 1991. "The Cost of Slowing Climate Change: a Survey," The Energy Journal, vol. 12, no. 1, pp. 37-65, Special Issue on Global Warming.

38. Pindyck, R.S., 1980. "Energy Price Increases and Macroeconomic Policy," The Energy Journal, vol. 1, no. 4, pp. 1-20, October 1980.

39. Sheiton, R., U.S. Department of Transportation, National Highway Traffic Safety Administration, Plans and Policy, 1990. "Cost Effectiveness Analysis," Appendix A to unpublished draft report, October 2, 1990, Washington, D.C.

40. SRI, International, 1991. "Potential for Improved Fuel Economy in Passenger Cars and Light Trucks," SRI Project 1955, Menlo Park, CA, July 1991.

41. Shin, D., 1990. "The Costs and Benefits of Federally Mandated Policies to Promote Energy Conservation: The Case of the Automobile Efficiency Standard," Research Study \#050, American Petroleum Institute, Washington, D.C., May.

42. Sovran, G. S. and Bohn, M. S. "Formula for the Tractor Energy Requirements of Vehicles During the EPA Schedule" Society of Automotive Engineering Paper 810184, Lindale, PA, February 1981. 
43. U.S. Congress, Office of Technology Assessment (OTA), 1984. "U.S. Vulnerability to an Oil Import Curtailment," OTA-E-243, Washington, D.C., September.

44. U.S. Department of Energy (DOE), 1987. Energy Security: A Report to the President of the United States, Washington, D.C., March.

45. U.S. Department of Energy, Energy Information Administration, 1990a. "Household Vehicles Energy Consumption 1988," DOE/EIA-0464(88), Washington, D.C., February 1990.

46. U.S. Department of Energy, Energy Information Administration, 1990b. International Energy Outlook 1990, DOE/EIA-0484(90) Washington, D.C., March.

47. U.S. Department of Transportation, Federal Highway Administration, National Transportaticz Strategic Planning Study, Washington, D.C., April 6, 1990, p. 10-25.

48. U.S. Department of Transportation, Federal Highway Administration, 1989. Highway Statistics 1989, Washington, D.C.

49. U.S. Department of Transportation, National Highway Traffic Safety Administration, 1989. "Papers on Car Size - Safety and Size Trends," DOT HS 807 444, Washington, D.C., June 1989.

50. U.S. Environmental Protection Agency, Office of Air and Radiation, 1990. "Emission Factor Projections (1990-2001), memorandum, tables and electronic data files covering 1990 to 2020, from Terry P. Newell, Test and Evaluation Branch, Emission Control Technology Division, to Ken Zerafa, Certification Policy and Support Branch, Ann Arbor, Michigan, October 2, 1990.

51. U.S. General Accounting Office (GAO), 1988. "ENERGY SECURITY: An Overview of Changes in the World Oil Market," GAO/RCED-88-170, Report to Congress, Washington, D.C.

52. Westbrook, F. and P.D. Patterson, 1989. "Changing Driving Patterns and Their Effect on Fuel Economy," presented May 2, 1989 at the 1989 Society of Automotive Engineers Government/Industry Meeting, Washington, D. C., supplied by Dr. Philip Patterson, Office of Transportation Systems, U.S. Department of Energy, Washington, D.C.

53. Williams, R.H., 1990. "Low-Cost Strategies for Coping with $\mathrm{CO}_{2}$ Emissions Limits," The Energy Journal, vol. 11, no. 3, pp. 35-59. 


\section{APPENDIX A \\ FUEL ECONOMY SCENARIO CALCULATIONS}

This appendix describes analyses of fuel economy potential supporting the three scenarios analyzed for this report. The essence of our approach to projecting MPG is to begin with manufacturers' plans for developing new carlines and modifying existing products. We estimate the effects of known MPG-improving technologies, weight and performance changes, as well as safety and emissions standards, are likely to have on fleet average MPG. We then explore what levels could be achieved by greater use of known fuel economy technologies. Details are provided for the Base Case and for Level 3, the highest fuel economy level. The intermediate fuel economy scenario, Level 2 , simply represents a point interpolated between the Base Case and Level 3.

The reader will note a few minor discrepancies between the MPG projections in this appendix and those shown in tables 1 and 2. None differ by more than 0.5 MPG. Subsequent to completion of the cost/benefit calculations, a few minor errors were discovered in the MPG projections. Since their effects will be negligible and well within reasonable error bounds on the projections in any case, we decided not to redo the cost benefit calculations.

The analysis presented in this section remains consistent with the projections shown in tables 1 and 2 on which the cost/benefit calculations are based. 


\section{Technologies for Improved Fuel Efficiency}

Automobile fuel economy can be improved by two basically different kinds of measures--reducing the loads on the automobile, thus reducing the work needed to move it; and increasing the efficiency of converting energy contained in the fuel to work. The loads consist of the force needed to accelerate the auto (to overcome inertia), air resistance, and rolling resistance of the tires and drivetrain. The efficiency of conversion is determined by the efficiencies of the drivetrain components--engine, transmission, and axles, and poiver consumed by accessories such as the water pump, alternator, fuel pump, and power steering.

In city driving, the three types of loads on the automobile are comparable. In steady, level driving, the inertia load is essentially zero, but most urban driving consists of repeated acceleration and deceleration, making the inertia load high. Because the force needed to accelerate a vehicle is purely a function of weight, weight reduction through improved design, acceptance of less space, or materials substitution is a critical factor in fuel economy, especially for the urban part of the cycle. On the highway, however, air resistance tends to dominate the total load, because resistance increases with the square of velocity--wind resistance at $60 \mathrm{mph}$ is 9 times resistance at $20 \mathrm{mph}$. Thus, reducing the aerodynamic load on the auto by increasing its "slipperiness" (reducing its drag coefficient) or reducing its cross-sectional area will greatly improve highway fuel economy and have a smaller but important effect on all but very low-speed urban driving.

Aside from reducing the loads, fuel economy can be improved by improving the engine's efficiency in converting fuel chemical energy into mechanical energy delivered to the wheels. The conversion of chemical to heat energy and then to mechanical energy results in an energy loss inversely proportional to combustion temperature (that is, the higher the temperature, the lower the loss). Current limitations in the ability of materials to function at very high temperatures (as well as emissions regulations, especially for nitrogen oxides) 
limit combustion temperature to a level that results in a theoretical 70-percent maximum utilization of the total energy available in the fuel. Other practical considerations related to the combustion cycle result in gasoline engines having an efficiency of only about 35 percent at their optimal operating points (i.e., this is their peak efficiency). ${ }^{7}$ Since the Federal Test Procedure driving cycle has variable loads and speeds, engines operate well below their peak for significant portions of the test cycle (this is true as well for most normal driving). At idle, for example, engine "efficiency" is zero. On average, over entire fuel economy test, the engine operating efficiency is about one-half peak efficiency.

The engine average efficiency can be improved by three different methods: increasing thermodynamic efficiency, reducing frictional losses, and reducing pumping losses (pumping losses are the energy needed to pump air and fuel into the cylinder and push out the products of combustion). The first, increasing thermodynamic efficiency, is limited by the characteristics of the spark ignition engine. Increasing the compression ratio increases thermodynamic efficiency; but other parameters related to fuel octane, nitrogen oxide emissions, and friction (emissions and friction increase with increasing compression ratio, and the octane level limits how high the ratio can go without obtaining premature combustion) result in declining benefits as compression ratios increase from today's 9.0 to 10.0 and beyond. Combustion chamber redesign can provide small increases in thermal efficiency.

Mechanical friction can be reduced by improving design of rubbing and sliding surfaces or using new materials and lubricants. Decreasing the weight of the piston, connecting rod, valves, and valve springs also reduces frictional losses. Replacing sliding contact surfaces with rolling contacts can provide significant benefits in friction reduction. No theoretical limit currently exists for reducing mechanical friction, and historically, engine friction has declined

7 Based on brake specific fuel consumption of $240 \mathrm{~g} / \mathrm{BHP}-\mathrm{hr}$. 
8 percent per decade. ${ }^{8}$ Pumping losses include losses due to throttling (that is, restricting air flow to maintain proper air/fuel ratios when the engine must be operated at a fraction of its peak power capability) and losses due to aerodynamic friction in the intake and exhaust system. Throttling loss is proportional to the degree of restriction of the airflow (throttle setting); it is zero at wide open throttle. Throttling loss can be reduced by operating the engine at a lower rpm but higher load for a given vehicle speed, or by using "lean burn" combustion (where excess air is not a problem). For example, the diesel engine uses lean burn and is completely unthrottled. Throttling loss can also be reduced by controlling valve lift and timing or by deactivating cylinders at low loads (so the engine essentially becomes smaller and can operate closer to peak capacity).

Aerodynamic (pumping) losses are associated with the air/fuel mixture as it flows through the air cleaner, intake manifold, and valve orifices, as well as the exhaust as it flows through the valves, manifold, muffler, and catalyst. This loss is proportional to the airmass flow and increases at higher loads and speeds. Aerodynamic losses can be reduced by tuned intake manifolds, increased valve area (or increased numbers of valves), tuned exhaust manifolds, and reduced pressure drop in the catalyst and muffler.

Efficiency improvements in the remainder of the drivetrain can be obtained by reducing frictional loss in the gearbox, axle (or transaxle for front-wheel-drive cars), wheel joints, wheel bearings, brakes, and oil seals. Those improvements can be small individually but provide a measurable cumulative benefit. The use of more gears in the transmission, however, improves efficiency by allowing the engine to operate closer to peak efficiency, rather than by reducing drivetrain loss.

${ }^{8}$ Honda Motor Company, Private Communication to Mr. K.G. Duleep, EEA, 1989. 
Finally, accessory drives can be made more efficient. Most front-wheel- drive cars already use an electric radiator fan which is engaged only when needed. "Smart" alternators that reduce the load when the battery is fully charged, more efficient water pumps, electric power steering, etc. can reduce the accessory loads that currently account for 8 to 12 percent of all fuel consumed over the test cycle. 9

Specific technologies available to reduce vehicle loads and reduce losses are considered below. These technologies have been documented in detail in a recent EEA report to Martin Marietta. ${ }^{10}$

Weight Reduction: Reducing vehicle weight without reducing practical space for passengers and cargo involves three strategies--substitution of lighter- weight materials without comprornising structural strength (e.g., aluminum or plastic for steel); improvement of packaging efficiency, that is, redesign of drivetrain or interior space to eliminate wasted space; and technological change that eliminates equipment or reduces the size of equipment. Our analysis does not isolate weight reduction directly associated with other efficiency changes, for example, reduced engine weight due to the downsizing (decrease in engine displacement) made possible by engine efficiency improvement, but instead counts the weight reduction as part of the overall fue! economy increase associated with the efficiency change. Most weight reduction gains are expected after 1995 . The fuel economy gain available from a 10-percent weight reduction is estimated to be 6.6 percent, including the effect of engine downsizing to maintain constant performance. Without engine down-sizing, the fuel economy benefit would be 4.2 percent. Materials substitution could reduce average vehicle weight 10 percent under

9 Sovran, G.S. and Bohn, M.S. "Formula for the Tractor Energy Requirements of Vehicles During the EPA Schedule" SAE Paper 810184, February 1981.

10 EEA "Documentation of the Characteristics of Technologies to Improve Fuel Economy" Report to Martin Marietta, October 1991. 
1987 levels by 2001 , and 18 to 25 percent under 1987 levels by 2010, with additional weight reduction (3 to 8 percent, depending on market class) possible from improved packaging.

Acrodynamic Drag Reduction: Aerodynamic drag on a car is the product of its frontal area, its drag coefficient, and the square of its speed. The squared velocity factor means that drag increases very rapidly with speed, and aero-dynamic drag is the most important power drain at highway speeds. Reducing frontal area is difficult because, with limited exception, this will compromise interior space. Reducing the drag coefficient involves smoothing out the basic shape of the vehicle, raking the windshield, eliminating unnecessary protrusions, controlling airflow under the vehicle (and smoothing out the underside), and designing the rear end to avoid turbulence and to control behavior of the boundary layer. A 10-percent reduction in the drag coefficient will yield about a 2.3-percent fuel economy gain if the top gear ratio is adjusted to match the engine's operating point to the reduced power requirement. For cars redesigned between now and 1995-96, an average drag coefficient might be 0.335 , down from 0.375; for cars redesigned between 1996 and 2001, average drag coefficient can be further reduced to 0.30 , which is the level of the most streamlined cars in the U.S. fleet today. Further reductions should be feasible by 2010--drag coefficients of 0.23 to 0.24 seem attainable, and coefficients as low as 0.20 are possible, but may compromise passenger comfort so that it may not be attainable in production.

Front-wheel Drive: Shifting from rear-to front-wheel drive provides a number of fuel-saving benefits, including the ability to mount engines transversely, reducing engine compartment length; elimination of the transmission tunnel, which provides important packaging efficiency gains in the passenger compartment; and elimination of the weight of the propeller shaft and rear differential and drive axle. Counterbalancing these benefits, front-wheel drive changes vehicle handling characteristics in ways objectionable to some drivers (though it offers clear advantages in slippery conditions) and compromises trailer-lowing capability. Total fuel 
savings available from a shift to front-wheel drive are about 10 percent for vehicles replacing 1970's vintage designs (body on frame), and about 5 percent for those where some potential benefits had already been gained through 1980's redesign (unit body).

Overhead Cam Engines: Overhead cam (OHC) engines are used in all imported vehicles; only U.S. manufacturers still sell overhead valve (OHV) engines. Older OHV engines produced less than $40 \mathrm{bhp} / \mathrm{iter}$, but more modern OHV engines provide $45 \mathrm{bhp} / \mathrm{liter}$. In contrast, modern OHC engines provide 50 to $55 \mathrm{bhp} / \mathrm{liter}$ in non-sports car applications. The higher specific output is due to the low mass of the valve train that makes it easier to open and close the valves, thereby improving breathing efficiency. A modern OHC engine providing equal performance (i.e., smaller displacement) will yield a 3-percent benefit in fuel economy over a modern OHV engine and up to 6 percent over an older OHV engine. The OHC engine must be 10 percent smaller in displacement than the OHV engine, but the axle ratio must be increased to maintain low speed drive-ability.

Four-vatve-per-cylinder: Adding two extra valves to each cylinder improves an engine's ability to feed air and fuel to the cylinder and discharge exhaust. Four-valve engines typically have sharply higher horsepower than two-valve engines of the same displacement, though peak horsepower is reached at much higher engine speeds, and torque (pulling power) at low engine speeds generally is not improved nearly as much. The major fuel economy gain of a four-valve engine is achieved by downsizing the engine, since this can be done without performance loss; the greater valve area also reduces pumping losses, and the more compact combustion chamber geometry and central spark plug location allows an increase in compression ratio. However, engine downsizing can-not be proportional to horsepower gain because of the resulting lack of low end torque. Available fuel economy gain over a two-valve overhead cam engine with the same number of cylinders is 5 percent; the gain is 8 percent if a four-cylinder engine replaces a two-valve six cylinder engine, or a six replaces 
an eight. The gain includes the effect of using a compact combustion chamber and increasing compression ratio from 9.0 to 10.0, which by itself is responsible for a 2-percent gain. By 2010, an increase in compression ratio to 11.0 should be possible, yielding an additional 1-percent gain in fuel economy. These benefits do not include the effect of downsizing the engine to the extent where aggressive transmission management would be necessary.

Variablo Vatue Timing: All engines have traditionally utilized fixed valve timing since a simple, reliable mechanism to vary timing had not been designed until recently. Thus, valve timing has always been a compromise between high rpm power output and low rpm torque. At part load, it is more efficient to close the intake valves early rather than pump air across the throttle. New devices to vary both valve timing and lift have been commercialized, and such systems have provided up to 15 percent gain in low-speed torque and/or 25-percent gain in specific power. A valve lift and timing control system can provide 6-percent benefit in fuel economy if the engine is downsized to provide equal low-speed performance, although there may be unfavorable synergies with more advanced transmissions that also reduce pumping loss (these transmissions re-duce the amount of time that engines operate at inefficient low-load conditions, when intake valve control is most effective). Valve control systems are most easily incorporated into a double overhead cam, four-valve engine.

Torque Converter Lockup: Current automatic transmissions utilize a hydraulic torque converter, where an impeller pushes fluid past a turbine to transmit engine torque to the wheels. This hydraulic connection is useful at idle and during acceleration, where it can provide torque multiplication. At higher speeds and low acceleration rates, the system is wasteful as there is some "slippage" between the impeller and turbine. A rigid mechanical link, called a lockup, prevents this slippage and provides a 3-percent benefit in fuel economy if employed in all gears except first. The lockup mechanism also transfers more vibration to 
the driveline, creating some negative response toward its use. Lockup is now widely used, so available gains are limited.

Accessory Improvements: Accessories driven by the engine include the air-conditioner, water pump, oll pumps, hydraulic power steering pump, alternator, and, in some cases, the radiator fan. Modest benefits are available in the redesign of all those systems to reduce total energy use. For example, a "smart" alternator can be electronically controlled to provide battery charging only when desirable. Power steering pumps are very wasteful at speed, as they are sized for idle, when steering loads are greatest. Most cars already employ electric fans for the radiator which are switched on when necessary, but further improvement is possible if their speed can be varied. Individually, these accessory benefits are very small but together they can provide a 0.5 - to 1.0 -percent benefit in fuel economy. One possibility is completely eliminating the hydraulic power steering pump and replacing it with electric power steering. This action alone can increase fuel economy by another 1 percent. However, the electrical power demand is so large that electric power steering may be impractical for intermediate and large cars.

Advanced Transmissions: A particular power demand can be met by an engine at different operating points since:

$$
\text { power }=\text { torque }^{*} \text { speed. }
$$

At any level of power demand, the highest torque and lowest engine speed combination--up to a certain point--offers the best fuel economy. Adding gears to an automatic transmission allows operation closer to the optimal combination of torque and speed for any given power demand. Theoretically, a continuously variable transmission (CVT) can keep engine speed at optimal rates for all vehicle speeds. Current CVT designs appear practical only for smaller cars, with two-liter engines or smaller, because of limitations on the amount of power that can 
be transmitted by the flexible belts in the transmission. Average fuel economy improvement in moving from three-speed transmission with lockup to four-speed with lockup is 4.5 percent, with an additional 2.5 percent available from adding a fifth gear, or an additional 3.5 percent avallable from moving to a CVT.

Electronic Transmission Control: Most automatic transmissions currently use mechanical controls to shift gears or engage the torque converter lockup. The controls have been highly developed over the years to match the requirements of the test cycie. Electronic controls can offer a minor benefit by shifting gears and engaging the lockup more efficiently, but the fuel economy gain on the cycle is only 0.5 percent. Under real-world conditions, it is expected to provide greater benefits, especially at operating points outside the test cycle envelope.

Throttle Body and Multipoint Fucl Injection: Most vehicles already utilize fuel injection systems that have replaced carburetors. Fuel injection systems are of two types: throttle body, that essentially replaces a carburetor with one or two injectors that supply fuel to all cylinders; and multipoint, that utilizes one injector per cylinder metering fuel directly into the intake port. Fuel injection allows more precise control of fuel quantity metered during transient operation (such as acceleration or deceleration) and also atomizes fuel more completely. These factors allow less fuel to be used during cold starts and transients and also improve emissions. The throttle body system provides a 3 -percent benefit over a carburetor, if adopting the system eliminates the air pump required to meet emission standards. Widespread use limits available fleet gains, however. A multipoint fuel injection system allows the inlet manifold to be tuned to maximize airflow, as no fuel flows through the manifold. The tuned inlet manifold can increase torque by 3 percent. A "sequential" multipoint fuel injection system allows fuel shutoff during deceleration. The multipoint system also mitigates fuel distribution problems, allowing leaner mixtures during warmup and slightly more aggressive spark timing after warmup. The combination of a multipoint system with a tuned 
intake manifold and deceleration fuel shutoff provides a 3-percent benefit in fuel economy relative to the throttle body system.

Improved Tires and Lubricants: Longstanding trends toward slipperier oil and tires with lower rolling resistance will continue. The recently displayed GM prototype electric car, the Impact, has tires with half the rolling resistance of modern radials. Traditionally, the rolling resistance reduction has adversely impacted handling and traction properties. New developments in the cord and rubber materials reduce tire flexing losses without the adverse effect on handling. The fuel economy benefit of using the best available oils (5W-30 replacing 10W-40) and tires, now in use on about 20 percent of the 1988 fleet, is about 1 percent. Incremental improvements in tires beyond 1995, available to the fleet in 2001, should yield at least another 0.5-percent gain. Tires like those of the Impact, if they prove practical, would yield additional gains.

Engine Friction Reduction: Engine friction is predominantly in the pistons/rings, valve train, and crankshaft. On average about 20 percent of potential engine power is lost to friction; this represents one third of total output power. Engine friction reduction in the 1987 to 1995 timeframe will involve reducing piston ring tension, redesigning the piston skirts (or load bearing area), and improving manufacturing methods to reduce cylinder bore distortions. These efforts will provide a 2-percent fuel economy benefit. Roller cam followers reduce valve train friction by replacing the sliding contact between the roller cam and camshaft with a rolling contact, also providing a 2-percent fuel economy benefit. After 1995, friction reduction will involve the use of lightweight valves and springs, reduction in piston and connecting rod mass through the use of fiber-reinforced composite materials, and possibly, use of only two rings rather than three, with a potential additional 2-percent fuel economy gain by 2001 . 
In the following tables, we have denoted the technologies adopted in a business as usual scenario (i.e. the product plan) as the base case. Utilizing all available technologies to the maximum extent possible is denoted as Level 3. The available lead time does not permit much technology to be introduced by 1995 over and above the business-as-usual scenario, but some minor improvements are possible. By 2001, significant improvement is possible, both from technology, and by reduction in size/performance from anticipated 2001 levels to 1990 levels. A Level 2 scenario corresponds to a fuel economy level between the base case and Level 3 case. In the Level 2 scenario (not shown), performance size are kept at 1990 levels, and technologies that pay for themselves over 10 years of ownership (at $\$ 1.20 /$ gallon fuel) are adopted to the penetration shown in Level 3. Projections have been made for domestic and Japanese manufacturers' automobiles and for domestic light trucks. Since we do not have sufficient data to prepare detailed projections of imported light truck fuel economy, we relied on our own judgment to supply these projections. In general, they are consistent with improvements by domestic light truck manufacturers with respect to MPG gain and cost.

Technology incremental costs are the average retail price increase associated with technology adoption. For example, the incremental price of a four speed automatic transmission is based on the price difference between an otherwise identical pair of vehicles, one with a three speed automatic and one with a four-speed automatic. Costs for technologies were derived from four different methodologies.

- Actual retail prices

- Manufacturer submissions to DOT

- Prices de ived from production costs and investments

- Supplier industry based data, with markups for overheads, taxes and dealer markups

Actual retail prices could be used for some technologies which are available in the same vehicle model as sptions. These include engine options and transmissions options. Actual 
retail prices were collerted for mass market models (i.e. non-luxury) and these prices were averaged across models to provide a retail price increment.

Manufacturer submissions to DOT in the mid-1980's were prowided to the DOE under a confidentiality agreement. These submissions contained data on retail price increments associated with technologies that could not be isolated as options in models. Such technologies include material substitution, engine friction reduction, accessory improvements, etc.

Prices derived from costs were based on detailed manufacturing cost studies developed by Lindgren for he DOE. The variable costs were marked up to cover factory overhead, corporatc overhead, taxes, profit margins and dealer markup, as well as the amortization of the capital investment. The markup factors and amortization rates are provided by Lindgren."

Supplier based data were utilized in a limited number of cases when a large supplier provides a technology to several manufacturers. Technologies for which supplier based data was obtained include tires, lubricants, electronic controls, fuel injection systems and roller cam followers. Supplier prices were marked up by auto manufacturer overheads to derive retail price equivalents.

In most cases, more than one method was utilized to derive the retail price increments. If different methods provided similar results, the actual retail price increment (if available) was chose. Prices derived from costs were chosen for several technologies were

11 Lindgren, L.H., Jones, D., "Automotive Technologies and Manufacturing Investment Costs" Report to the DOE, May 1986. 
retail prices could not be identified. A detailed list of prices of each technology is provided in the attached tables. 
1995 DOMESTIC MANUFACTURERS' FUEL ECONOMY

BASE CASE

Technology

$\mathrm{F} / \mathrm{E}$

Gain

(\%)

Penetration

Increase from

$1987(\%)$

10.0
$2.3 / 4.6^{* *}$

Front Wheel Drive

4.5

12

etration

Drag Reduction $\left(C_{D} \sim 0.33\right)$

4-speed Automatic

Transmission

Torque Converter Lock-up

3.0

0.5

Electronic Transmission

Control

Accessory Improvements

0.5

Lubricant/Tire Improvements

1.0

$65 / 15$

86

1.20

2.19

40

$\sim 100$

1.80

Engine Improvements

- Advanced Pushrod

- Overhead Camshaft

- Roller Cam Followers

3.0

2.0

- Low Friction Pistons/Rings

2.0

- Throttle Body FI

- Multi-point FI

(over throttle body)

3.0

3.0

20

80

0.60

80

80

0.40

4 valves per cylinder engine

- 4 cylinder replacing $6^{*}$

- 6 cylinder replacing $8^{*}$

8.0

8.0

80

N/M

0.40

100

100

1.00

Total F/E Benefit

(40)

45

40

80

(30)

69

95

100

12

12
40

60
1.20

1.35

0.80

1.60

0.36

0.36

Number in parenthesis for advanced pushrod indicates 45 percent of pushrod engines replaced by OHC engines.

N/M: Not meaningful.

* 1987 distribution: $20.5 \%$ V-8, 29.5\% V-6, 50\% 4 cylinder

** Drag reduction for large/luxury cars from $C_{D}=0.42$ baseline. 


\section{DOMESTIC MANUFACTURERS \\ FUEL ECONOMY UNDER ALTERNATIVE SCENARIOS \\ BASE CASE}

1987 Fuel Economy:

26.7 MPG

1995 Fuel Economy w/o size or performance increase

30.9 MPG

Size/weight Increase

$-1.4 \mathrm{MPG}$

Performancè Increase

-0.7 MPG

Effect of Emission/Safety Standards

$-\underline{0.8}$ MPG

1995 Product Plan F/E

28.0 MPG

1995 LEVEL 3 CASE

1995 Fuel Economy w/o size or performance increase

$30.9 \mathrm{MPG}$

Effect of Emission/Safety Standards

$-0.8 \mathrm{MPG}$

Replace all TBI of wiîh MPFI

$+0.32 \mathrm{MPG}$

Increase $\mathrm{OHC}$ penetration to $80 \%$

$+0.08 \mathrm{MPG}$

Size/Weight increase to ' 90 (est.)

$-0.60 \mathrm{MPG}$

Performance Increase to '90 (est.)

$-0.40 \mathrm{MPG}$

1995 Max Tech Case at 1990

29.5 MPG

size and performance 


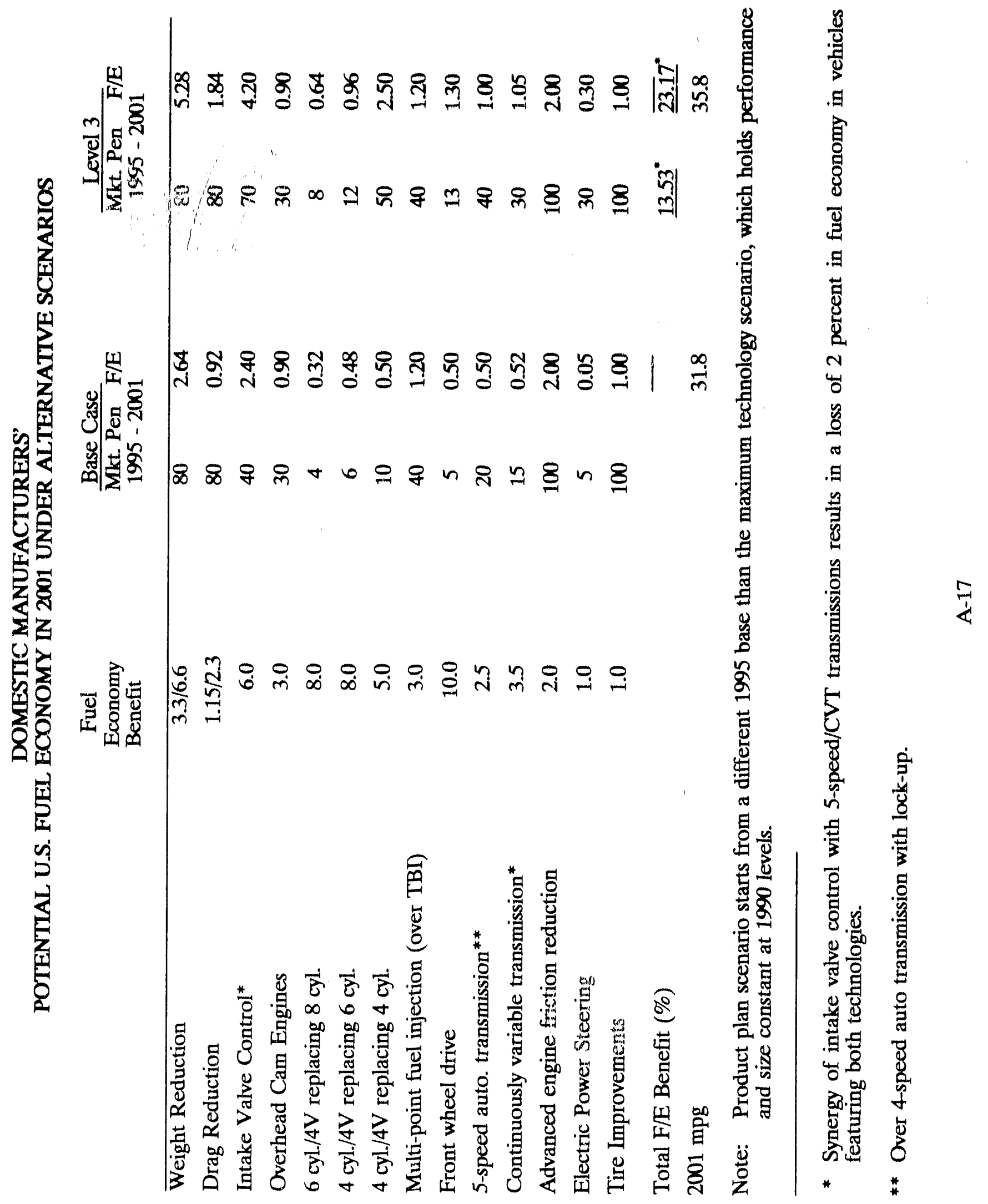




\section{5 \\ IMPORT MANUFACTURERS \\ FUEL ECONOMY \\ BASE CASE \\ (JAPANESE FULLLINE MANUFACTURERS)}

Technology

Front Wheel Drive*

Drag Reduction I

4-speed Auto. Trans.

Torque Converter LU

Elec. Trans. Control

Accessory Improvements

Tires/Lubricants

Roller Cam Followers

Low Friction Piston/Rings

Throttle Bouly FI** $^{\text {** }}$

Multi-Point

4 Valves/Cylinder

TOTAL F/E BENEFTT (\%)
Penetration Increase from 1988

3

80

16

9

44

80

100

50

80

25

20

20
$1995 \quad$ Fleet

Penetration F/E Gain

90

0.15

1.84

47

0.72

53

0.27

47

0.22

0.40

N/M

1.00

100

1.00

2.0

2.0

3.0

5.0
1.60

0.50

0.60

1.00

9.30

* F/E gain liatsed on conversion of unit body RWD vehicle.

** Benefit of THI is lower than for domestic cars because air pumps are not used in carburetted import cars. 


\section{5 \\ IMPORT MANUFACTURERS \\ FUEL ECONOMY \\ UNDER ALTERNATIVE, SCENARIOS \\ (JAPANESE FULL-LINE MANUFACTURERS)}

\section{Base Case}

1988 Fuel Economy

31.4 MPG

1995 Fuel Economy thout size or performance increase

34.32 MPG

Size/Weight increase

$-1.66 \mathrm{MPG}$

Performance Increase

$-0.90 \mathrm{MPG}$

Effect of Safety/Emission Std.

$-0.94 \mathrm{MPG}$

1995 Product Plan F/E

$\overline{30.82} \mathrm{MPG}$

Level 3

1995 Fuel Economy without size or performance increase

34.32 MPG

Effect of Safety/Emission Standard

$-0.94 \mathrm{MPG}$

Replace all TBI with MPFI

$+0.23 \mathrm{MPG}$

Increase roller cam penetration to $80 \%$

$+0.19 \mathrm{MPG}$

Size/weight increase to 1990

$-1.08 \mathrm{MPG}$

Performance increase to 1990

$-0.78 \mathrm{MPG}$

1995 Maximum Technology F/E

$\overline{31.94}$ MPG 


\section{IMPORT MANUFACTURERS \\ FUEL ECONOMY IN 2001 \\ (JAPANESE FULL-LINE MANUFACTURERS)}

Technology

Weight Reduction

Drag Reduction

Intake Valve Control

4-Valve Engine

Multi-point FI

Front Wheel Drive

5-Speed Auto. Trans.

CVT

Advanced Friction Reduction

Electric Power Steering

Tire Improvements

TOTAL F/E BENEFTT (\%)

2001 MPG
F/E Benefit

$3.3 / 6.6$

$1.15 / 2.3$

6.0

5.0

3.0

10.0

2.5

3.5

2.0

1.0

1.0
Base Case

Mkt. Pen. F/E Gain

90

2.97

80

0.92

1.80

0.50

0.75

0.00

0.15

0.91

2.00

0.10

0.80

$\overline{11.50}$

34.3

80
Level 3 Case"*

Mkt. Pen. F/E Gain

90

5.94

1.84

3.60

2.50

0.00

0.50

0.30

1.40

2.00

0.35

80

0.80

$\overline{18.98}$

38.0

Synergy with 5-spd auto-transmission/CVT results in 2 percent loss in $\mathrm{F} / \mathrm{E}$ when both technologies are used in the same vehicle.

* $\quad$ Maintains 1990 level of size/performance. 


\section{DOMESTIC MANUFACTURER'S FUEL ECONOMY \\ BASE CASE}

\begin{tabular}{|c|c|c|c|c|}
\hline Technology & $\begin{array}{l}\mathrm{F} / \mathrm{E} \\
\text { Gain \% }\end{array}$ & $\begin{array}{c}1988 \\
\text { Penctration } \\
\end{array}$ & $\begin{array}{c}1988-1995 \\
\text { Pen. Increase } \\
\end{array}$ & $\begin{array}{l}\text { Fleet } \mathrm{H}^{\prime} / \mathrm{E} \\
\text { Gain } \\
\end{array}$ \\
\hline $\begin{array}{l}\text { Weight Reduction } \\
\text { (Std. Pickup/Utility) }\end{array}$ & 1.65 & 15 & 20 & 0.33 \\
\hline Drag Reduction I & 2.30 & 15 & 85 & 1.95 \\
\hline Automatic Overdrive Trans & 4.50 & 49 & 20 & 0.90 \\
\hline TCLU & 3.00 & 61 & 14 & 0.42 \\
\hline Electronic Trans. Control & 0.50 & 0 & 64 & 0.32 \\
\hline Roller Cam Followers & 2.00 & 50 & 50 & 1.00 \\
\hline Eng. Friction Reduction & 2.00 & 0 & 80 & 1.60 \\
\hline MPI over TBI & 3.00 & 47 & 4 & 0.60 \\
\hline over Carburetor & 6.00 & - & 60 & 0.24 \\
\hline Advanced OHV engine & 3.00 & 24 & 60 & 1.80 \\
\hline $\mathrm{OHC} / 2 \mathrm{~V}$ engine & 3.00 & 16 & 10 & 0.30 \\
\hline Improved Tires & 0.50 & 0 & 100 & 0.50 \\
\hline SW-30 oil & 0.50 & 0 & 100 & $\underline{0.50}$ \\
\hline Total & & & & 10.46 \\
\hline
\end{tabular}


1995 BASE CASE

LDT FUEL ECONOMY

1987 Base Fuel Economy

20.6 MPG

1995 Fuel Economy w/o Size or

Performance Increase

22.75

Compact Vehicle Size Increase

$-0.35$

Performance Increase

$-0.68$

Tier I Emission Penalty

$-0.20$

Safety (Weight) Penalty

$-0.62$

Effect of New Van Introduction

$\pm 0.41$

21.31 MPG

1995 Base Case F/E

1995 Level 3 Case

1995 Base Case F/E

21.31 MPG

$100 \%$ Use of MPI

$+0.19 \mathrm{MPG}$

Replace all 3-speed auto trans.

with 4-speed auto trans.

$+0.06 \mathrm{MPG}$

Reduce performance to 1990 Level

$+0.29 \mathrm{MPG}$

1995 Level 3 MPG

21.80 MPG 


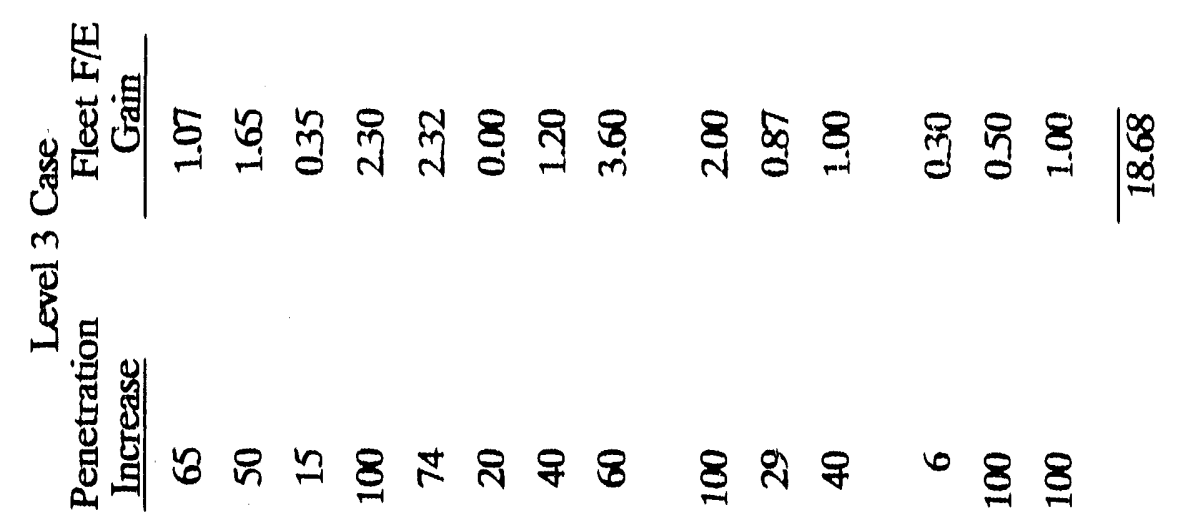

ถู่

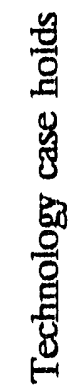

目

舟

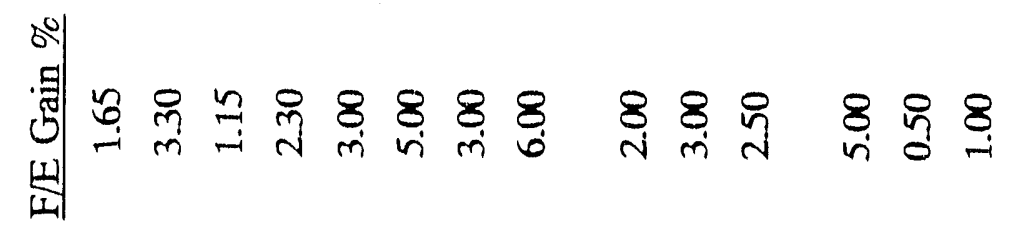

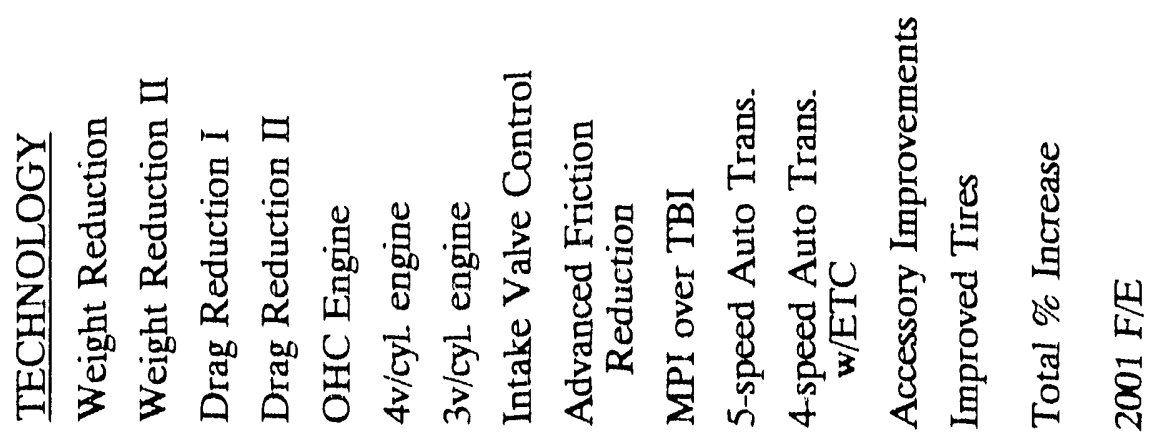




\section{INCREMENTAL RETAIL PRICE \\ OF TECHNOLOGY (1985)}

Front Wheel Drive

Drag Reduction to $C_{D}=0.33$

Drag Reduction to $C_{D}=0.30$

4-Speed Auto Trans.

Torque Converter Lockup

Electronic Transmission Control

Accessory Improvements

OHC Engine: 4-cylinder 6-cylinder

110

8-cylinder

160

200

4-valve heads: 4-cylinder 6-cylinder 8-cylinder

140)

180

225

Roller cams

4 per cylinder

Friction reduction I:

4-cylinder

6-cylinder

8-cylinder

30

40

50

"Advanced Pushrod"

40 (6 cylinder)

42 (one injector)

70 (two injector)

MPFI over TBI

- 4-cylinder

-6-cylinder

-8-cylinder

48

64

80

12 (4 tires)

Tire Improvements

Oil (5W-30)

5-speed Automatic (over 4-speed)

2

100

CVT (over 4-speed auto)

100

Advanced Friction Reduction

same as Friction

Reduction I

Tire Improvements (1995-2001)

Intake Valve Control

- 4-cylinder

- 6 cylinder 


\section{APPENDIX B}

TABLE 1. PROJECTED LIGHT DUTY VEHICLE FUEL USE (Units in billions, except vehicles in millions) Automoblles, NES Reference Case

$\begin{array}{lrrrrrrrrr}\text { BASE CASE } & 1990 & 1995 & 2000 & 2005 & 2010 & 2015 & 2020 & 2025 & 2030 \\ \text { FUEL USE } & 69.1 & 66.0 & 67.4 & 69.8 & 72.7 & 75.2 & 77.2 & 78.8 & 80.6 \\ \text { VMT } & 1434.5 & 1469.2 & 1502.4 & 1579.7 & 1665.8 & 1731.6 & 1777.0 & 1814.9 & 1856.3 \\ \text { MPO } & 20.6 & 22.2 & 22.3 & 22.6 & 22.9 & 23.0 & 23.0 & 23.0 & 23.0 \\ \text { VEHICLES } & 119.5 & 118.2 & 122.1 & 127.9 & 134.0 & 138.7 & 141.8 & 144.2 & 146.4 \\ \text { MILES/VEH. } & 12008 & 12434 & 12306 & 12350 & 12430 & 12483 & 12532 & 12588 & 12680 \\ \text { CPM ELAST. } & -0.2 & & & & & & & & \\ & & & & & & & & & \\ \text { LEVEL 2 } & 1990 & 1995 & 2000 & 2005 & 2010 & 2015 & 2020 & 2025 & 2030 \\ \text { FUEL USE } & 69.5 & 66.0 & 66.5 & 67.3 & 69.1 & 71.3 & 73.2 & 74.1 & 76.1 \\ \text { ADJ. FUEL USE } & 69.5 & 66.0 & 66.6 & 67.5 & 69.4 & 71.6 & 73.4 & 74.5 & 76.4 \\ \text { VMT } & 1434.5 & 1469.2 & 11.05 .8 & 1588.7 & 1678.3 & 1746.1 & 1792.4 & 1831.0 & 1873.1 \\ \text { MHQ } & 20.6 & 22.2 & 22.6 & 23.6 & 24.3 & 24.5 & 24.5 & 24.7 & 24.6 \\ \text { VEHICLES } & 119.5 & 118.2 & 122.1 & 127.7 & 133.6 & 138.2 & 141.3 & 143.7 & 146.0 \\ \text { MILES/VEH. } & 12008 & 12434 & 12336 & 12444 & 12564 & 12632 & 12682 & 12739 & 12832 \\ \text { ADJ VMT } & 1434.5 & 1469.2 & 1506.8 & 1593.0 & 1684.9 & 1753.1 & 1799.2 & 1840.7 & 1881.1 \\ & & & & & & & & 2019 \\ \text { LEVEL 3 } & 1990 & 1995 & 2000 & 2005 & 2010 & 2015 & 2020 & 2025 & 2030 \\ \text { FUEL USE } & 69.5 & 65.4 & 64.7 & 64.6 & 66.1 & 68.2 & 69.9 & 71.4 & 73.1 \\ \text { ADJ. FUEL USE } & 69.5 & 65.5 & 65.0 & 65.4 & 67.1 & 69.2 & 71.0 & 72.5 & 74.2 \\ \text { VMT } & 1434.5 & 1470.8 & 1507.0 & 1586.0 & 1672.9 & 1740.0 & 1786.6 & 1825.4 & 1867.5 \\ \text { MPO } & 20.6 & 22.5 & 23.3 & 24.5 & 25.3 & 25.5 & 25.6 & 25.5 & 25.5 \\ \text { VEHICLES } & 119.5 & 118.1 & 121.7 & 126.8 & 132.3 & 136.8 & 139.9 & 142.3 & 144.6 \\ \text { MILES/VEH. } & 12008 & 12449 & 12383 & 12511 & 12645 & 12717 & 12768 & 12826 & 12919 \\ \text { ADJ VMT } & 1434.5 & 1472.5 & 1515.7 & 1605.4 & 1699.0 & 1767.8 & 1814.3 & 1853.0 & 1895.2\end{array}$


TABLE 2. PROJECTED LIGHT DUTY VEHICLE FUEL USE (Units in billions, except vehicles in millions)

Light Trucks, MES Reference Case

\begin{tabular}{|c|c|c|c|c|c|c|c|c|c|}
\hline BASE CASE & 1990 & 1995 & 2000 & 2005 & 2010 & 2015 & 2020 & 2025 & 2030 \\
\hline FUEL USE & 29.2 & 31.1 & 33.6 & 35.6 & 37.4 & 38.8 & 39.8 & 40.7 & 41.6 \\
\hline VMT & 464.3 & 528.3 & 568.1 & 599.6 & 632.3 & 657.1 & 674.4 & 688.7 & 704.3 \\
\hline MPG & 15.9 & 17.0 & 16.8 & 16.8 & 16.9 & 16.9 & 16.9 & 16.9 & 16.9 \\
\hline VEHICLES & 47.6 & 51.9 & 57.0 & 60.6 & 63.7 & 65.9 & $67: 4$ & 68.5 & 69.6 \\
\hline MILES/VEH. & 9745 & 10175 & 9932 & 9891 & 9929 & 9964 & 10003 & 10048 & 10121 \\
\hline CPM ELAST. & -0.2 & & & & & & & & \\
\hline LEVEL 2 & 1990 & 1995 & 2000 & 2005 & 2010 & 2015 & 2020 & 2025 & 2030 \\
\hline FUEL UUE & 29.2 & 31.1 & 33.1 & 34.1 & 35.2 & 36.4 & 37.4 & 38.2 & 39.0 \\
\hline ADJ. FUEL USE & 29.2 & 31.1 & 33.2 & 34.2 & 35.5 & 36.7 & 37.6 & 38.4 & 39.3 \\
\hline VMT & 464.3 & 528.3 & 567.3 & 602.6 & 636.4 & 662.1 & 679.9 & 694.6 & 710.5 \\
\hline MPG & 15.9 & 17.0 & 17.1 & 17.7 & 18.1 & 18.2 & 18.2 & 18.2 & 18.2 \\
\hline VEHICLES & 47.6 & 51.9 & 57.0 & 60.4 & 63.3 & 65.6 & 67.0 & 68.2 & 69.3 \\
\hline MILES/VEH. & 9745 & 10175 & 9958 & 9974 & 10050 & 10099 & 10140 & 10185 & 10260 \\
\hline ADJ VMT & 464.3 & 528.3 & 568.1 & 605.5 & 640.7 & 666.6 & 684.1 & 698.7 & 714.5 \\
\hline LEVEL 3 & 1990 & 1995 & 2000 & 2005 & 2010 & 2015 & 2020 & 2025 & 2030 \\
\hline FUEL USE & 29.2 & 31.0 & 32.4 & 32.6 & 33.3 & 34.3 & 35.2 & 36.0 & 36.8 \\
\hline ADJ. FUEL USE & 29.2 & 31.0 & 32.6 & 33.1 & 34.0 & 35.0 & 35.9 & 36.7 & 37.5 \\
\hline VMT & 464.3 & 528.7 & 567.9 & 601.6 & 634.2 & 659.7 & 677.6 & 692.5 & 708.5 \\
\hline MPG & 15.9 & 17.1 & 17.5 & 18.5 & 19.1 & 19.2 & 19.3 & 19.3 & 191.3 \\
\hline VEHICLES & 47.6 & 51.9 & 56.9 & 60.0 & 62.6 & 64.7 & 66.2 & 67.4 & $68 ., 4$ \\
\hline AILES/VEH. & 9745 & 10185 & 9987 & 10029 & 10131 & 10191 & 10233 & 10279 & 10354 \\
\hline ADJ VMT & 464.3 & 528.9 & 570.8 & 610.7 & 647.6 & 674.1 & 641.9 & 706.6 & 722.5 \\
\hline
\end{tabular}


TABLE 3. PROJECTED LIGHT DUTY VEHICLE FUEL USE (Units in billions, except vehicles in millions) Automobiles, High Oil Price Case

$\begin{array}{lrrrrrrrrr}\text { BASE CASE } & 1990 & 1995 & 2000 & 2005 & 2010 & 2015 & 2020 & 2025 & 2030 \\ \text { FUEL USE } & 69.3 & 63.9 & 65.3 & 67.3 & 69.8 & 72.4 & 74.4 & 76.3 & 78.1 \\ \text { VIT } & 1429.4 & 1421.6 & 1456.4 & 1523.2 & 1599.3 & 1665.7 & 1713.8 & 1757.1 & 1799.7 \\ \text { MPG } & 20.6 & 22.2 & 22.3 & 22.6 & 22.9 & 23.0 & 23.0 & 23.0 & 23.0 \\ \text { VEHICLES } & 119.5 & 118.2 & 122.1 & 127.9 & 134.0 & 138.7 & 141.8 & 144.2 & 146.4 \\ \text { MILES/VES. } & 11965 & 12031 & 11929 & 11909 & 11933 & 12008 & 12086 & 12187 & 12293 \\ \text { CPM ELAST. } & -0.2 & & & & & & & & \\ & & & & & & & & & \\ \text { LEVEL 2 } & 1990 & 1995 & 2000 & 2005 & 2010 & 2015 & 2020 & 2025 & 2030 \\ \text { FUEL USE } & 69.3 & 63.9 & 64.5 & 64.9 & 66.4 & 68.6 & 70.6 & 72.4 & 74.1 \\ \text { ADJ. FUEL USE } & 69.3 & 63.9 & 64.5 & 65.1 & 66.7 & 68.9 & 70.8 & 72.6 & 74.4 \\ \text { VMT } & 1429.4 & 1421.6 & 1459.7 & 1531.9 & 1611.3 & 1679.6 & 1728.6 & 1772.7 & 1816.0 \\ \text { MPG } & 20.6 & 22.2 & 22.6 & 23.6 & 24.3 & 24.5 & 24.5 & 24.5 & 24.5 \\ \text { V.MICLES } & 119.5 & 118.2 & 122.1 & 127.7 & 133.6 & 138.2 & 141.3 & 143.7 & 146.0 \\ \text { MILES/VEH. } & 11965 & 12031 & 11958 & 11999 & 12063 & 12151 & 12231 & 12334 & 12441 \\ \text { ADJ VMT } & 1429.4 & 1421.6 & 1460.7 & 1536.0 & 1617.6 & 1686.3 & 1735.1 & 1779.0 & 1822.1 \\ & & & & & & & & & \\ \text { LEVEL 3 } & 1990 & 1995 & 2000 & 2005 & 2010 & 2015 & 2020 & 2025 & 2030 \\ \text { FUEL USE } & 69.3 & 63.3 & 62.7 & 62.3 & 63.5 & 65.6 & 67.4 & 69.2 & 70.9 \\ \text { ADJ. FUEL USE } & 69.3 & 63.3 & 63.0 & 63.1 & 64.5 & 66.6 & 68.5 & 70.2 & 71.9 \\ \text { VMT } & 1429.4 & 1423.1 & 1460.8 & 1529.2 & 16,06.1 & 1673.8 & 1723.0 & 1767.2 & 1810.6 \\ \text { MPG } & 20.6 & 22.5 & 23.3 & 24.5 & 25.3 & 25.5 & 25.6 & 25.6 & 25.5 \\ \text { VEHICLES } & 119.5 & 118.1 & 121.7 & 126.8 & 132.3 & 136.8 & 139.9 & 142.3 & 144.6 \\ \text { MILES/VEH. } & 11965 & 12045 & 12004 & 12064 & 12140 & 12233 & 12314 & 12417 & 12525 \\ \text { ADJ VMT } & 1429.4 & 1424.7 & 1469.3 & 1548.0 & 1631.2 & 1700.5 & 1749.8 & 1794.0 & 1837.4\end{array}$


TABLE 4. PROJECTED LIGHT DUTY VEHICLE FUEL USE

(Units in billions, except vehicles in millions)

Light Trucks, High Oil Price Case

\begin{tabular}{|c|c|c|c|c|c|c|c|c|c|}
\hline BASE CASE & 1990 & 1995 & 2000 & 2005 & 2010 & 2015 & 2020 & 2025 & 2030 \\
\hline FUEL USE & 29.1 & 30.1 & 32.6 & 34.3 & 35.9 & 37.3 & 38.4 & 39.4 & 40.3 \\
\hline VMT & 462.7 & 511.1 & 548.8 & 578.2 & 607.0 & 632.1 & 650.4 & 666.8 & 682.8 \\
\hline MPG & 15.9 & 17.0 & 16.8 & 16.8 & 16.9 & 16.9 & 16.9 & 16.9 & 16.9 \\
\hline VEHICLES & 47.6 & 51.9 & 57.0 & 60.6 & 63.7 & 65.9 & 67.4 & 68.5 & 69.6 \\
\hline MILES/VEH. & 9711 & 9845 & 928 & 9538 & 9532 & 9585 & 9647 & 9728 & 9812 \\
\hline CPM ELAST. & -0.2 & & & & & & & & \\
\hline LEVEL 2 & 1990 & 1995 & 2000 & 2005 & 2010 & 2015 & 2020 & 2025 & 2030 \\
\hline FUEL USE & 29.1 & 30.1 & 32.1 & 32.9 & 33.8 & 35.0 & 36.0 & 36.9 & 37.8 \\
\hline ADJ. FUEL USE & 29.1 & 30.1 & 32.2 & 33.0 & 34.0 & 35.3 & 36.3 & 37.2 & 38.1 \\
\hline VAT & 462.7 & 511.1 & 550.0 & 581.1 & 611.0 & 636.9 & 655.7 & 672.5 & 688.8 \\
\hline MPG & 15.9 & 17.0 & 17.1 & 17.7 & 18.1 & 18.2 & 18.2 & 18.2 & 18.2 \\
\hline VEHICLES & 47.6 & 51.9 & 57.0 & 60.4 & 63.3 & 65.6 & 67.0 & 68.2 & 69.3 \\
\hline MILES/VEH. & 9711 & 9845 & 9653 & 9617 & 9648 & 9715 & 9779 & 9861 & 9947 \\
\hline ADJ VAT & 462.7 & 511.1 & 550.7 & 583.8 & 615.1 & 641.2 & 659.8 & 676.4 & 692.7 \\
\hline LEVEL 3 & 1990 & 1995 & 2000 & 2005 & 2010 & 2015 & 2020 & 2025 & 2030 \\
\hline FUEL USE & 29.1 & 30.0 & 31.6 & 31.4 & 32.0 & 33.0 & 33.9 & 34.8 & 35.7 \\
\hline ADJ. FUEL USE & 29.1 & 30.0 & 31.6 & 31.9 & 32.6 & 33.7 & 34.7 & 35.6 & 36.4 \\
\hline VMT & 462.7 & 511.6 & 550.5 & 580.1 & 608.8 & 634.6 & 653.5 & 673.8 & 686.9 \\
\hline MPG & 15.9 & 17.1 & 17.5 & 18.5 & 19.1 & 19.2 & 19.3 & 19.3 & 19.3 \\
\hline VEHICLES & 47.6 & 51.9 & 56.9 & 60.0 & 62.6 & 64.7 & 66.2 & 67.4 & 68.4 \\
\hline MILLs,:"ic:: & 9711 & 9855 & 9681 & 9671 & 9727 & 9803 & 9869 & 10001 & 10038 \\
\hline ADJ VAT & 462.7 & 511.8 & 553.4 & 588.9 & 621.7 & 648.4 & 667.2 & 684.8 & 700.5 \\
\hline
\end{tabular}


TABLE 5. PROJECTEd LIGHT DUTY VEHICLE FUEL USE (Units in billions, except vehicles in millions) Automobiles, Low Oil Price Case

$\begin{array}{lrrrrrrrrr}\text { BASE CASE } & 1990 & 1995 & 2000 & 2005 & 2010 & 2015 & 2020 & 2025 & 2030 \\ \text { FUEL USE } & 69.3 & 67.4 & 69.2 & 71.9 & 75.3 & 78.3 & 4.1 & 82.5 & 84.7 \\ \text { VMT } & 1429.4 & 1499.2 & 1543.7 & 1628.9 & 1725.2 & 1802.8 & 1855.5 & 1900.6 & 1951.2 \\ \text { MPG } & 20.6 & 22.2 & 22.3 & 22.6 & 22.9 & 23.0 & 23.0 & 23.0 & 23.0 \\ \text { VEHICLES } & 119.5 & 118.2 & 122.1 & 127.9 & 134.0 & 138.7 & 141.8 & 144.2 & 146.4 \\ \text { MILES/VEH. } & 11965 & 12688 & 12644 & 12735 & 12873 & 12997 & 13085 & 13183 & 13328 \\ \text { CPM ELAST. } & -0.2 & & & & & & & & \\ & & & & & & & & & \\ \text { LEVEL 2 } & 1990 & 1995 & 2000 & 2005 & 2010 & 2015 & 2020 & 2025 & 2030 \\ \text { FUEL USE } & 69.3 & 67.4 & 68.4 & 69.4 & 71.6 & 74.3 & 76.4 & 78.3 & 80.4 \\ \text { ADJ. FUEL USE } & 69.3 & 67.4 & 68.4 & 69.6 & 71.9 & 74.6 & 76.7 & 78.5 & 80.6 \\ \text { MMT } & 1429.4 & 1499.2 & 1547.1 & 1638.2 & 1738.2 & 1817.9 & 1871.6 & 1917.6 & 1968.9 \\ \text { MPG } & 20.6 & 22.2 & 22.6 & 23.6 & 24.3 & 24.5 & 24.5 & 24.5 & 24.5 \\ \text { VEHICLES } & 119.5 & 118.2 & 122.1 & 127.7 & 133.6 & 138.2 & 141.3 & 143.7 & 146.0 \\ \text { MILES/VEH. } & 11965 & 12688 & 12675 & 12831 & 13013 & 13151 & 13242 & 13341 & 13488 \\ \text { ADJ VMT } & 1429.4 & 1499.2 & 1548.2 & 1642.6 & 1745.0 & 1825.1 & 1878.6 & 1924.3 & 1975.5 \\ & & & & & & & & 2015 \\ \text { LEVEL 3 } & 1990 & 1995 & 2000 & 2005 & 2010 & 2015 & 2020 & 2025 & 2030 \\ \text { FUEL USE } & 69.3 & 66.7 & 66.4 & 66.6 & 68.5 & 71.0 & 73.0 & 74.8 & 76.8 \\ \text { ADJ. FUEL USE } & 69.3 & 66.8 & 66.8 & 67.4 & 69.5 & 72.1 & 74.1 & 76.0 & 78.0 \\ \text { MMT } & 1429.4 & 1500.8 & 1548.4 & 1635.4 & 1732.6 & 1811.6 & 1865.5 & 1911.6 & 1963.0 \\ \text { MPG } & 20.6 & 22.5 & 23.3 & 24.5 & 25.3 & 25.5 & 25.6 & 25.6 & 25.6 \\ \text { VEHICLES } & 119.5 & 118.1 & 121.7 & 126.8 & 132.3 & 136.8 & 139.9 & 142.3 & 144.6 \\ \text { MILES/VEH. } & 11965 & 12703 & 12723 & 12901 & 13097 & 13240 & 13332 & 13432 & 13580 \\ \text { ADJ VMT } & 1429.4 & 1502.6 & 1557.3 & 1655.4 & 1759.6 & 1840.5 & 1894.5 & 1940.5 & 1992.2\end{array}$


TABLE 6. PROJECTED LIGHT DUTY VEHICLE FUEL USE (Units in billions, except vehicles in millions)

Light Trucks, Low oil Price Case

$\begin{array}{lrrrrrrrrr}\text { BASE CASE } & 1990 & 1995 & 2000 & 2005 & 2010 & 2015 & 2020 & 2025 & 2030 \\ \text { FUEL USE } & 29.1 & 31.8 & 34.6 & 36.7 & 38.7 & 40.4 & 41.6 & 42.6 & 43.7 \\ \text { VMT } & 462.7 & 539.0 & 581.7 & 618.3 & 654.9 & 684.2 & 704.2 & 721.3 & 740.3 \\ \text { MPG } & 15.9 & 17.0 & 16.8 & 16.8 & 16.9 & 16.9 & 16.9 & 16.9 & 16.9 \\ \text { VEHICLES } & 47.6 & 51.9 & 57.0 & 60.6 & 63.7 & 65.9 & 67.4 & 68.5 & 69.6 \\ \text { MILES/VEH. } & 9711 & 10382 & 10205 & 10199 & 10283 & 10374 & 10445 & 10523 & 10638 \\ \text { CPM ELAST. } & -0.2 & & & & & & & & \\ & & & & & & & & & \\ \text { LEVEL 2 } & 1990 & 1995 & 2009 & 2005 & 2010 & 2015 & 2020 & 2025 & 2030 \\ \text { FUEL USE } & 29.1 & 31.8 & 34.0 & 35.1 & 36.5 & 37.9 & 39.0 & 40.0 & 41.0 \\ \text { ADJ. FUEL USE } & 29.1 & 31.8 & 34.1 & 35.3 & 36.7 & 38.2 & 39.3 & 40.2 & 41.3 \\ \text { VMT } & 462.7 & 539.0 & 582.9 & 621.4 & 659.2 & 689.3 & 709.9 & 727.4 & 746.8 \\ \text { MPG } & 15.9 & 17.0 & 17.1 & 17.7 & 18.1 & 18.2 & 18.2 & 18.2 & 18.2 \\ \text { VEHICLES } & 47.6 & 51.9 & 57.0 & 60.4 & 63.3 & 615.6 & 67.0 & 68.2 & 69.3 \\ \text { MILES/VEH, } & 9711 & 10382 & 10232 & 10285 & 10408 & 10514 & 10588 & 10667 & 10784 \\ \text { ADJ VMT } & 462.7 & 539.0 & 583.7 & 624.4 & 663.6 & 694.0 & 714.4 & 731.7 & 751.0 \\ & & & & & & & & & \\ \text { LEVEL 3 } & 1990 & 1995 & 2000 & 2005 & 2010 & 2015 & 2020 & 2025 & 2030 \\ \text { FUEL USE } & 29.1 & 31.6 & 33.3 & 33.6 & 34.5 & 35.7 & 36.8 & 37.7 & 38.7 \\ \text { ADJ. FUEL USE } & 29.1 & 31.6 & 33.4 & 34.1 & 35.2 & 36.5 & 37.5 & 38.4 & 39.5 \\ \text { VMT } & 462.7 & 539.5 & 583.5 & 620.4 & 656.8 & 686.8 & 707.5 & 725.2 & 744.8 \\ \text { MPG } & 15.9 & 17.1 & 17.5 & 18.5 & 19.1 & 19.2 & 19.3 & 19.3 & 19.3 \\ \text { VEHICLES } & 47.6 & 51.9 & 56.9 & 60.0 & 62.6 & 64.7 & 66.2 & 67.4 & 68.4 \\ \text { MILES/VEH. } & 9711 & 10393 & 10262 & 10342 & 10493 & 10610 & 10685 & 10765 & 10884 \\ \text { ADJ VMT } & 462.7 & 539.7 & 586.5 & 629.7 & 670.7 & 701.8 & 722.4 & 740.0 & 759.5 \\ & & & & & & & & & \end{array}$


TABLE 7. FUEL SAVINGS

(Units in Billions of Gallons/Year)

\begin{tabular}{|c|c|c|c|c|c|c|c|c|c|}
\hline $\begin{array}{l}\text { Reference case } \\
\text { Moderate }\end{array}$ & 1990 & 1995 & 2000 & 2005 & 2010 & 2015 & 2020 & 2025 & 2030 \\
\hline \multicolumn{10}{|l|}{ Cars } \\
\hline Level 2 & 0 & 0 & -0.89 & -2.58 & -3.64 & -4.06 & -4.18 & -4.86 & -4.68 \\
\hline Level 3 & 0 & -0.66 & -2.63 & -4.88 & -6.18 & -6.69 & -6.88 & -7.03 & -7.19 \\
\hline \multicolumn{10}{|l|}{ Light Trucks } \\
\hline Level 2 & 0 & 0 & -0.53 & -1.53 & -2.16 & -2.41 & -2.49 & -2.54 & -2.60 \\
\hline Level 3 & 0 & -0.18 & -1.23 & -2.82 & -3.81 & -4.20 & -4.33 & -4.42 & -4.52 \\
\hline \multicolumn{10}{|l|}{ Favorable } \\
\hline Level 2 & 0 & 0 & -0.94 & -2.72 & -3.84 & -4.28 & -4.40 & -5.12 & .4 .93 \\
\hline Level 3 & 0 & -0.70 & -2.77 & -5.14 & -6.51 & -7.05 & -7.25 & $\cdot 7.40$ & -7.57 \\
\hline \multicolumn{10}{|l|}{ Light Trucks } \\
\hline Level 2 & 0 & 0 & -0.56 & -1.61 & -2.28 & -2.54 & -2.62 & -2.68 & -2.74 \\
\hline Level 3 & 0 & -.019 & -1.30 & -2.97 & -4.0 .1 & -4.42 & -4.55 & -4.65 & -4.75 \\
\hline \multicolumn{10}{|l|}{ Unfavorable } \\
\hline \multicolumn{10}{|l|}{ Cars } \\
\hline Level 2 & 0 & 0 & -0.79 & -2.30 & -3.24 & -3.62 & -3.73 & -4.33 & -4.17 \\
\hline Level 3 & 0 & -0.59 & -2.34 & -4.36 & -5.52 & -5.98 & -6.15 & -6.28 & -6.43 \\
\hline \multicolumn{10}{|l|}{ Light Trucks } \\
\hline Level 2 & 0 & 0 & -0.47 & -1.36 & -1.93 & -2.1 .5 & -2.22 & -2.27 & -2.32 \\
\hline Level 3 & 0 & -0.16 & -1.10 & -2.52 & -3.40 & -3.75 & -3.87 & -3.95 & -4.04 \\
\hline \multicolumn{10}{|l|}{ Low oil Price Case } \\
\hline Level 2 & 0 & 0 & -0.91 & -2.66 & -3.77 & -4.22 & -4.36 & -4.47 & -4.59 \\
\hline Level 3 & 0 & -0.67 & -2.70 & -5.03 & -6.40 & -6.97 & -7.19 & -7.36 & -7.56 \\
\hline \multicolumn{10}{|l|}{ Light Trucks } \\
\hline Level? & 0 & 0 & -0.55 & -1.58 & -2.24 & -2.51 & -2.60 & -2.66 & -2.73 \\
\hline Level 3 & 0 & -0.19 & -1.27 & -2.91 & -3.94 & -4.37 & -4.52 & -4.63 & -4.75 \\
\hline \multicolumn{10}{|l|}{$\begin{array}{c}\text { High Oil Price Case } \\
\text { Cars }\end{array}$} \\
\hline Level 2 & 0 & 0 & -0.86 & -2.48 & -3.49 & -3.90 & -4.03 & -4.13 & -4.23 \\
\hline Level 3 & 0 & -0.64 & -2.54 & -4.71 & -5.93 & -6.44 & -6.64 & -6.81 & -6.97 \\
\hline \multicolumn{10}{|l|}{ Light Trucks } \\
\hline Level 2 & 0 & 0 & -0.51 & -1.48 & -2.08 & -2.32 & -2.40 & -2.46 & -2.52 \\
\hline Level 3 & 0 & -0.18 & -1.20 & -2.72 & -3.65 & -4.04 & -4.17 & -4.43 & -4.38 \\
\hline
\end{tabular}


TABLE 8. OIL PRICE CHANGE

(Dollars per barrel)

\begin{tabular}{|c|c|c|c|c|c|c|c|c|c|}
\hline $\begin{array}{l}\text { Reference Case } \\
\text { Moderate } \\
\text { Cars }\end{array}$ & 1990 & 1995 & 2000 & 2005 & 2010 & 2015 & 2020 & 2025 & 2030 \\
\hline Level 2 & so & 50 & $-\$ 0.04$ & $-\$ 0.14$ & $-\$ 0.20$ & $-\$ 0.23$ & $-\$ 0.24$ & $-\$ 0.29$ & $-\$ 0.28$ \\
\hline Level 3 & $\$ 0$ & $-\$ 0.02$ & $-\$ 0.12$ & $-\$ 0.26$ & $-\$ 0.34$ & $-\$ 0.38$ & $-\$ 0.40$ & $-\$ 0.42$ & $-\$ 0.43$ \\
\hline \multicolumn{10}{|l|}{ Light Trucks } \\
\hline Level 2 & $\$ 0$ & $s 0$ & $-\$ 0.02$ & $-\$ 0.08$ & $-\$ 0.12$ & -50.14 & -50.14 & $-\$ 0.15$ & $-\$ 0.16$ \\
\hline Level 3 & so & $-\$ 0.01$ & $-\$ 0.06$ & $-\$ 0.15$ & $-\$ 0.21$ & $-\$ 0.24$ & $-\$ 0.25$ & $-\$ 0.26$ & $-\$ 0.27$ \\
\hline \multicolumn{10}{|l|}{ Favorable } \\
\hline \multicolumn{10}{|l|}{ Cars } \\
\hline Level 2 & $\$ 0$ & 30 & $-\$ 0.05$ & $-\$ 0.17$ & $-\$ 0.25$ & $-\$ 0.29$ & -50.31 & $-\$ 0.36$ & $-\$ 0.35$ \\
\hline Level 3 & so & $-\$ 0.03$ & $-\$ 0.15$ & $-\$ 0.32$ & $-\$ 0.43$ & $-\$ 0.47$ & $-\$ 0.50$ & $-\$ 0.52$ & $-\$ 0.55$ \\
\hline \multicolumn{10}{|l|}{ Light Trucks } \\
\hline Level 2 & $\$ 0$ & $\$ 0$ & $-\$ 0.03$ & $-\$ 0.10$ & $-\$ 0.15$ & $-\$ 0.17$ & $-\$ 0.18$ & $-\$ 0.19$ & $-\$ 0.20$ \\
\hline Level 3 & $\$ 0$ & $-\$ 0.01$ & $-\$ 0.07$ & $-\$ 0.19$ & $-\$ 0.27$ & $-\$ 0.30$ & -50.32 & $-\$ 0.33$ & $-\$ 0.34$ \\
\hline \multicolumn{10}{|l|}{$\begin{array}{l}\text { Unfavorable } \\
\text { Cars }\end{array}$} \\
\hline Level 2 & $\$ 0$ & $\$ 0$ & $-\$ 0.02$ & $-\$ 0.07$ & $-\$ 0.11$ & $-\$ 0.12$ & -50.13 & $-\$ 0.15$ & $-\$ 0.15$ \\
\hline Level 3 & so & -50.01 & $-\$ 0.07$ & $-\$ 0.14$ & $-\$ 0.18$ & $-\$ 0.20$ & $-\$ 0.21$ & $-\$ 0.22$ & $-\$ 0.23$ \\
\hline \multicolumn{10}{|l|}{ Light Trucks } \\
\hline Level 2 & so & $\$ 0$ & $-\$ 0.01$ & $-\$ 0.04$ & $-\$ 0.06$ & $-\$ 0.07$ & $-\$ 0.08$ & $-\$ 0.08$ & $-\$ 0.08$ \\
\hline Level 3 & so & so & $-\$ 0.03$ & $-\$ 0.08$ & $-\$ 0.11$ & $-\$ 0.13$ & -50.13 & $-\$ 0.14$ & $-\$ 0.15$ \\
\hline \multicolumn{10}{|l|}{$\begin{array}{l}\text { Low Oil Price Case } \\
\text { Cars }\end{array}$} \\
\hline Level 2 & so & $\$ 0$ & $-\$ 0.03$ & -50.09 & $-\$ 0.13$ & $-\$ 0.14$ & $-\$ 0.15$ & -50.16 & $-\$ 0.16$ \\
\hline Level 3 & so & $-\$ 0.02$ & $-\$ 0.08$ & $-\$ 0.18$ & $-\$ 0.23$ & $-\$ 0.24$ & $-\$ 0.25$ & $-\$ 0.26$ & $-\$ 0.26$ \\
\hline \multicolumn{10}{|l|}{ Light Trucks } \\
\hline Level 2 & so & 50 & $-\$ 0.02$ & $-\$ 0.05$ & $-\$ 0.08$ & $-\$ 0.09$ & $-\$ 0.09$ & $-\$ 0.09$ & $-\$ 0.09$ \\
\hline Level 3 & so & $\$ 0$ & $-\$ 0.04$ & $-\$ 0.10$ & $-\$ 0.14$ & $-\$ 0.15$ & $-\$ 0.16$ & $-\$ 0.16$ & $-\$ 0.16$ \\
\hline \multicolumn{10}{|l|}{$\begin{array}{l}\text { Migh ojl Price Case } \\
\text { Cars }\end{array}$} \\
\hline Level 2 & $\$ 0$ & $\$ 0$ & $-\$ 0.05$ & $-\$ 0.18$ & $-\$ 0.27$ & $-\$ 0.30$ & $-\$ 0.33$ & $-\$ 0.35$ & $-\$ 0.38$ \\
\hline Level 3 & '\$O & $-\$ 0.03$ & $-\$ 0.15$ & $-\$ 0.34$ & -50.46 & $-\$ 0.50$ & $-\$ 0.54$ & $-\$ 0.58$ & $-\$ 0.62$ \\
\hline \multicolumn{10}{|l|}{ Light Trucks } \\
\hline Level 2 & $\$ 0$ & \$o & $-\$ 0.03$ & -50.11 & $-\$ 0.16$ & $-\$ 0.18$ & $-\$ 0.20$ & $-\$ 0.21$ & $-\$ 0.22$ \\
\hline Level 3 & $\$ 0$ & $-\$ 0.01$ & $-\$ 0.07$ & .50 .19 & -50.28 & $-\$ 0.31$ & -50.34 & $-\$ 0.38$ & $-\$ 0.39$ \\
\hline
\end{tabular}


TABLE 9. TOTAL CHANGE ON EMISSIONS (1000's of Tons)

$\begin{array}{lrrrrrrrrr}\begin{array}{l}\text { Reference Cese } \\ \text { Moderate } \\ \text { Cars }\end{array} & 1990 & 1995 & 2000 & 2005 & 2010 & 2015 & 2020 & 2025 & 2030 \\ \text { Level 2 } & & & & & & & & & \\ \quad \text { Change in HC } & 0 & 0 & -10.2 & -31.8 & -46.8 & -52.5 & -54.1 & -63.8 & -61.0 \\ \text { Change in CO } & 0 & 0 & 15.1 & 46.7 & 72.3 & 84.4 & 87.1 & 100 & 96.4 \\ \text { Change in NOX } & 0 & 0 & 1.5 & 4.1 & 5.5 & 6.4 & 6.6 & 7.6 & 7.3 \\ \text { Level 3 } & & & & & & & & & \\ \text { Change in HC } & 0 & -4.8 & -26.3 & -57.0 & -79.1 & -87.4 & -90.1 & -92.0 & -94.1 \\ \text { Change in CO } & 0 & 26.9 & 76.8 & 131.1 & 158.7 & 170.2 & 174.7 & 178.3 & 182.3 \\ \text { Change in NOX } & 0 & 4.6 & 8.4 & 12.4 & 12.0 & 12.9 & 13.2 & 13.5 & 13.8\end{array}$

Light Trucks

Level 2

$\begin{array}{lrrrrrrrrr}\text { Change in HC } & 0 & 0 & -2.7 & -8.9 & -13.6 & -15.2 & -15.7 & -16.1 & -16.4 \\ \text { Change in CO } & 0 & 0 & 10.0 & 25.2 & 32.4 & 36.8 & 37.8 & 38.5 & 39.2 \\ \text { Change in NOX } & 0 & 0 & 1.4 & 3.2 & 4.0 & 4.6 & 4.7 & 4.8 & 4.9 \\ \text { Level 3 } & & & & & & & & & \\ \text { Change in HC } & 0 & -0.5 & -4.7 & -14.0 & -23.1 & -26.3 & -27.2 & -27.8 & -28.5 \\ \text { Change in CO } & 0 & 6.4 & 34.8 & 66.7 & 70.9 & 76.3 & 78.2 & 79.6 & 81.3 \\ \text { Change in NOX } & 0 & 0.7 & 4.8 & 8.1 & 8.5 & 9.2 & 9.4 & 9.6 & 9.8\end{array}$

Favorable

Cars

Level 2

$\begin{array}{lrrrrrrrrr}\text { Change in HC } & 0 & 0 & -11.4 & -35.0 & -51.4 & 57.6 & -59.5 & -70.0 & -67.0 \\ \text { Change in CO } & 0 & 0 & 7.4 & 23.7 & 39.1 & 46.9 & 48.3 & 54.6 & 52.9 \\ \text { Change in HOX } & 0 & 0 & 0.7 & 2.2 & 3.0 & 3.5 & 3.7 & 4.2 & 4.0 \\ \text { Level 3 } & & & & & & & & & \\ \text { Change in HC } & 0 & -5.8 & -29.8 & -63.1 & -86.9 & -95.8 & -98.8 & -100.9 & -103.2 \\ \text { Change in CO } & 0 & 20.9 & 53.4 & 86.4 & 100.8 & 106.7 & 109.2 & 111.4 & 113.8 \\ \text { Change in NOX } & 0 & 3.8 & 6.1 & 8.8 & 7.6 & 8.0 & 8.2 & 8.4 & 8.6\end{array}$

Light Trucks

Level 2

Change in $C$

Change in NOX

8.1

8.59 .2

9.4

9.8

\section{Level 3}

Change in HC

Change in $\mathrm{CO}$

Change in NOX

0
0
0
0

0
0
-0
4
0

\section{$-3.3$}

$-10.4$

$-15.6$

$-17.5$

.18 .1

$\begin{array}{rr}-18.5 & -18.9 \\ 21.9 & 22.3 \\ 2.6 & 2.7\end{array}$

0.9

15.2

18.5

21.1

21.6

2.6

$-0.8 \quad-6.0$

$-16.7-26.6$

$-30$.

$4.6 \quad 25.7$

47.6

45.6

48.2

$\begin{array}{lll}-31.3 & -32.0 & -32.8\end{array}$

$0.5 \quad 3.6$

$5.7 \quad 5.2$

5.6

$\begin{array}{lll}49.1 & 49.9 & 50.9\end{array}$ 
TABLE 9. TOTAL CHAMGE ON EMISSIONS (cont'd) ( $1000^{\prime}$ 's of Tons)

$\begin{array}{lllllllll}1990 & 1995 & 2000 & 2005 & 2010 & 2015 & 2020 & 2025 & 2030\end{array}$

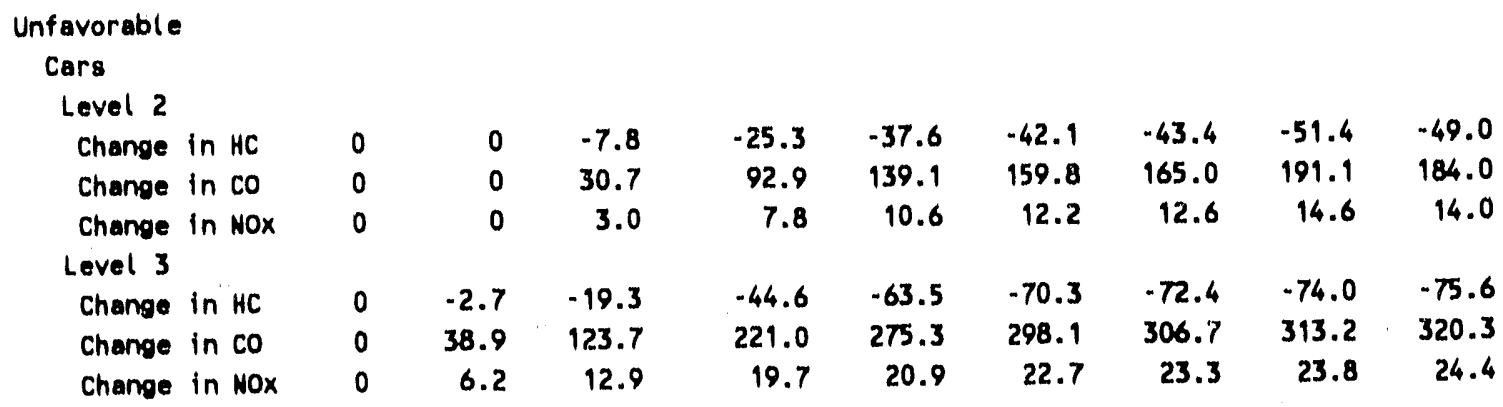

Light Trucks

Level 2

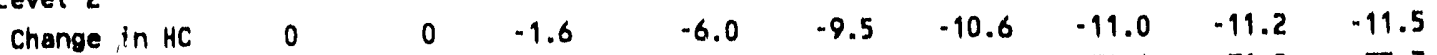

$\begin{array}{llllllllll}\text { Change in CO } & 0 & 0 & 17.7 & 45.4 & 60.4 & 68.3 & 70.4 & 71.8 & 73.3\end{array}$

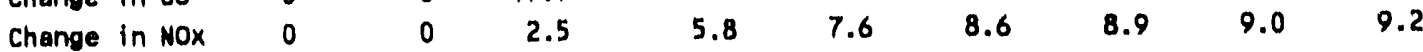

Level 3

$\begin{array}{lrrrrrrrrr}\text { Change in HC } & 0 & 0 & -2.1 & -8.5 & -15.9 & -18.2 & -18.9 & -19.3 & -19.8 \\ \text { Change in CO } & 0 & 10.1 & 52.9 & 105.1 & 121.8 & 133.2 & 137.0 & 139.7 & 142.8\end{array}$

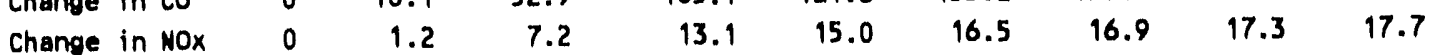

Low Oil Price case

Cars

Level 2

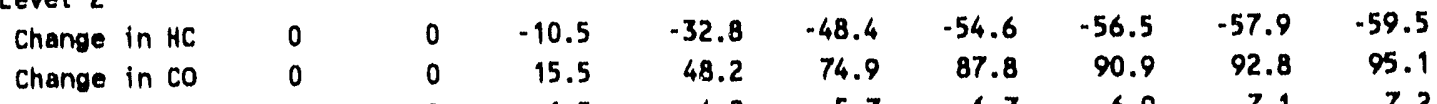

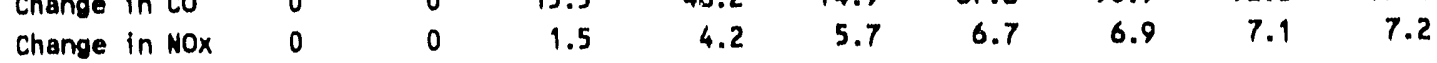

Level 3

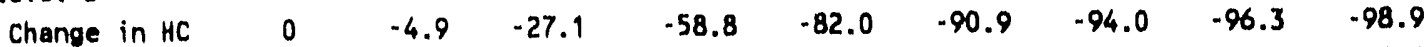

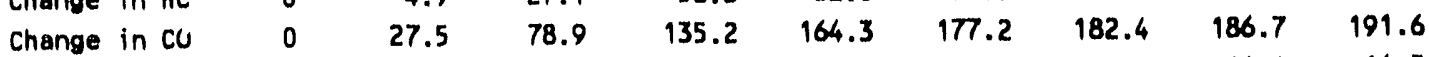

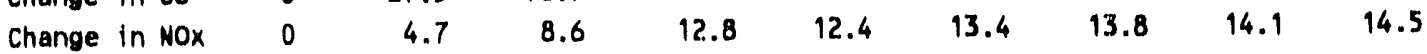

\section{Light rrucks}

Level 2

$\begin{array}{lrrrrrrrrr}\text { Change in HC } & 0 & 0 & -2.8 & -9.2 & -14.0 & -15.8 & -16.4 & -16.8 & -17.3 \\ \text { Change in CO } & 0 & 0 & 10.2 & 26.0 & 33.6 & 38.3 & 39.5 & 40.3 & 41.3 \\ \text { Change in NOX } & 0 & 0 & 1.5 & 3.3 & 4.2 & 4.7 & 4.9 & 5.0 & 5.1 \\ \text { Level 3 } & & & & & & & & & \\ \text { Change in HC } & 0 & -0.6 & -4.8 & -14.4 & -23.9 & -27.3 & -28.4 & -29.2 & -30.0 \\ \text { Change in CO } & 0 & 6.6 & 35.7 & 68.7 & 73.4 & 79.5 & 81.6 & 83.4 & 85.5 \\ \text { Change in NOX } & 0 & 0.7 & 4.9 & 8.4 & 8.8 & 9.6 & 9.8 & 10.0 & 10.3\end{array}$


TABLE 9. TOTAL CHANGE OM EMISSIONS (Cont'd)

(1000's of Tons)

$\begin{array}{lllllllll}1990 & 1995 & 2000 & 2005 & 2010 & 2015 & 2020 & 2025 & 2030\end{array}$

Migh Oil Price Cose

Cars

Level 2

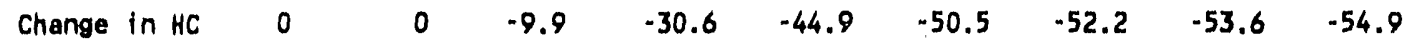

$\begin{array}{llllllllll}\text { Change in CO } & 0 & 0 & 14.7 & 45.1 & 69.4 & 81.2 & 84.0 & 85.8 & 87.7\end{array}$

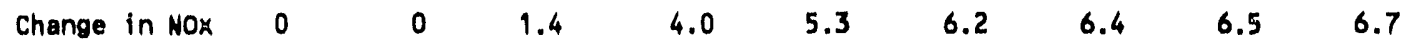

Level 3

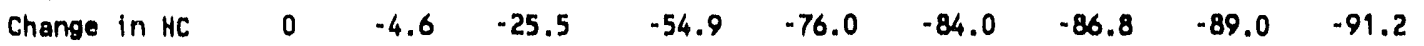

$\begin{array}{llllllllll}\text { Change in CO } & 0 & 26.1 & 74.4 & 126.4 & 152.3 & 163.7 & 168.5 & 172.6 & 176.7\end{array}$

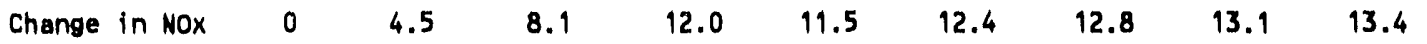

Light Trucks

Level 2

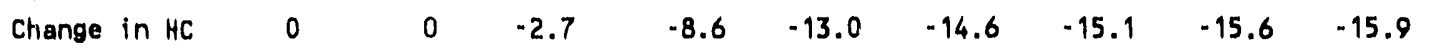

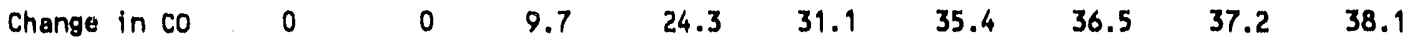

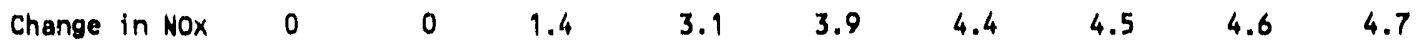

Level 3

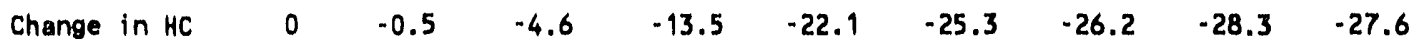

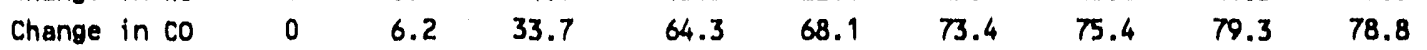

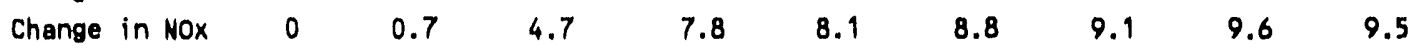


TABLE 10. FLEET AVERAGE WEIGHT RECUCTION

(Pounds)

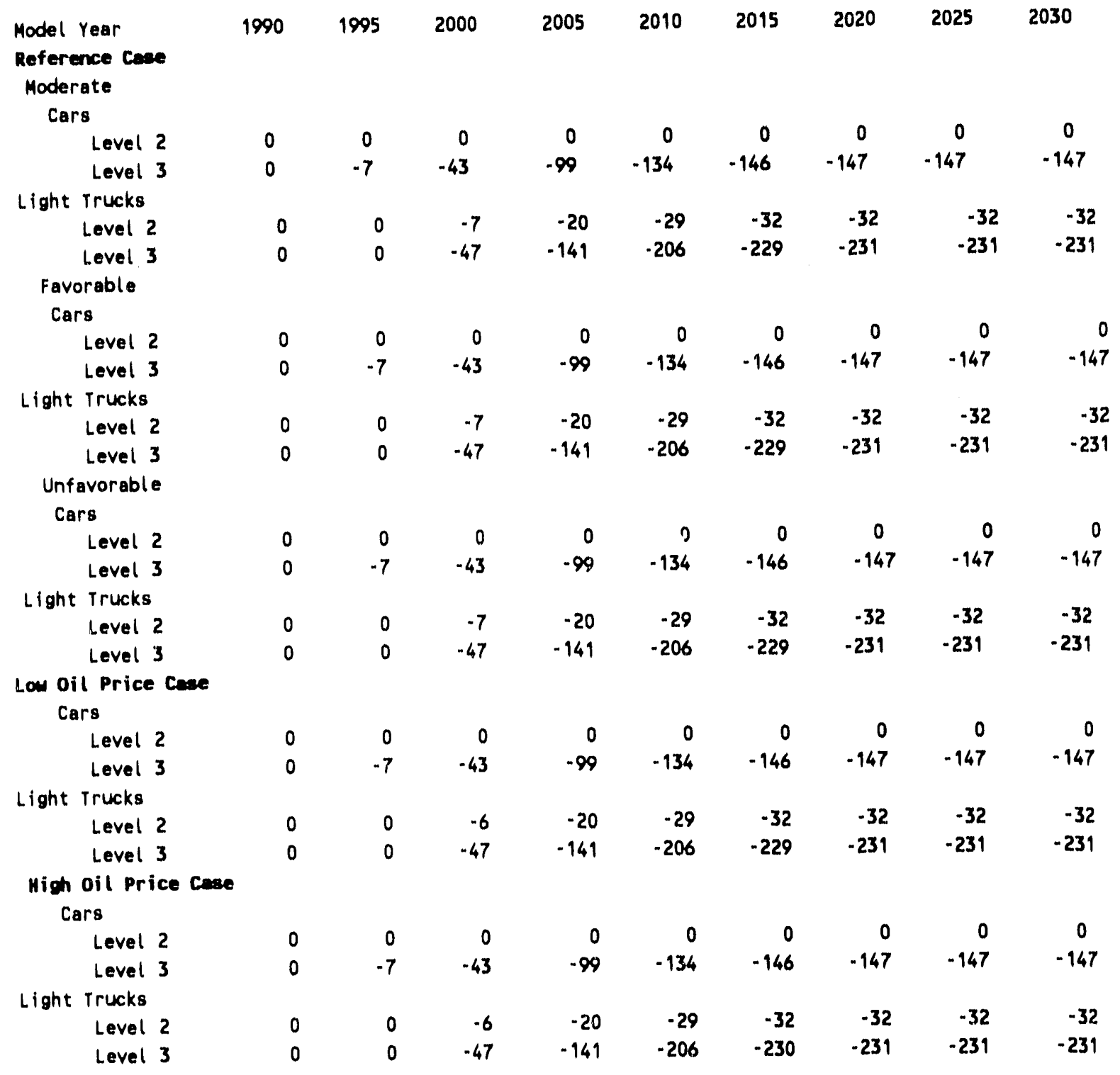




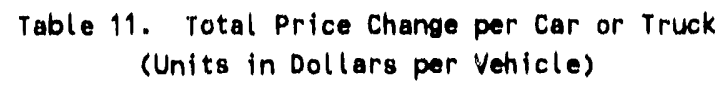

\begin{tabular}{|c|c|c|c|c|}
\hline $\begin{array}{l}\text { Referenre Case } \\
\text { Mode'ste }\end{array}$ & 1990 & 1995 & 2000 & 2005 \\
\hline \multicolumn{5}{|l|}{ Cars } \\
\hline Level 2 & $\$ 0$ & $\$ 0$ & $\$ 169$ & $\$ 203$ \\
\hline Level 3 & so & $\$ 206$ & $\$ 469$ & $\$ 523$ \\
\hline \multicolumn{5}{|l|}{ Light Trucks } \\
\hline l.evel 2 & $\$ 0$ & $\$ 0$ & $\$ 258$ & $\$ 310$ \\
\hline Level 3 & so & $\$ 89$ & $\$ 615$ & $\$ 719$ \\
\hline \multicolumn{5}{|l|}{ Favorable } \\
\hline \multicolumn{5}{|l|}{ Cars } \\
\hline Level 2 & so & $\$ 0$ & $\$ 169$ & $\$ 203$ \\
\hline Level 3 & $\$ 0$ & $\$ 206$ & $\$ 469$ & $\$ 523$ \\
\hline \multicolumn{5}{|l|}{ Light Trucks } \\
\hline Level 2 & so & $\$ 0$ & $\$ 258$ & $\$ 310$ \\
\hline Level 3 & $\$ 0$ & $\$ 89$ & $\$ 615$ & $\$ 719$ \\
\hline \multicolumn{5}{|l|}{ Unfavorable } \\
\hline \multicolumn{5}{|l|}{... Cars } \\
\hline Level 2 & so & $\$ 0$ & $\$ 169$ & $\$ 203$ \\
\hline Level 3 & so & $\$ 206$ & $\$ 469$ & $\$ 523$ \\
\hline \multicolumn{5}{|l|}{ Light Trucks } \\
\hline Level 2 & $\$ 0$ & $\$ 0$ & $\$ 258$ & $\$ 310$ \\
\hline Level 3 & $\$ 0$ & $\$ 89$ & $\$ 615$ & $\$ 719$ \\
\hline
\end{tabular}

Low oil Price Case

$\begin{array}{lrrrr}\text { Cars } & & & & \\ \text { Level 2 } & \$ 0 & \$ 0 & \$ 169 & \$ 203 \\ \text { Level 3 } & \$ 0 & \$ 206 & \$ 469 & \$ 523 \\ \text { Trucks } & & & & \\ \text { Level 2 } & \$ 0 & \$ 0 & \$ 258 & \$ 310 \\ \text { Level 3 } & \$ 0 & \$ 89 & \$ 615 & \$ 719\end{array}$

High oil Price case

Cars

$\begin{array}{llrrr}\text { Level } 2 & \$ 0 & \$ 0 & \$ 169 & \$ 203 \\ \text { Level } 3 & \$ 0 & \$ 206 & \$ 469 & \$ 523\end{array}$

Light Trucks

$\begin{array}{lrrrr}\text { Level } 2 & \$ 0 & \$ 0 & \$ 258 & \$ 310 \\ \text { Level } 3 & \$ 0 & \$ 89 & \$ 615 & \$ 719\end{array}$

* Note: Price changes after the year 2005 are the same as the price change in 2005. 
Table 12. Change in Carbon Dioxide Emissions

(Millions of Tons)

\begin{tabular}{|c|c|c|c|c|c|c|c|c|c|}
\hline $\begin{array}{l}\text { Reference Case } \\
\text { Moderate } \\
\text { Cars }\end{array}$ & 1990 & 1995 & 2000 & 2005 & 2010 & 2015 & 2020 & 2025 & 2030 \\
\hline Level 2 & 0.0 & 0.0 & -8.7 & -25.4 & -35.9 & -40.0 & -41.2 & -47.9 & -46.1 \\
\hline Level 3 & 0.0 & -6.5 & -25.9 & -48.1 & -60.9 & -65.9 & -67.8 & -69.3 & -70.8 \\
\hline \multicolumn{10}{|l|}{ Light Trucks } \\
\hline Level 2 & 0.0 & 0.0 & -5.2 & -15.1 & -21.3 & -23.8 & -24.5 & -25.0 & -25.6 \\
\hline Level 3 & 0.0 & -1.8 & -12.1 & -27.8 & -37.5 & -41.3 & $-i, 2.6$ & -43.5 & -44.5 \\
\hline \multicolumn{10}{|l|}{$\begin{array}{l}\text { Favorable } \\
\text { Cars }\end{array}$} \\
\hline Level 2 & 0.0 & 0.0 & -9.2 & -26.8 & -37.8 & -42.1 & -43.4 & -50.4 & -48.5 \\
\hline Level 3 & 0.0 & -0.9 & -27.3 & -50.6 & -64.1 & -69.4 & -71.4 & -72.9 & -74.6 \\
\hline \multicolumn{10}{|l|}{ Light Trucks } \\
\hline Level 2 & 0.0 & 0.0 & -5.5 & 15.9 & -22.5 & -25.0 & -25.8 & -26.4 & -27.0 \\
\hline Level 3 & 0.0 & -1.9 & -12.8 & -29.3 & -39.5 & -43.5 & -44.8 & -45.8 & -46.8 \\
\hline \multicolumn{10}{|l|}{ Unfavorable } \\
\hline Level 2 & 0.0 & 0.0 & -7.8 & -22.6 & -32.0 & -35.6 & -36.7 & -42.7 & -41.1 \\
\hline Level 3 & 0.0 & -5.8 & -23.0 & -42.9 & -54.4 & -58.9 & -60.6 & -61.9 & -63.3 \\
\hline \multicolumn{10}{|l|}{ Light Trucks } \\
\hline t.evel 2 & 0.0 & 0.0 & -4.7 & -13.4 & -19.0 & -21.2 & -21.9 & -22.3 & -22.8 \\
\hline Level 3 & 0.0 & -1.6 & -10.8 & -24.8 & -33.5 & -37.0 & -38.1 & -38.9 & -39.8 \\
\hline \multicolumn{10}{|c|}{$\begin{array}{l}\text { Low oil Price Case } \\
\text { Cars }\end{array}$} \\
\hline Level 2 & 0.0 & 0.0 & -9.0 & -26.2 & -37.1 & -41.6 & -43.0 & -44.0 & -45.2 \\
\hline Level 3 & 0.0 & -6.6 & -26.6 & -49.6 & -63.1 & -68.6 & -70.8 & -72.5 & -74.5 \\
\hline \multicolumn{10}{|l|}{ Light Trucks } \\
\hline Level 2 & 0.0 & 0.0 & -5.4 & -15.5 & -22.1 & -24.7 & -25.6 & -26.2 & -26.9 \\
\hline Level 3 & 0.0 & -1.9 & -12.5 & -28.7 & -38.8 & -43.0 & -44.5 & -45.6 & -46.8 \\
\hline \multicolumn{10}{|c|}{$\begin{array}{l}\text { Migh Oil Price Case } \\
\text { Cars }\end{array}$} \\
\hline Level 2 & 0.0 & 0.0 & -8.5 & -24.5 & -34.4 & -38.4 & -39.7 & -40.7 & -41.7 \\
\hline Level 3 & 0.0 & -6.3 & -25.1 & -46.4 & -58.4 & -63.4 & -65.4 & -67.1 & -68.7 \\
\hline \multicolumn{10}{|l|}{ Light Trucks } \\
\hline Level 2 & 0.0 & 0.0 & -5.1 & -14.5 & -20.5 & -22.9 & -23.6 & -24.2 & -24.8 \\
\hline Level 3 & 0.0 & -1.8 & -11.8 & -26.8 & -36.0 & -39.8 & -41.1 & -43.7 & -43.1 \\
\hline
\end{tabular}




\section{INTERNAL DISTRIBUTION}

1. T. J. Blasing

2. M. S. Bronzini

3. J. B. Cannon

4. F. C. Chen

5. S. Das

6. S. R. Elliott

7. J. T. Ensminger

8. S. Fischer

9. P. S. Gillis

10-33. D. L. Greene

34. J. Hadder

35. L. J. Hill

36. E. L. Hillsman

37. E. Hirst

38. D. W. Jones

39. J. Kolb

40. M. Kuliasha
41. R. Lee

42. P. Leiby

43. D. P. Lombardi

44. L. N. McCold

45. V. C. Mei

46. S. P. Miaou

47. R. D. Perlack

48. D. E. Reichle

49. R. B. Shelton

50. M. L. Socolof

51. J. W. Van Dyke

52. T. J. Wilbanks

53. ORNL Patent Office

54. Central Research Library

55. Document Reference Section

56-58. Laboratory Records

59. Laboratory Records--RC

\section{EXTERNAI DISTRIBUTION LIST}

60. B. G. Buchanan, Computer Science Department, University of Pittsburgh, 206 Mineral Industries Building, Pittsburgh, PA 15260

61. A. Hirsch, Vice President, Environmental Sciences, Director, Washington Operations, Midwest Research Institute, 5109 Leesburg Pike, Suite 414, Falls Church, VA 22041

62. H. M. Ingram, Director, Udall Center for Studies in Public Policy, The University of Arizona, 803/811 East First Street, Tuscon, AZ 85719

63. C. D. MacCracken, President, Calmac Manufacturing Corporation, 101 West Sheffield Avenue, P. O. Box 710, Englewood, NJ 07631

64. J. B. Shrago, Director, Office of Technology Transfer, 4405 Kirkland Hall, Vanderbilt University, Nashville, TN 37240

65. M. Williams, Professor, Department of Economics, Northern Illinois University, DeKalb, IL 60115

66. Office of Assistant Manager for Energy Research and Development, DOE-ORO, P. O. Box 2001, Oak Ridge, TN. 37831-8600

67-76. OSTI, U. S. Department of Energy, P. O. Box 62, Oak Ridge, TN 37831

77-88. K. G. Duleep, 1655 North Ft. Myer Drive, Suite 600, Arlington, VA 22209

89. Michael A. Ball, Transport Canada, Place de Ville, Ottawa, Ontario K1A 0N5

90. O. M. S. Colavincenzo, Ministry of Transportation, 1201 Wilson Avenue, 3rd Floor, Central Building, Downsview, Ontario M3M 1J8 
91. Mark A. Deluchi, University of California at Davis, Institute of Transportation Studies, Davis, CA 95616

92. David Hitchcock, Houston Advanced Research Center, Center for Global Studies, 4800 Research Forest Drive, The Woodlands, TX 77381

93. Orron E. Kee, U. S. Department of Transportation, Office of Market Incentives, 4007 th Street, S.W., Washington, DC 20590

94. Don Knight, Eno Transportation Foundation, Inc., 8150 Leesburg Pike, Suite 700, Vienna, VA 22182

95. David L. Kulp, Ford, Fuel Economy Planning \& Compliance Department, The American Road, P. O. Box 1899, Dearborn, MI 48121-1899

96. Eton Lawrence, Transport Canada, Canada Building, 344 Slater Street, Ottawa, Ontario K1A 0N5

97. Robert Lopez, State of Wisconsin, Department of Natural Resources, AM/10 P. O. Box 7921, Madison, WI 53707-7921

98. Peter Reilly-Roe, Energy, Mines, and Resources Canada, 580 Booth Street, Ottawa, Ontario, C'anada K1A 0E4

99. Siegbert P. Schacknies, U. S. Department of Transportation, Federal Highway Administration, Office of International Programs, 400 7th Street, SW, Washington, DC 20590

100. Cheryl A. Donahue, U. S. General Accounting Office, 370 L'enfant Promenade, SW, Suite 802, Washington, DC 20024

101. Hal Harvey, The Energy Foundation, 775 Federal Street, San Francisco, CA 94107

102. Thomas B. Gage, Chiysler Motors Corporation, 12000 Chrysler Drive, CIMS 415 04-07, Highland Park, MI 48288-0857

103. Eric O. Stork, Eric Stork and Associates, '104 North Powhatan Street, Arlington, VA 22205

104. Paul D. McCarthy, Ford, The American Road, Dearborn, MI 48121

105. Gilbert DuBois, Delegation of the Commission of the European Communities, 7th Floor, $2100 \mathrm{M}$ Street, NW, Washington, DC 20037

106. Michael A. Lobue, ARCO, 1333 New Hampshire Avenue, NW, Suite 1ח1, Washington, DC 20036

107. Wilfrid L. Kol!l, The John Hopkins University, 1619 Massachusetts Avenue, NW, Washington, DC' 20036

108. Edward Weiner, U. S. Department of Transportation, 400 Seventh Street, SW, Washington, DC 20590

109. H. Lee Solsbery, International Energy Agency, 2, Rue Andre-Pascal, 75775 Paris Cedex 16

110. Michael F. Lawrence, Jack Faucett Associates, 4550 Montgomery Avenue, Suite 300 North, Bethesda, MD 20814

11i. Robin Miles-McLean, U. S. Environmental Protection Agency, PM-221, 401 M Street, SW, Washington, DC 20460

112. Debbie Gordon, Union of Concerned Scientists, 2397 Shattuck Avenue, Suite 203, Berkeley, CA 94704

113. Herbert Weinblatt, JFA, 7300 Pearl Street, Bethesda, MD 20816

114. Edward Weiner, U. S. Department of Transportation, 400 Seventh Street, SW, Washington, DC 20590

115. Frank von Hippel, Princeton University, Princeton, NJ 08544-5263

116. James L. Sweeney, Stanford University, Terman Engineering Center, Stanford, CA $94305-4025$ 
117. Darid Shin, American Petrolium Institute, Policy Analysis Department, $1220 \mathrm{~L}$ Street, NW, Washington, DC 20005

118. Michael Shelby, Environmantal Protection Agency, 401 M Streat, SW, Washington, DC 20460

119. Will Schroer, U. S. Erivironmental Protection Agency, Office of Policy, Planning, and Evaluation, PM-221, 401 M Street, SW, Washington, DC 20460

120. Rolf R. Schmitt, Federal Highway Administration, HPP-12, Room 3324, 400 Seventh Street, SW, Washington, DC 20590

121. Lee Schipper, Lawrence Berkeley Laboratory, 4000 Building 90, Berkeley, CA 94720

122. Danilo J. Santini, Argonne National Laboratory, 9700 South Cass Avenue, ES/362 2B, Argonne, IL 60439-4815

123. Marc H. Ross, University of Michigan, Physics Department, Ann Arbor, MI 48109

124. John K. Pollard, DTS 45, U. S. Department of Transportation, Kendall Swuare, Cambridge, MA 02142

125. Don H. Pickrell, U. S. Department of Transportation, Kendall Square, Cambridge, MA 02142

126. Edith B. Page, Congress of the United States, Office of Technology Assessment, Washington, DC 20510-8025

127. Gary Occhiuzzio, California Energy Commission, MS-22, 1516 Ninth Street, Sacramento, CA 95814-5512

128. J. Dillard Murrell, Environmental Protecticn Agency, 2565 Plymouth Roau, Ann Arbor, MI 48105

129. David Montgomery, Charles River Associates, 55513 th Street, NW, Suite 330 East, Washington, DC 20004

130. Marianne Millar, Center for Transportation Research, Argonne National Laboratory, 9700 Ssith Cass Avenue, Argonne, IL 60439

131. Jim March, Office of Policy Development, FHWA HPP-12, 400 Seventh Street, SW, Washington, DC 201590

132. Dev Mani, Energy Engineering Board, 2101 Constitution Avenue, NW, Washington, DC 20418

133. Stephen Lockwood, Department of Transportation, Federal Highway Administration, HPL-1, Room 3317, 400 Seventh Street, SW, Washington, DC 20590

134. James R. Link, U. S. Department of Transportation, Federal Highway ridministration, HPP-10, 400 7th Street, SW, Washington, DC 20590

135. Marc Ledbetter, American Council for an Energy Efficient Economy, 1001 Connecticut Avenue, NW, Suite 535, Washington, DC 20036

136. Charles A. Lave, University of California, Economics Department, Institute of Transportation Studies, Irvine, CA 92717

137. Kenneth Koyama, State of California, California Energy Commission, 1516 9th Street, MS-41, Sacramento, CA 95814-5512

138. Andrew Kleit, Federal Trade Commission, Bureau of Economics, 601 Pennsylvania Avenue, NW, Suite 5605, Washington, DC 20580

139. Jeff Haugh, Federal Highway Administration, Office of Highway Information Management (HPM-30), 400 Seventh Street, SW, Washington, DC 20590

140. Donald J. Igo, U. S. Department of Transpoitation, Office of the Secretary, 4007 th Street, SW, Washington, DC 20590

141. David A. Hensher, Transport Research Centre, School of Economic and Financial Studies, Macquarie University, N.S.W. 2.109 Australia 
142. Karl Hellman, Environmental Protection Agency, 2565 Plymouth Road, Ann Arbor, MI 48105

143. Darwin C. Hall, California State University, Department of Economics, 1250 Bellflower Boulevard, Long Beach, CA 90840-4607

144. John German, Environmental Protection Agency, 2565 Plymouth Rodd, Ann Arbor, MI 48105

145. Dermot Gately, New York University, Economics Department, New York, NY 10003

146. Kenneth Friedman, CE-10, Department of Energy, Office of Transportation Systems, 1000 Indejendence Avenue, SW, Washington, DC 20585

147. Richard Farmer, Natural Resource and Commerce Division, CBO, House Annex No. 2, Second and D Street, SW, Washington, DC 20515

148. E. Eugene Ecklund, HCR-72, Box 547.B LOW, Locust Grove, VA 22508

149. Barry Cohen, EI-621, Room 1H-050, Department of Energy, 1000 Independence Avenue, SW, Washington, DC 20585

150. W. V. Bussman, Chrysler Corporation, 12000 Chrysler Drive, CIMS 416-14-32, Highland Park, MI 48288-1919 

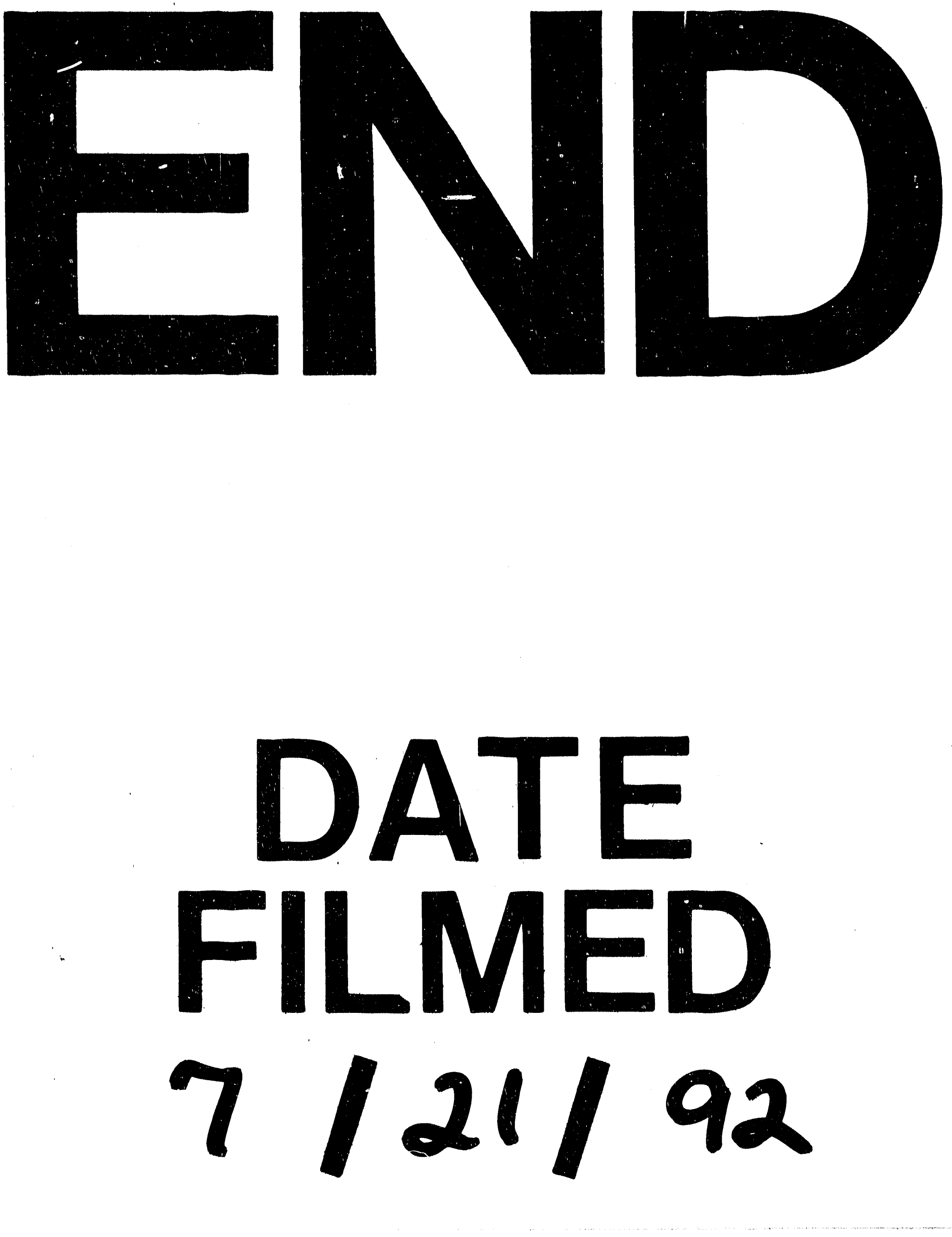
